University of Louisville

ThinkIR: The University of Louisville's Institutional Repository

$12-2020$

\title{
A phenomenological study of kindergarten teachers' perceptions of their students in the age of kindergarten readiness.
}

Adam Nelson Stephens

University of Louisville

Follow this and additional works at: https://ir.library.louisville.edu/etd

Part of the Early Childhood Education Commons, and the Elementary Education Commons

\section{Recommended Citation}

Stephens, Adam Nelson, "A phenomenological study of kindergarten teachers' perceptions of their students in the age of kindergarten readiness." (2020). Electronic Theses and Dissertations. Paper 3536. https://doi.org/10.18297/etd/3536

This Doctoral Dissertation is brought to you for free and open access by ThinkIR: The University of Louisville's Institutional Repository. It has been accepted for inclusion in Electronic Theses and Dissertations by an authorized administrator of ThinkIR: The University of Louisville's Institutional Repository. This title appears here courtesy of the author, who has retained all other copyrights. For more information, please contact thinkir@louisville.edu. 


\title{
A PHENOMENOLOGICAL STUDY OF KINDERGARTEN TEACHERS' PERCEPTIONS OF THEIR STUDENTS IN THE AGE OF KINDERGARTEN READINESS
}

\author{
By \\ Adam Nelson Stephens \\ University of Louisville \\ B.A., University of Kentucky, 1999 \\ M.Ed., University of Kentucky, 2003 \\ Ed.S., University of Kentucky, 2013
}

\begin{abstract}
A Dissertation
Submitted to the Faculty of the

College of Education and Human Development of the University of Louisville In Partial Fulfillment of the Requirements

For the Degree of
\end{abstract}

Doctor of Education in Educational Leadership and Organization Development

Department of Educational Leadership, Evaluation, and Organizational Development University of Louisville

Louisville, Kentucky

December 2020 
Copyright 2020 by Adam Nelson Stephens

All rights reserved 



\title{
A PHENOMENOLOGICAL STUDY OF KINDERGARTEN TEACHERS' PERCEPTIONS OF THEIR STUDENTS IN THE AGE OF KINDERGARTEN READINESS
}

\author{
By \\ Adam Nelson Stephens \\ University of Louisville \\ B.A., University of Kentucky, 1999 \\ M.Ed., University of Kentucky, 2003 \\ Ed.S., University of Kentucky, 2013
}

A Dissertation Approved on

November 17, 2020

By the following Dissertation Committee:

Dr. Mary Brydon-Miller, Ph.D., Chair

Dr. Deborah Powers, Ed.D.

Dr. Bryon Keith Davis, Ed.D.

Dr. Douglas Stevens, Ph.D. 


\section{DEDICATION}

This dissertation is dedicated to my three lovely children who remind me that we all start curious, resilient, and brave. Their development from fumbling blocks to asking me to explain how extinction occurs and what we can do about it reinvigorates my sense of

wonder about the marvels of the human condition and my sadness that so many suppress or squander it.

For Rob, Sam, and Charlotte 


\section{ACKNOWLEDGMENTS}

Though my name appears on this dissertation, know that a wonderful host of advocates, critics, and friends have supported me by recommending that I read ten more research papers on a topic, striking out pages of perfectly appropriate writing, and causing me to rethink my process hundreds of hours into writing this study. To these academic sadists, I say thank you.

Counted among my antagonizers, Dr. Deborah Powers has been one of my most stalwart professional advocates, who through two leadership institutes and a doctorate program has cajoled me with Kentucky's finest homemade salsa to continue bettering myself academically and professionally. I would also like to acknowledge Dr. Doug Stevens for his kindness, candles, and comfort food through multiple semesters of figuring this all out together. His insightful criticisms, masked in the Trojan Horse of middle-American hospitality, offered guidance when most needed. I also appreciate Dr. Keith Davis for reminding me that this program was being offered in Kentucky. Few in this program had the colloquial wit and humor he provided and fewer still appreciated it. I always looked forward to his comments, which offered a mix of Mark Twain and David Sedaris, on my work. To Dr. Brydon-Miller, who charged into my dissertation with fearless wisdom, thank you for reading every word I sent you. Your unapologetic criticism moved my study in a direction that enriched its findings and my professional growth through the process. 
Last, I would like to thank my family: my father for his stoicism, my mother for her creativity, my siblings for taking the roads less traveled, my in-laws for their unwavering support, and my wife for handling our three little children throughout the purgatory of 2020 while I drowned out the cacophony with Max Richter in the basement and wrote this study. 


\begin{abstract}
A PHENOMENOLOGICAL STUDY OF KINDERGARTEN TEACHERS' PERCEPTIONS OF THEIR STUDENTS IN THE AGE OF KINDERGARTEN READINESS

Adam N. Stephens
\end{abstract}

November 17, 2020

Kindergarten has changed dramatically from a play-based, social experience a generation ago to the literacy- and numeracy-based curricula of today. With this shift in academic expectations, children now take a kindergarten readiness assessment at the beginning of the school year to determine their likelihood of success based on their prekindergarten preparation. While previous studies have examined teachers' perceptions of current kindergarten practices, expectations, and students, few use teachers' descriptions as the data (Abry et al., 2015; Hustedt et al., 2018). This phenomenological study reports how kindergarten teachers at three Central Kentucky elementary schools describe their attitudes about their own kindergarten teaching experiences, vocation, and students in an era of kindergarten readiness. This study uses semi-structured interviews to explore kindergarten teachers' perceptions of their experiences with kindergarten students concerning their perceptions of their own kindergarten experience and how teaching kindergarten has affected their personal and professional lives.

Keywords: teacher perception, kindergarten readiness, teacher vocation 


\section{TABLE OF CONTENTS}

PAGE

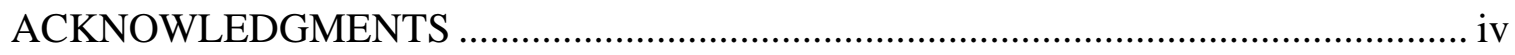

ABSTRACT ......................................................................................................... vi

CHAPTER I: INTRODUCTION ...................................................................... 1

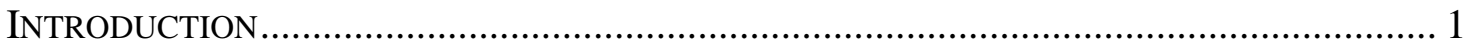

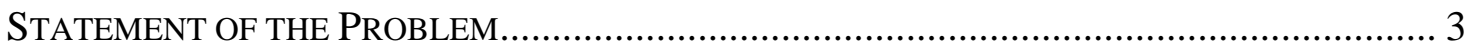

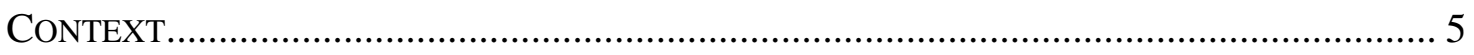

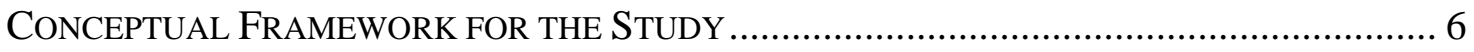

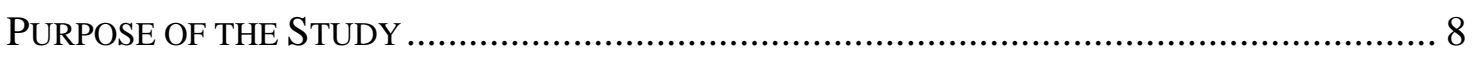

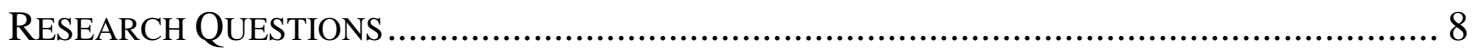

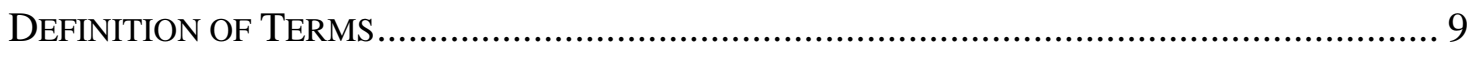

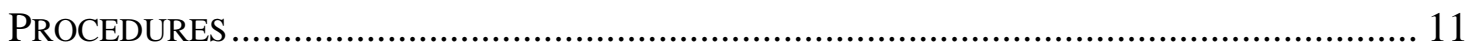

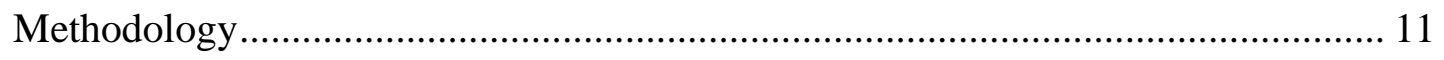

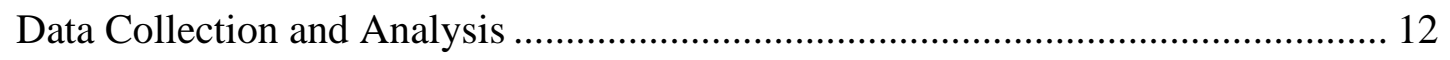

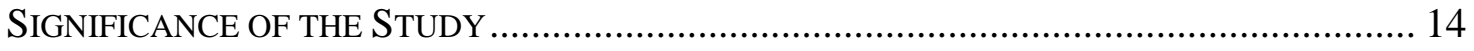

LIMITATIONS OF THE STUDY ........................................................................... 14

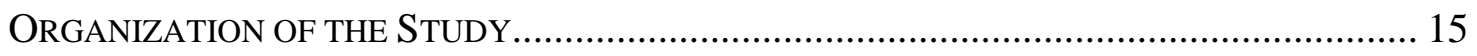

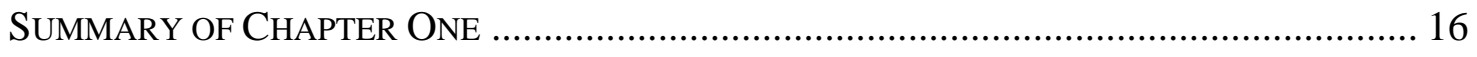




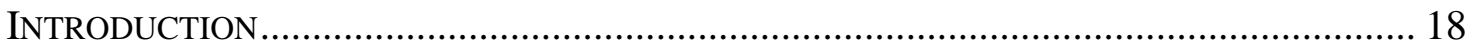

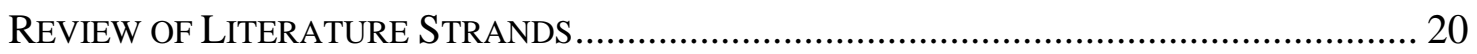

Strand 1: Kindergarten Readiness ........................................................................ 20

Assessments Used to Determine Kindergarten Readiness......................................... 25

Funds of Knowledge: An Alternative to Kindergarten Readiness Paradigms. ......... 27

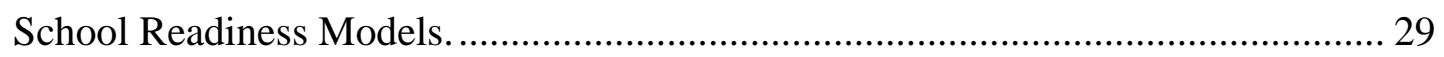

Strand 2: Risk and Protective Factors...................................................................... 38

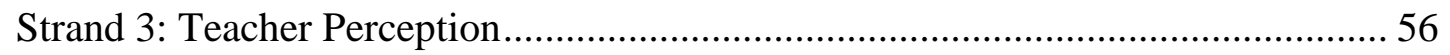

SUMMARY AND IMPLICATIONS OF THE LITERATURE REVIEW .......................................... 60

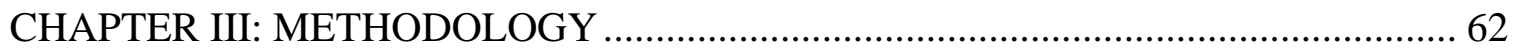

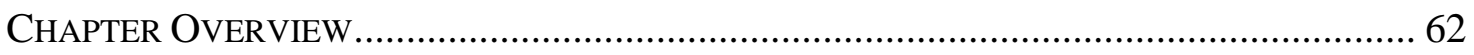

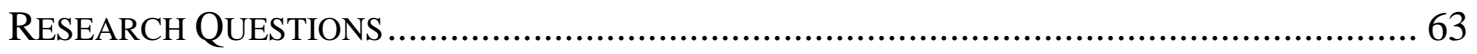

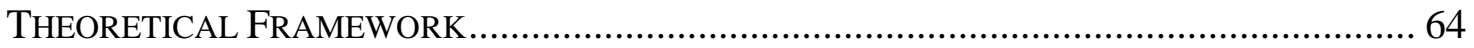

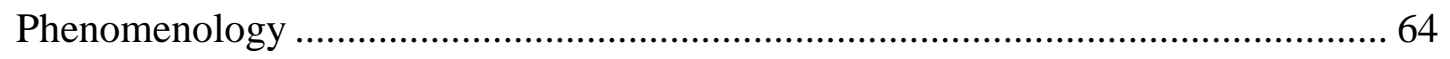

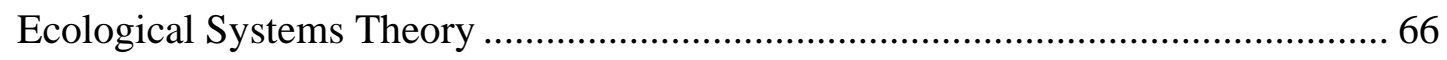

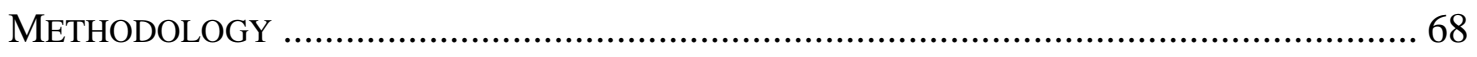

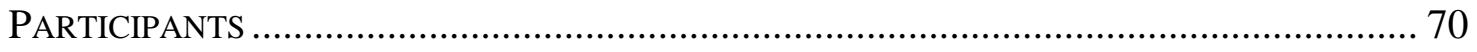

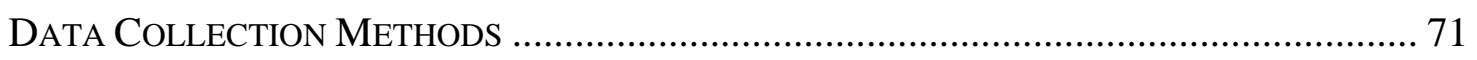

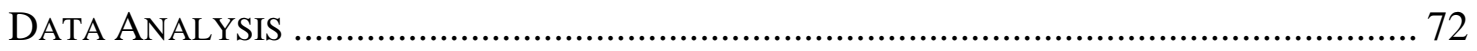

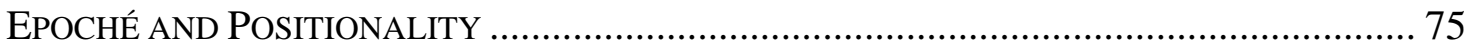

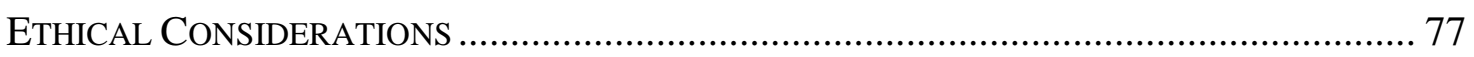

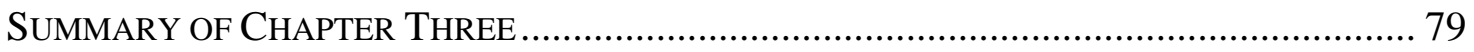




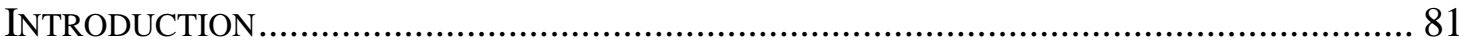

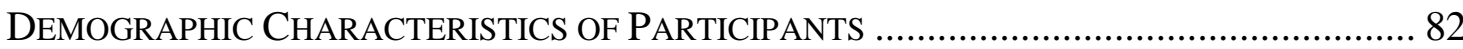

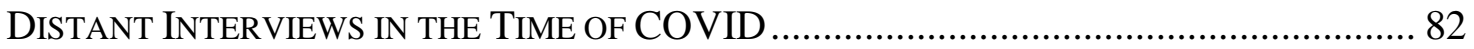

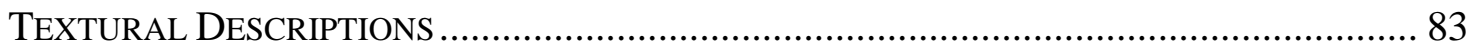

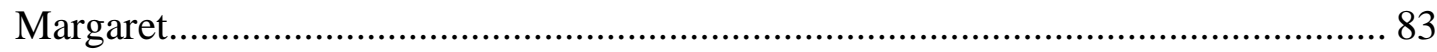

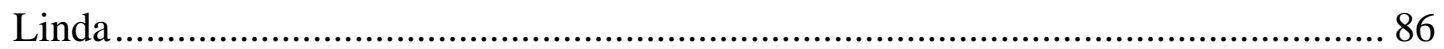

Maria

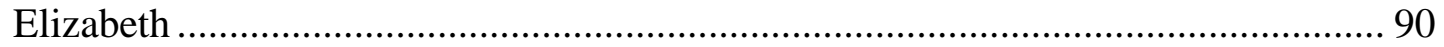

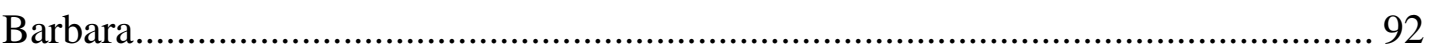

Mary

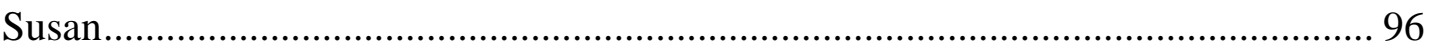

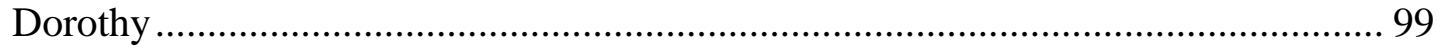

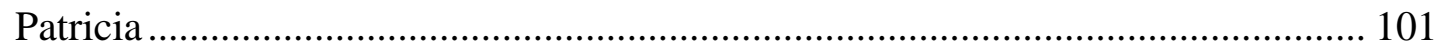

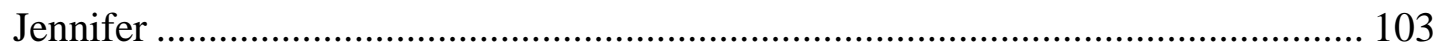

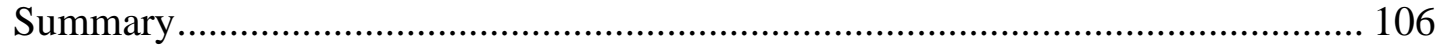

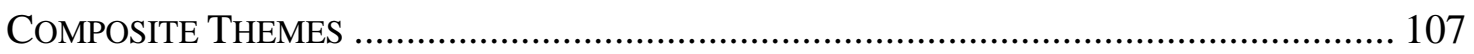

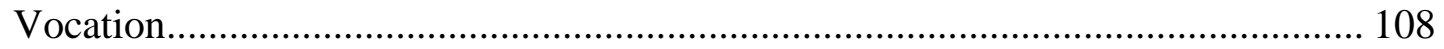

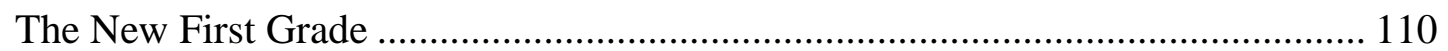

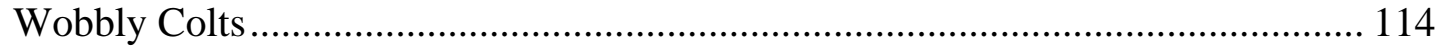

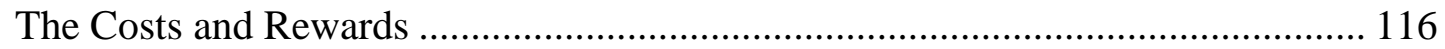

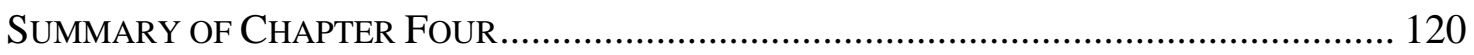

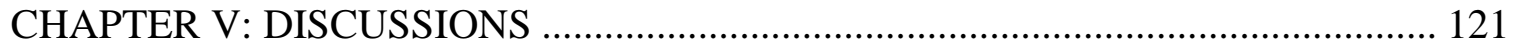




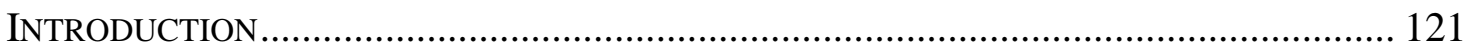

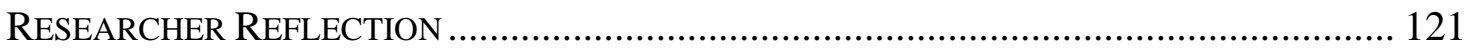

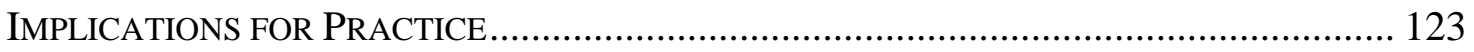

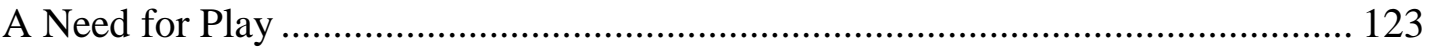

Broadening Our Thinking of Readiness ................................................................ 127

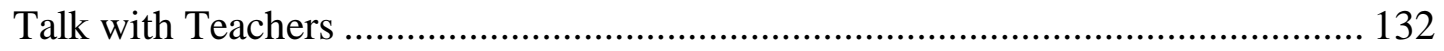

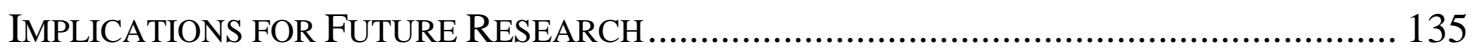

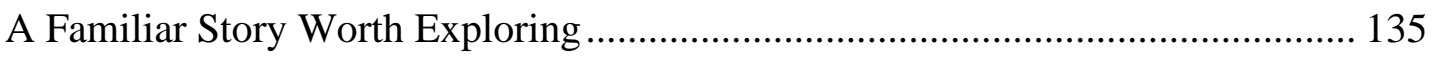

Expanding Explorations of Perception ................................................................. 136

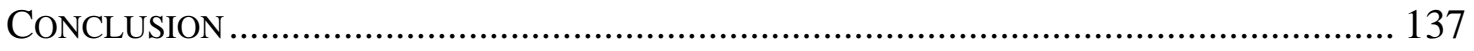

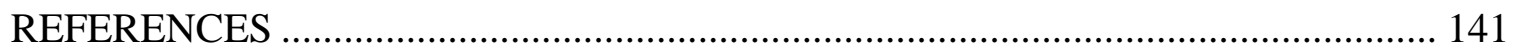

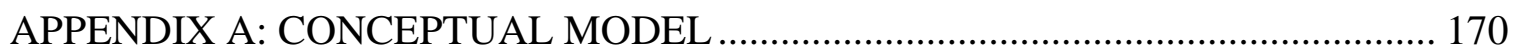

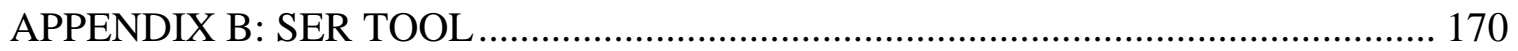

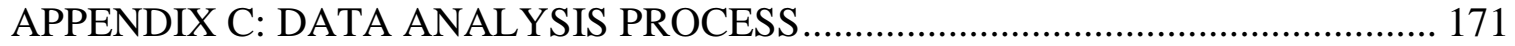

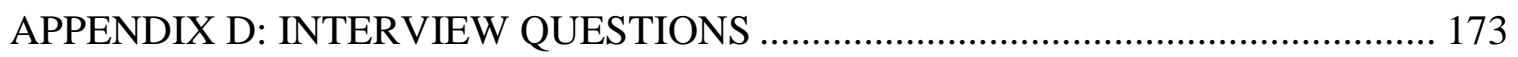

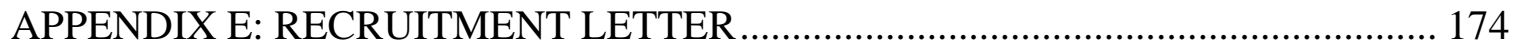

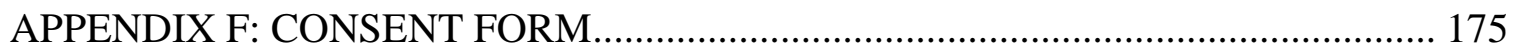

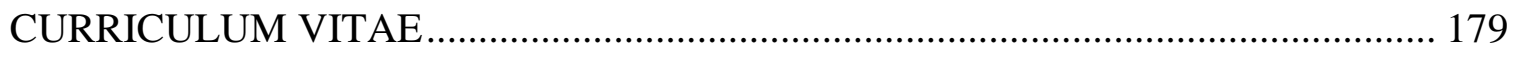




\section{CHAPTER I}

\section{INTRODUCTION}

\section{Introduction}

For many, the first experience of school is affectionately associated with primary colors, crayons, playing with new friends, and the thoughtful guidance of a caring kindergarten teacher. Kindergarten teachers are often the first adults other than our parents who are entrusted with our wellbeing and development. Because kindergarten is

often remembered fondly, we view kindergarten teachers as archetypes, caring custodians who happily spend their days creating fun activities and tending their flocks. Teachers, however, are as complex and varied as their students. Each teacher, molded by their circumstances, culture, and social interactions, provides students with a unique learning experience. These intricate teacher and student interactions are an essential part of the multifaceted process by which students prepare and are being prepared for ensuing curricula and life in general.2

While some scholars suggest that the phenomenon of school readiness should be studied from the vantage point of parents (Coley et al., 2015; Holliday et al., 2014), others favor examining the experiences of students (File \& Gullo, 2002). Both perspectives are necessary to understand how children's lives before kindergarten shape their development, but examining teacher experiences is essential to understand how student readiness affects not only the learner and subsequent learning but also 
teachers' pedagogies. Such studies may provide insights into the onboarding of students from diverse backgrounds, the potential consequences of household disorder and other risk factors, and the potential inequities that occur when student readiness assessments herald high-stakes accountability testing at the moment when children are transitioning from home to school.

Although research studying pre-school and early education topics survey parents of children at preschool ages (Coley et al., 2015) and others examine student perceptions after entering school (File \& Gullo, 2002; Vernon-Feagans et al., 2016), kindergarten teachers - the professionals entrusted with closing kindergarten-readiness gaps and improving learning — are frequently sidelined (Coley et al., 2015; File \& Gullo, 2002; Holliday et al., 2014; Vernon-Feagans et al., 2016). Furthermore, research studies may examine the instructional practices of preschool or kindergarten teachers, but teachers' experiences with those strategies and the contextual experiences framing those implementations are largely absent from the literature (Duncan et al., 2007; File \& Gullo, 2002; Xue \& Meisels, 2004). Finally, research studies that offer descriptions of preschool and kindergarten teachers' experiences may be less relevant or universal because of the time the study was conducted or the representation of teachers' experiences as quantitative data (Fantuzzo et al., 2012; Smith \& Shepard, 1988). Such representations offer the semblance of teachers' experiences but lack substantive contexts that enrich understanding.

Though the research literature emphasizes the importance of kindergarten readiness, the potential inequities such designations may cause, and the complications of students entering school not ready, greater attention to the experiences of teachers may 
illuminate student group disparities due to access, disabilities, and poverty (Duncan et al., 2007). Professional perceptions, including attitudes and beliefs about closing achievement gaps, are largely missing from the conversation. Descriptions of teachers' experiences are needed to holistically account for the complex transaction between evolving professional strategies and dispositions and the diverse funds and needs of students who enter schools. Such research may be a missing component in the ongoing analysis of how schools onboard half of the population coming to school unprepared (Kentucky Department of Education, 2020).

This phenomenological study intends to elevate the voices and lived experiences of kindergarten teachers as a means to explore the phenomenon of kindergarten readiness through teacher perception. Though many qualitative studies have analyzed risk factors that could negatively impact kindergarten readiness as well as the diverse home ecologies in which students develop, few studies offer kindergarten teacher experiences as another framework for analysis. Furthermore, I hope that this study, through my analysis of the thick descriptions provided by participant teachers, not only humanizes the kindergarten readiness discourse that is generally dependent on disaggregated benchmark scores but enriches and informs professional development discussions focused on meeting the needs of teachers and students to improve academic achievement (Geertz, 1973).

\section{Statement of the Problem}

Although children's varied home ecologies and funds of knowledge, the potential, deleterious effects of household disorder and other risk factors on child development, and the potential difficulties students encounter transitioning to school are well documented, less is known about how students' perceived lack of knowledge affects kindergarten 
teachers and their pedagogies (Duncan et al., 2007; Fantuzzo et al., 2012; File \& Gullo, 2002; González et al., 2005; Hogg, 2011; Moll, 2000; Moll \& González, 1997; Smith \& Shepard, 1988; Rodriguez, 2013; Riojas-Cortez \& Bustos Flores, 2009; Rios-Aguilar et al., 2011; Vélez-Ibáñez \& Greenberg, 1992; Xue \& Meisels, 2004; Zipin2009). Moreover, research focused on the phenomenon of kindergarten and ecological transitioning to the school microsystem (i.e., transitioning from largely living at home to spending time in the school setting) examines parent and student experiences but rarely elicit the perspectives of teachers. Research studies that have relied on teachers' perspectives collected data through surveys. While quantitative data collected from these surveys provide insights into teachers' preferred methodologies (Hustedt et al., 2018; Lin et al., 2003), exploring the phenomenon of kindergarten readiness from teachers' perspectives requires retaining the nuanced complexities of their voices through interviews.

Like students, teachers are influenced by the relationship between home and workplace microsystems (Bronfenbrenner, 1979). Unlike students, however, teachers have experienced many ecological shifts during their longer life spans. Whereas students' mesosystems are generally composed of two distinct microsystems, home and school, teachers are influenced by a complex history of microsystems including their childhood ecologies, various home and work settings, and other networks and social systems (e.g., clubs, social organizations, and friendship networks); therefore, while students are heavily influenced by the interpersonal relationships with caregivers, affective relations, balances of power, and molar activities of two microsystems, teachers' past experiences and ecological transitions affect their participation in the 
immediate school microsystem (Bronfenbrenner, 1979). As such, teachers have formed schemas that may affect how they perceive their students and how they interpret the reciprocal relationships within the school ecology (Goodwyn, 2010; Laughlin \& Tiberia, 2012).

\section{Context}

Many children starting kindergarten are identified as having insufficient skills and knowledge. In Kentucky, the setting of this study, almost half of all students entering kindergarten are not considered kindergarten ready. Kindergarten readiness is defined as the pre-kindergarten cognitive skills and knowledge necessary to succeed in kindergarten. Kindergarten readiness evaluation checklist indicators generally include understanding basic book features, knowing the alphabet and the sounds letters make, counting, demonstrating fine and gross motor skills, and demonstrating developmentallyappropriate graphomotor and writing skills (Blair et al., 2007; Blair \& Raver, 2015; Graue, 2006; Meisels, 1996; O’Connor \& McCartney, 2007; Pierson, 2018). These checklists, however, do not measure the complex funds of knowledge students develop in diverse home ecologies that could potentially enrich teachers' perceptions of their students as well as the strategies intended to promote academic achievement (González et al., 2005; Hogg, 2011; Moll, 2000; Moll \& González, 1997; Rodriguez, 2013; RiojasCortez \& Bustos Flores, 2009; Vélez-Ibáñez \& Greenberg, 1992). Consequently, exploring the complex student onboarding and development process through teachers' experiences may illuminate how readiness data are used, how these data inform teachers' perceptions of their students, and what if any other information teachers synthesize with assessment data to inform instruction. 
Although research studies examining the effects of home ecologies on child development concerning kindergarten readiness are many, studies utilizing kindergarten teacher perceptions to explore the phenomenon are few; therefore, this study provides an analysis of teachers' lived experiences through semi-structured interviews. Participating teachers, from urban and suburban Central Kentucky elementary schools, participated in interviews intended to explore their past experiences as kindergarten students, their senses of vocation, their perceptions of their students, and how teaching kindergarten has affected their personal and professional lives and instructional practices. Interviewed teachers represent a range of experience levels, ages, geographic origins, work experiences, etc. that provide diverse viewpoints on their profession and the students they serve.

The schools in which the participants of this study work are located in a district that provides both urban and suburban settings. The students with whom the teachers work also vary in racial and ethnic diversity, socioeconomic status, and home ecologies. Therefore, though the readiness and grade-level standards are the same, classroom ratios of students identified as ready for kindergarten and not ready for kindergarten, the varied home ecologies from which students arrive, and the necessary instructional strategies and pedagogies diverge. Moreover, class sizes and the available assistance in the classroom from kindergarten assistants, paraeducators, and student teachers also differ.

\section{Conceptual Framework for the Study}

This study explores the lived experiences of kindergarten teachers as they work to meet the needs of their students, particularly those designated as not ready for kindergarten. Phenomenological research studies attempt to explore how participants 
construct meaning from their experiences; therefore, this study offers participants' verbatim responses to invite interpretation and increase validity (Bronfenbrenner, 1979; Creswell et al., 2007). This study's research design adheres to Husserl's phenomenological method in that I attempted to bracket ${ }^{1}$ myself to mitigate the influence of preconceptions and experiences in exploring participants'

lifeworlds (Creswell et al., 2007;

Husserl, 1964; Tufford \& Newman, 2012). Furthermore, this study follows Giorgi's (1985) four-step phenomenological data analysis method in that the holistic meanings of

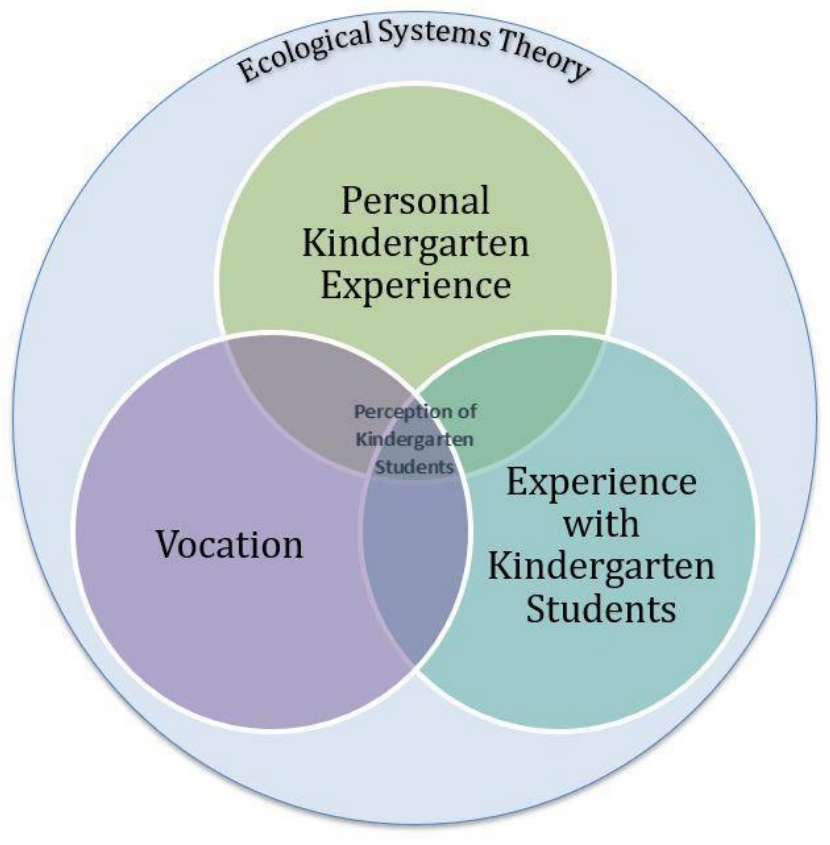

Figure 1 provides a conceptual model of the phenomenon that this study investigates and the supporting theories. participants' experiences are determined by transforming parts of interview data into meaning units to determine structures and themes.

In addition to the phenomenological methodological framework, this study builds upon a supporting theory, ecological systems theory. Bronfenbrenner's theory of

1 Bracketing to account for the researcher's beliefs and opinions, immersion in the study to increase open-mindedness of the meaning or meanings of the phenomenon, data analysis involving multiple phases of coding to identify themes, describing and defining the phenomenon. 
ecological development (1979) holds that children are influenced by different ecosystems of varying degrees of intimacy and proximity. The most influential ecosystem, the microsystem, includes immediate environments such as a home or school and persons who influence the child. Extending beyond the microsystem, the mesosystem, exosystem, macrosystem, and chronosystem represent expanding spheres of social and cultural influence. Bronfenbrenner's theory (1979) informs this study in that (a) teachers and students inhabit the same microsystems and thus are potentially influencing each other's perceptions and actions and (b) teachers themselves are potentially influenced by their experiences as kindergarten teachers and past kindergarten experiences as students.

\section{Purpose of the Study}

The purpose of this phenomenological study is to report how kindergarten teachers at three Central Kentucky elementary schools describe their attitudes about their own kindergarten teaching experiences, vocation, and students in an era of kindergarten readiness. This study also explores kindergarten teachers' perceptions of their experiences with kindergarten students concerning their perceptions of their own kindergarten experience and how teaching kindergarten has affected their personal and professional lives.

\section{Research Questions}

The explored phenomenon began with a series of inquiries intended to initiate the discovery process. These questions included forays into kindergarten teachers' experiences working with kindergarten students including those labeled not ready for kindergarten, the effects of working with kindergarteners on teachers' professional and personal lives, and teachers' memories of being kindergarten students themselves. 
Questions used to explore kindergarten teachers' complex interpretations and responses to the phenomenon of readying students for subsequent schooling include: How have teachers' experiences as kindergarten students formed their expectations for their students? How has teaching kindergarten, particularly those students labeled not ready for kindergarten, affected teachers' professional and personal lives? How has teaching students who are identified as not ready for kindergarten affected teachers' instructional practices?

Generative Questions:

RQ1: How have teachers' experiences as kindergarten students formed their expectations for and perceptions of their students?

RQ2: How do kindergarten teachers perceive their students, especially those labeled not ready for kindergarten?

RQ3: How has teaching kindergarten, particularly those students labeled not ready for kindergarten affected teachers' professional and personal lives?

RQ4: How has teaching students who are identified as not ready for kindergarten affected teachers' instructional practices?

\section{Definition of Terms}

Ecological systems theory - a framework that examines interpersonal relationships within ecological systems: microsystem, mesosystem, exosystem, macrosystem, and chronosystem (Bronfenbrenner, 1979).

Ecological transition - occurs whenever a person's position in the ecological environment is altered as the result of a change in role, setting, or both (Bronfenbrenner, 1979, p. 21). 
Funds of knowledge - knowledge and competencies students historically and socially develop in home ecosystems (Moll \& González, 1997; Vélez-Ibáñez \& Greenberg, 1992)

Household disorder - Home microsystems characterized by recurrent distractions, limited structure and routines, and frequent changes in family structure and residential moves (Garrett-Peters et al., 2016, p. 1).

Phenomenology - A reduction of the experiences of persons with a phenomenon to a description of the universal essence (Creswell et al., 2013).

Protective factor - Beneficial ecological factors (e.g., maternal education level, low-population density residence, attachment to adults) that influence the social and emotional development of children (Bender et al., 2011).

Kindergarten readiness - The emergent outcome of the interaction between child and environment characteristics consistent with an overarching developmental science approach to child development (Blair et al., 2007).

Mesosystem - a set of interrelations between two or more settings in which the developing person becomes an active participant (Bronfenbrenner, 1979, p. 209).

Microsystem - a pattern of activities, roles, and interpersonal relations experienced by the developing person in a given setting with particular physical and material characteristics (Bronfenbrenner, 1979, p. 22).

Molar activities - constitute both the internal mechanisms and the external manifestations of psychological growth (Bronfenbrenner, 1979, p. 6). 
Not ready for kindergarten - A student designation, typically determined by statewide kindergarten readiness tests, that indicates that a child has not acquired the learning and developed the skills necessary to succeed in kindergarten.

Risk factor - Detrimental ecological factors (e.g., poverty, relationship and residential instability, crime) that influence the social and emotional development of children (Bender et al., 2011).

School readiness gap - The variations in academic performance and certain social skills among children entering kindergarten (Sadowski, 2006).

\section{Procedures}

\section{Methodology}

The experiences of kindergarten teachers regarding responding to students identified as not ready for kindergarten are absent from the research literature analyzing school readiness and its relationship with subsequent achievement (Bronfenbrenner, 1979; Coley et al., 2015; File \& Gullo, 2002; Holliday et al., 2014; Vernon-Feagans et al., 2016). Therefore, I chose a phenomenological design to acquire a deeper understanding of the meaning of this phenomenon through interviews intended to elicit kindergarten teachers' experiences. I used a Husserlian phenomenological approach that explores the lifeworlds of kindergarten teachers as a means to define the common homeworld experienced by kindergarten teachers in general (Husserl, 1964). Moreover, I chose a Husserlian phenomenological design because it requires that I am aware of my own biases of and experiences with kindergarten education (Husserl, 1983). As an educator and evaluator of education, I must enact an epochē, a process by which my 
preconceived notions are set aside, for the exploratory process to be directed primarily by the participants' lived experiences with the phenomenon.

Despite evidence from previous studies indicating that kindergarten teachers prioritize social skills development over academic growth, my experiences with kindergarten teachers are markedly different (Fantuzzo et al., 2012; Smith \& Shepard, 1988). The kindergarten teachers with whom I have collaborated have built empathetic relationships with their students and worked diligently to improve students' phonemic awareness, basic numeracy skills, and emerging writing. Social skills, often kindergarten teachers' main focus during the first weeks of school, were instilled fairly quickly for most students so academic work can begin. Although recalibration and frequent reminders of norms were typical, the instructional focus shifted to academic standards as soon as possible because kindergarten students were expected to be first-grade ready by the end of the school year. Despite my own experiences, phenomenological research requires that I bracket my paradigms and biases to approach the phenomenon openly (Creswell et al., 2007; Creswell \& Poth, 2018; Husserl, 1964, 1983).

\section{Data Collection and Analysis}

I invited kindergarten teachers from three Central Kentucky elementary schools to participate in the study. Based on the responses, I randomly selected willing participants from each of the schools. Participants were selected because they offer varying demographic differences such as years of service, age, geographic origin, and educational experience. Although I would have preferred to have participants of varying ethnicities, kindergarten teachers in the region are almost exclusively white and female; therefore, respondents to my requests for interviews lack my preference for ethnic diversity but 
offer myriad other complex, nuanced perceptions worth of study. Interview times and locations were chosen by the participants. The interviews were conducted through Microsoft Teams and private to ensure confidentiality. Interviews were audio-recorded on my laptop and cellular phone to guard against technology issues and later transcribed by Rev, a paid transcription service. To ensure accuracy, I reviewed each transcription against the recorded interview and invited participants to check audio recordings and transcriptions for accuracy.

I conducted ten interviews with semi-structured and open inquiry to create conditions conducive for dialogue. Though all interviews featured previously written, semi-structured questions, responsive questions varied based on teachers' responses. The semi-structured questions were shared with participants before the interview to encourage participation by allaying fears and to elicit feedback. Participants were interviewed in a singular sitting consisting of three parts: past perceptions and experiences as kindergarten students themselves, present experiences and perceptions of the phenomenon of educating children in the current environment of school readiness, and the effect of the phenomenon on their professional and personal lives.

Throughout the data collection process, iterative and progressive analysis of new data was recursive and holographic. That is, the data analysis process repeated as new interview data were collected and older analyses were updated to account for new trends and themes found in the totality of data collected. Once interviews were complete, interview transcription data were analyzed through a process called horizontalization wherein data were reevaluated without redundancies and given equal value to further ensure that textual descriptions of participants' experiences were accurate (Creswell, 
2013). In the final series of reductive coding, I identified significant statements (narrow units) and categorized these statements into meaning units during open coding and throughout the coding process to discover common perceptions and themes. Next, a fellow reader and I reviewed open codes and heuristically identified patterns during axial coding to improve validity by collaboratively categorizing codes into broader concepts. Last, axial codes were further analyzed during the selective coding stage to establish core categories and theoretical models of the observed phenomena (Creswell, 2013; Miles et al., 2014; Saldaña, 2016).

\section{Significance of the Study}

Teachers' perceptions-influenced by their own kindergarten, life, and work experiences — could affect their expectations for incoming students, particularly those labeled not ready for kindergarten, and their pedagogies. Moreover, school and state expectations for transitioning kindergarten students to first grade as well as a lack of effective professional development and other supports could affect teachers' professional and personal lives. While a myriad studies examine kindergarten readiness and the readiness gaps that appear predicated on socioeconomics and racial identities, few studies offer kindergarten teacher experiences as another framework for analysis. This study offers the experiences of kindergarten teachers to broaden and enrich the discourse of meeting the academic needs of students. I hoped that such explorations would not only illuminate the personal and professional costs and needs of kindergarten teachers to improve support but inform the potential professional development necessary to meet the needs of students from various home ecologies as well.

\section{Limitations of the Study}


Though I used a phenomenological framework for this study, my analysis of teachers' interviews is limited by my own experiences. Despite my attempts to bracket my own biases, paradigms, and schemas, the very act of bracketing these preconceptions was limited by my understanding of the process and my decision making throughout the process of horizontalizing and coding data to identify themes and meaning. Moreover, potential teacher participants employed in the district work in suburban and urban public schools. Rural and private school kindergarten teachers, though equally important, were not interviewed because of a lack of availability and scope. Last, another limitation of this study may have been the balance of power between myself and the participants. Because I am a school administrator and my participants are teachers, responses may have been influenced by the power imbalance despite my efforts to build rapport and regardless of my non-evaluative relationship with interviewees.

\section{Organization of the Study}

This study is organized into five chapters. The first chapter provides an introduction to the research phenomenon, questions, and significance. The second chapter offers a review of literature on the topics of kindergarten readiness, protective and risk factors for child development, and kindergarten teacher perception. The third chapter conveys the study's research methodology including the primary theoretical framework, Husserlian phenomenology, and the supporting theory, ecological systems theory, that provide the relevant theoretical assumptions used to limit generalizations made about the phenomenon.

Details concerning participants and interview structures, the recursive and holographic data analysis processes, and a general justification of methodological choices made to 
explore the phenomenon are also provided in the third chapter. The penultimate chapter offers textural descriptions of participant interviews and the themes pertaining to the phenomenon of kindergarten readiness and the lived experiences of kindergarten teachers. The final chapter provides conclusions and the relevance of the findings to the existing literature as well as suggestions for applications to professional development and future research on the topic.

\section{Summary of Chapter One}

This chapter provided an introduction to the studied phenomenon, how kindergarten teachers' lived experiences were explored, and the potential benefits this study may effectuate. In addition to explaining how my interest in this topic developed from past work experiences and professional interests, this chapter presented the theoretical framework and supporting theory employed to conceptualize and limit the phenomenon to specific foci. With the phenomenon defined and the analytic parameters explained, this chapter provided the salient definitions necessary to understand common terms used in the research literature to understand this study's findings. Last, the significance of this study to teacher support, preparation, and development, as well as the limitations of the study and the need for additional research, are conveyed to provide the actionable extensions from this study to practitioner and academic settings.

The literature review chapter that follows offers my exploration of three literature strands intended to provide me with a better awareness of kindergarten readiness, cognitive development and home-school transitioning, and teacher perception. The research necessary to understand not only the different assessments used by states and districts for kindergarten readiness but also divergent models of kindergarten readiness is 
provided to illuminate competing definitions and measures used to determine school readiness. The second literature strand intends to inform my understanding of home microsystems and risk and protective factors for child cognitive and social development to appreciate the possible reasons students are or are not ready for the ecological transition to formal school microsystems. Last, the literature review offers a survey of research that focuses on kindergarten teachers' perspectives because this study hopes to improve understanding of teachers' lived experiences. 


\section{CHAPTER II}

\section{LITERATURE REVIEW}

\section{Introduction}

My visceral understanding of kindergarten readiness was conceived on my first day as an elementary administrator as I met our new kindergarteners off the bus. The first day of formal schooling was exciting and awkward for all of the students, but some more easily transitioned than others. Most of the students, as expected, appeared lost and confused albeit happy and enthusiastic. A few others were resistant, antisocial, and pouty. One girl barked at me as she exited the bus and tried to run away. Later that day, I attempted to no avail to teach her how to use a fork. I had worked with thousands of students, many of whom were varied in their academic and social skills, throughout my professional career as a high school teacher and administrator, but I had never encountered students at the starting gate of public education, at the first contact between home and school.

As the year progressed, I became more aware of our kindergarten students' home lives. Some were being raised by drug addicts while others were the sole progeny of two educated parents; some moved frequently while others had lived in the same house their entire lives; some of the children's parents read to them frequently while others' parents worked multiple shifts and did not have the leisure time to do so; some students did not sleep because of the noise of their cohabitating siblings or their neighborhoods while 
others in middle- or upper-class neighborhoods slept soundly in their bedrooms; some came to school ravenous while others ate breakfast at home and arrived in their classrooms ready to learn. In short, the home ecology differences in our kindergarten classes were stark despite the small area the school served.

My interest in what hindered the social and cognitive development associated with readiness was met by my intrigue in what we could do as educators to offset it. This interest is manifest in my research of risk factors, any exposure or characteristic that negatively affects wellbeing and development, and protective factors, any exposure or characteristic that positively affects wellbeing and development or offsets risk factors. Additionally, my interest in improving the academic trajectory of children required that I explore the definitions and models for how kindergarten readiness is defined and assessed as well as divergent models, such as funds of knowledge, that illuminates potential school-system inequities and how professional development may mitigate the problem. Though the research base on household disorder - an environment defined by a lack of safety, organization, and routine that contributes to confusion and agitation - is broad and comprehensive, societal changes necessitate continued research and synthesis to address the needs of new children entering school, a system that glacially changes and at times appears inadequate to meet the charge (Berry et al., 2016; Corapci \& Wachs, 2002; Matheny et al., 1995; Vernon-Feagans et al., 2016).

Despite the bureaucratic speed by which schools evolve, kindergarten teachers must constantly pivot to the evolving needs of their students. As such, kindergarten teachers serve the unique role of being empathetically responsive to the experiences and behaviors children bring into the classroom while onboarding their students to the 
increased academic expectations of kindergarten. A generation ago, students' kindergarten experiences mostly involved play and socialization. Now, many schools assess students' abilities before they ever step foot in a classroom. In fact, kindergarten has changed so much during the last twenty years that it is commonly called "the new first grade" (Bassok et al., 2015). Despite the importance of the work and the uniqueness of the position, kindergarten teachers' voices are largely missing from analyses of why children are not ready for kindergarten and how schools can improve academic achievement for all students regardless of access and opportunity.

This phenomenological study attempts to elevate the voices of kindergarten teachers to add their experiences to the ongoing discourse of kindergarten readiness. To effectively describe these experiences, several questions need to be explored: "How do kindergarten teachers perceive their students, especially those labeled not ready for kindergarten?", "How has teaching kindergarten, particularly those students labeled not ready for kindergarten, affected teachers' professional and personal lives?", and "How has teaching students who are identified as not ready for school affected teachers' instructional practices?" In addition to investigating how teaching kindergarten affects teachers' lives, teachers' accounts of their own kindergarten experiences are explored. This vital piece of how teachers initially constructed their schema of what kindergarten is and who kindergarteners are may provide insights into teachers' expectations of their students and how they define school readiness.

\section{Review of Literature Strands}

\section{Strand 1: Kindergarten Readiness}


General Definition. For much of kindergarten's 150-year existence in America, students' first year of formal schooling entailed spontaneous play, exploration, and socializing with classmates. The German theorist who founded kindergarten, Friedrich Froebel, first conceptualized kindergarten while tutoring children in a loaned garden (Eschner, 2017). Under his care, these children grew through hands-on experiences and direct observation. From this experience, Froebel derived the term Kindergarten to embody this experience— - kinder meaning children and garten meaning garden. Froebel opened his own kindergarten in 1837. In his classroom, children too young to previously attend school learned in much the same experiential and exploratory manner that his previous students had enjoyed in the garden (Eschner, 2017). For Froebel, providing early education for children was essential "because learning begins when consciousness erupts" (Early Childhood Today Editorial Staff, 2000). Children's emerging curiosity about how the world works and how we find our place in it was at the center of early kindergarten learning. Froebel called this educational approach self-activity, which allowed students to freely pursue learning through their interests, creativity, observations, and deductions (Early Childhood Today Editorial Staff, 2000).

Kindergarten remained relatively unchanged from Froebel's original model until the latter half of the twentieth century (Bloch \& Kim, 2015). Before the shift of academic expectations from primary to kindergarten, the kindergarten curriculum focused largely on socializing, moral conduct and behavior, play, and basic language development. Kindergarten was intended to bridge home life to the structured expectations of school, which represented the rigors and norms of society (Bloch \& Kim, 2015). In this sense, kindergarten was a cultural construct intended "to assimilate 
children to middle- and upper-class morality and conduct" (Bloch \& Kim, 2015, p. 3).

The notion of high-quality early education, based on the values of "certainty and mastery, linear progress and predetermined outcome, objectivity and universality, stability and closure" influenced policy and practice in the United States in the 1990s (Dahlberg et al., 2007, p. 22).

For many Americans, enrolling in kindergarten is a rite of passage. It marks the time in a child's life when further maturation requires leaving home and beginning the long journey to self-reliance and societal contribution. Parents generally begin thinking about kindergarten when their children are toddlers. I began to compare my first son's cognitive development to other children as early as six-months-old. Not only was I gauging his abilities but also my parenting as a means to help him prepare for the challenges of stepping into a much broader community. These comparisons and assessments are common. As far back as the Middle Ages, parents were told that children should start school when they could delay gratification by choosing money over fruit (Weil, 2007). During the Renaissance, German parents used the criterion of rationality, as subjective as that might be, to determine if a child was ready for school (Weil, 2007). Modern American kindergarten enrollment decisions are often dictated by state legislatures' seemingly arbitrary selection of a date on the calendar. Though these dates are clear cut-offs for when children may enroll in kindergarten, states like Kentucky allow districts the option to allow parents to enroll early if a child is deemed cognitively and socially ready or academically redshirt if a child needs another year at home (Kentucky Department of Education, 2015). Therefore, even though legislation dictates 
when children must enroll in kindergarten, parents continue to have some say as to when children are ready to enter school.

Per Pierson (2018), 26 states had either informally promoted or formally defined kindergarten readiness. Six additional states were in the process of creating a definition. These states defined kindergarten readiness to identify students with special needs, inform instruction and professional development, and provide a baseline for monitoring kindergarteners' progress over time (Pierson, 2018). Though many states have passed clear guidelines for when a child must enroll in public school, definitions of kindergarten readiness vary. All states have learning standards that address pre-kindergarten years and set kindergarten learning standards to some degree (Regenstein et al., 2017). For most states, the definition commonly identifies the point at which a child is ready for formal education (Pierson, 2018). While that definition seems fairly simple, determining when a child is ready and for what criteria is fraught with complexities. Each institution may have different demands, parents may value disparate abilities that denote maturity, and a myriad of other influences such as childcare costs, cultural precedents, social competitiveness, etc. likely influence school readiness decisions (Blair et al., 2007; Dhuey et al., 2017; Pierson, 2018).

Kentucky, the setting of this study, defines kindergarten readiness as: "School readiness means that a child enters school ready to engage in and benefit from early learning experiences that best promote the child's success. Families, early care and education providers, school staff and community partners must work together to provide environments and developmental experiences that promote growth and learning to ensure 
that all children in Kentucky enter school eager and excited to learn" (Curriculum Associates, 2019b).

Though this definition loosely articulates when a child should enter school and who should collaborate to teach students before they enter, it does not state how readiness should be measured. Like many states' definitions, Kentucky does not detail a process but rather values such as parent and community partnerships and exciting and engaging learning. Like other states, more specific expectations of kindergarten readiness can be found in the assessment or screener used rather than the general ideas expressed in the definition. Despite the lack of clarity state definitions provide for kindergarten readiness, abilities such as social skills, emergent literacy abilities, command of the language, motor skills, numeracy adeptness, and behavioral self-regulation are common indicators found in both research and the assessments many districts and schools employ to gauge readiness (Blair et al., 2007; Blair \& Raver, 2015; Graue, 2006; Meisels, 1996; O'Connor \& McCartney, 2007).

General kindergarten readiness standards and checklists provided to parents to gauge their children's' abilities before starting school include binary yes and no questions or checkboxes to indicate that children have acquired skills. Expressive and receptive language skills (e.g., speaks in complete sentences, understands commands, understands positional vocabulary), learning and cognition (e.g., matching pictures and recognizes sequences), phonological awareness and print knowledge (e.g., prints name, recognizes signs, knows letters), mathematics (e.g., counts to ten, understands more or fewer items, arranges numbers), social/emotional development (e.g., knows gender differences, knows name and names of family members, knows age), and physical development (e.g., can 
draw basic shapes, can use scissors, demonstrates gross motor skills development) are common on parent inventories of their children's emerging abilities (Meisels, 1996). Although these measured abilities offer clearer criteria for kindergarten entrance standards and assessments, states vary on which assessment model they use and the degree by which data are used to inform school-based decisions (Pierson, 2018).

Assessments Used to Determine Kindergarten Readiness. Most states rely on Kindergarten Entrance Assessments (KEAs) to determine a student's degree of readiness. These assessments offer what Elizabeth Graue (2006) called "a developmental buffet, representing many types of skills that children develop as they enter kindergarten." Using the Obama-era Race to the Top funds, four states collaborated with the John Hopkins University of Education to develop one such buffet assessment. Ohio, Maryland, South Carolina, and Michigan use the Kindergarten Readiness Assessment (KRA). The KRA assesses children's social foundations, language and literacy, mathematical ability, and physical well-being and motor development (Electric Learning Community of John Hopkins University School of Education, 2011). Alabama, Hawaii, Michigan, and Minnesota use the Teaching Strategies GOLD (TS GOLD) assessment to determine kindergarten readiness. Five additional states (Colorado, Delaware, Massachusetts, New Jersey, and Washington) are currently in various effectuation phases of the assessment as well (Pierson, 2018). The TS GOLD Kindergarten Entry Assessment Survey, like the KRA, assesses incoming students' skills, knowledge, and behaviors. Unlike the KRA, TS GOLD offers teachers instructional strategies and a curriculum grounded in 38 research-based objectives for development and learning 
(Teaching Strategies, 2013). Other states have developed their own KEA or have adopted a third-party program (Pierson, 2018).

Kentucky adopted the BRIGANCE Early Childhood Developmental Screener III to evaluate incoming kindergarteners for the 2012-2013 school year (Curriculum Associates, 2019b). This screener, like similar assessments, evaluates the key predictors of school success: language development, basic math proficiencies, and gross motor skills (Curriculum Associates, 2019a). This 15-minute assessment is used to inform subsequent academic and social instruction, special education, and general pedagogy decisions made by teachers and specialists. Though some researchers may argue the validity of using BRIGANCE to identify students with special needs and gifted students, the screener is generally used to raise awareness of students' abilities to inform additional testing (Glascoe, 1996, 1997). Typically, the screener is administered before the beginning or at the onset of the school year; however, Kentucky state regulation mandates that the screener be given no later than the 30th instructional day of the school year (Curriculum Associates, 2019b; Kentucky Department of Education, 2016). The timing of this assessment denotes the need for baseline data to inform instruction, differentiation, and intervention despite lacking the depth of the curriculum offered by other KEAs like TS GOLD.

Despite moving the goalposts for success, the influence Kentucky's educational agencies have had on how children are prepared before school has stagnated. While the percentage of students designated as not ready for kindergarten has decreased from $72 \%$ in the late 1990 s to $49 \%$ in 2019 , the percentage of students designated as ready for kindergarten has only increased by $2 \%$ during the past seven years (Kentucky 
Department of Education, 2020). The lack of kindergarten readiness progress is also apparent in ethnic subpopulation data. African American (+1.7\%), Hispanic (+2.9\%), White $(+2.3 \%)$, and Asian $(+.7 \%)$ children are minimally more prepared than they were five years before (Kentucky Department of Education, 2020). The greatest readiness gains since 2013 are found with students who attended state-funded preschool $(+6.5 \%)$ and Head Start $(+4.9 \%)$ while children being prepared exclusively at home $(-1.3 \%)$ and attending child care (-.8\%) saw decreases in readiness. Although additional research needs to be conducted on the probable reasons for these changes, the lack of progress of some microsystems, as opposed to others, raises questions of equity and access as well as the reliability of Kentucky's kindergarten readiness model (Kentucky Department of Education, 2020).

\section{Funds of Knowledge: An Alternative to Kindergarten Readiness Paradigms.}

Although schools across the country continue to benchmark students with kindergarten ready assessments, a growing body of literature and action research has questioned the legitimacy of these tests for socially and culturally diverse students (Andrews \& Yee, 2006; González et al., 2005; Hogg, 2011; Kelley, 2020; McDevitt, 2016; Moll, 2000; Moll \& González, 1997; Riojas-Cortez \& Bustos Flores, 2009; Rodriguez, 2013; VélezIbáñez \& Greenberg, 1992). Research of the sociocultural theory funds of knowledge argues that the bodies of knowledge (e.g., information, strategies, culture, and skills) students construct within the home ecology represent a richness of experience that could be potential education resources for the academic advancement of students from diverse families (González et al., 2005; Hogg, 2011; Kelley, 2020; McDevitt, 2016; Moll, 2000; Moll \& González, 1997; Riojas-Cortez \& Bustos Flores, 2009; Rodriguez, 2013; Vélez- 
Ibáñez \& Greenberg, 1992). Therefore, funds of knowledge, consistent with the social constructivist models Jean Piaget and Lev Vygotsky, acknowledges not only the knowledge and competencies students acquire during childhood but enjoin teachers to explore, understand, and utilize these experiences to promote learning and achievement (Riojas-Cortez \& Bustos Flores, 2009; Vélez-Ibáñez \& Greenberg, 1992).

Researchers of funds of knowledge argue that kindergarten assessment criteria are symptomatic of deficit theorizing in which the basis for academic failure is attributed to the students as well as their families, communities, and cultures (González et al., 2005; Hogg, 2011; Valencia, 2010; Moll, 2000; Moll \& González, 1997; Rodriguez, 2013). Therefore, students' academic inadequacies (e.g., home literacy practices, Englishlanguage usage, parental academic support) are the fault of home ecology insufficiencies and subsequent poor student achievement is not the fault of the school, teachers, and pedagogies intended to help students succeed (Hogg, 2011). In essence, a deficit thinking paradigm excuses educators from informing instructional practices with knowledge of students' home lives, experiences, and cultures to connect school-based learning with learning occurring outside of the school (Rodriguez, 2013; Valencia 2010). Culturally relevant teaching practices, by contrast, are intended to build teachers' knowledge of their students and consequently their acumen for matching instructional strategies to students' "intercultural and hybrid knowledge base" (Gonzalez et al., 2005, p. 37).

Increasingly, American students are more ethnically heterogeneous while their teachers continue to be comparatively homogenous - generally middle-class, white, and female (Hogg, 2011; Jones \& Sandridge, 1997). These ethnic and socioeconomic gaps necessitate that teachers not only align their pedagogical practices with an informed 
understanding of their students as cultural beings with their funds of knowledge but also question the benchmarks by which students are deemed kindergarten ready (Hogg, 2011; Vélez-Ibáñez \& Greenberg, 1992). Moreover, such explorations may improve educational settings characterized by mutual understanding for all participants, students and teachers alike (Rodriguez, 2013). By exploring the experiences of their students, teachers may find a wealth of funds students have already learned and acquired as well as opportunities for enhancing and expanding learning through connections of students' funds of knowledge with educational content (Andrews \& Yee, 2006; Velez-Ibanez \& Greenberg, 1992). Consequently, such practices may marginalize kindergarten readiness metrics as merely one source for student readiness analysis or dismiss the data entirely as being too narrow to effectively inform instructional strategies.

\section{School Readiness Models.}

Introduction. Despite the definition and assessment system either developed or adopted by states' departments of education, researchers differ on their definitions and models for kindergarten readiness. Most models broaden the definition of kindergarten readiness beyond cognitive and social abilities to fully account for the contexts, relationships, and other factors that may influence readiness (Pianta et al., 2007, 1999). Although there are numerous models, coined by researchers, that have overlapping indicators and descriptions, what follows are the models I identified in research that best represent the divergent views of what readies a child for school and what criteria should drive the evaluation of children's academic potential. This examination includes the maturational model, the interactionist perspective model, the developmental neuroscience model, the social constructivist model, and the ecological perspective model. 
Maturational Model. Maturationalists argue advancement to kindergarten and subsequent grades should only occur when students have exhibited competence of preschool or grade-level standards. Justice et al. (2017) define kindergarten readiness as "a multidimensional, theoretical construct representing children's preparedness for participation in formal schooling, which more often than not corresponds to kindergarten entrance in the twenty-first century" (p. 1). Hustedt et al. (2018) note that the changes in kindergarten readiness standards have created an "increasing emphasis on academic preparedness for elementary school" (p. 1). Words such as "preparedness" are not uncommon in the language of maturationalists. According to the National Household Education Survey, many parents also feel that cognitive and social skills were paramount for a successful transition to kindergarten (Kim et al., 2005).

The maturational model is also evident in the policies and readiness rhetoric of many institutions (Demma, 2010; Pierson, 2018). Many states' kindergarten readiness definitions assert that school readiness is defined by the mastery of pre-kindergarten skills that effectively transition children to kindergarten standards (Graue, 1992; Pierson, 2018; Smith \& Shepard, 1988). Virginia's readiness definition states that "School readiness' describes the capabilities of children ... that will best promote student success in kindergarten and beyond." Alabama's definition repeats the term "age-appropriate" in various indicators. Arkansas's definition states, "School ready children have the social and academic knowledge, skills and behaviors for school success and lifelong learning." Hawaii's readiness definition "means that young children are ready to have successful learning experiences in school.” Meanwhile, Arizona, Colorado, Kentucky, Louisiana, Massachusetts Minnesota, Missouri, New Hampshire, New Jersey, North Carolina, South 
Carolina, and Texas have the verbiage that identifies the child's emergent skills and abilities as indicators of readiness (Pierson, 2018).

Interactionist Perspective Model. Samuel Meisels defines readiness as a relational, interactional construct that entails more than simply knowledge of skills assessed on many kindergarten readiness assessments (Meisels, 1996). Meisels' interactionist perspective model asserts that the environments in which children are reared and the relationships they develop with those in the environments, particularly the adults entrusted with their care, are more indicative of academic and social success than the battery or skills assessed by most readiness tests and valued by empiricists (Meisels, 1996). Furthermore, Meisels (1996) asserts that readiness is a "bi-directional concept" that involves information about children and the environments and people with which they interact as well as the schools' capacities to meet children's needs. The interactionist perspective model differs from other models in that it views readiness as the contributions of children to learning and the contributions of teachers to children's learning over time rather than children's maturation or skill sets at the point of entering kindergarten (Meisels, 1996). This interaction between children (encompassing their genetics, environment, culture, lived experiences, etc.) and curriculum defines readiness as an evaluation over time rather than the results of a single assessment (Meisels, 1996). Therefore, children's readiness can only be determined by skilled educators as they interact with students and students interact with teachers, peers, and instructional materials (Meisels, 1996).

While Meisels (1996) acknowledges that children with "an unnaturally long attention span" exhibit behavior patterns that align with kindergarten readiness 
expectations, he does not explain how those attention spans are developed or how environmental influences might procure or hinder development. Moreover, although Meisels states that an interactionist perspective model lends itself to metacognition in that students self-assess their work as it develops in a work sampling system, he does not articulate how metacognition is developed or how students from adverse home environments might be better served by educators (Meisels, 1996). In short, his model provides a more thorough, longitudinal approach to assessing school readiness but it neglects to explain how prior experiences and relationships shape a child's ability to succeed in school.

Developmental Neuroscience Model. While researchers like Meisels relate environmental factors to child development loosely, researchers such as Clancy Blair define school readiness through neurobiology and neuroendocrinology. Blair's neuroscience development model focuses largely on the relations between emotional and cognitive development as well as neural plasticity and frontal-cortical functioning development (Blair, 2002). That is, Blair and similar researchers define school readiness through children's development of executive functioning, a system that entails working memory, attention, and self-regulatory control to plan and execute goal-directed activities (Bell, 1998). Blair (2002) argues that "high levels of motivation and self-regulation are clearly associated with academic achievement independent of measured intelligence." Moreover, other researchers associate reading and mathematical learning difficulties with insufficient executive functioning development (Morgan et al., 2017).

Proponents of the neuroscience development model argue that executive functioning development or a lack thereof is the best predictor of school readiness and 
probable learning difficulties (Morgan et al., 2017). These researchers explain that negative and positive environmental conditions and relationships affect our biology and shape the development of one's cognitive and behavioral abilities (Blair \& Raver, 2012). Therefore, experiences and relationships in childhood influence the expression of children's genomes and thus alter their physiological and psychological development (Blair \& Raver, 2015). As a result, children who experience adverse environments or relationships may not develop the same as their more fortunate peers. The variance between executive functioning development of students thus accounts for the kindergarten readiness gap and may offer opportunities to understand how to close generational gaps by modifying neurocognitive and neuroendocrine functions via early childhood education and intervention (Blair et al., 2014).

Social Constructivist Model. Built on the theories of Jean Piaget and Lev Vygotsky, the social constructivist model argues that the origin of learning is rooted in an engagement with the environment and social interaction. Therefore, rather than narrowly and concretely defining school readiness through chronology, precedent, or learned knowledge and abilities acquired or developed within the child, social constructivists explain that readiness is a construct of the meaning and values held by parents, schools, or other people in the school community (Graue, 1999; Schrader, 2015; Smith \& Shepard, 1988). Because knowledge cannot be separated from environment and context, some social constructivists argue that communities should create measures that incorporate their nuanced perspectives that assess the collective status of incoming kindergarteners rather than individual children (Graue, 1992; Love, 1995; Love et al., 1994). Love et al. (1994) suggest that these community readiness assessments should 
focus on the collective status of entering kindergarteners, rely on existing instruments, include multiple modes and perspectives in the assessment, be adaptable to local contexts, be appropriate for varied cultural and racial/ethnic groups, and balance positive and negative indicators of readiness dimensions. Such community readiness assessments would, therefore, better incorporate the social interactions and learning environment of discrete communities rather than the acquisition of knowledge and skills of a particular child.

Although the social constructivist model is defined by the anti-nativist belief that learning is inherent and social, there are divisions amongst social constructivists in the degree by which the environment influences the learner. Piagetian social constructivists argue that learning is the result of assimilation and accommodation. In this view, learners understand more complex abstractions as they actively deepen their engagement with the people and objects in the environment (Schrader, 2015). Sociocultural constructivism, based on Vygotsky's works, on the other hand, states that learning is inherently human and cultural. For sociocultural constructivists, culture primarily determines learning rather than simply the innate problem-solving experiences that occur in interactions with people and objects. Therefore, sociocultural constructivism favors the study of learning in the specific cultural context of the learner rather than the individual learning process of children in their environments (Schrader, 2015; Vygotsky, 1978).

The Ecological Perspective Model. The ecological perspective model, built on the work of Urie Bronfenbrenner, relates kindergarten readiness to the various spheres and levels of influence on children's readiness. Educational ecologists believe that the transition to school should be approached in terms of connections of social contexts 
rather than children's skills and abilities as predictors of school success (Pianta et al., 1999; Pianta et al., 2007). In essence, effective transition to formal schooling relies on positive effects from home microsystems, including home ecologies and relationships, school microsystems, consisting of children's teachers and peers, and surrounding school community microsystems (Bronfenbrenner, 1989). The combined collaborative efforts of each of these microsystems to support children's transition to kindergarten is necessary not only for intersystem connectedness but as a means to create networks that support children's engagement in education (Pianta et al., 1999; Pianta et al., 2007). The ecologies of the kindergarten classrooms are different from children's home ecologies and any prior preschool settings. Kindergarten environments are often more diverse and structured than preschool or home settings and thus children are inundated with new stimuli, relationships, and expectations (Fomby \& Mollborn, 2017; Pianta et al., 1999; Pianta et al., 2007). As such, children can often be overwhelmed by the rituals and socialization inherent in kindergarten without combined, collaborative parent-teacher partnerships from different social contexts, home and school (O'Connor \& McCartney, 2007; Pianta et al., 1999; Pianta et al., 2007).

The ecological perspective model also accounts for the effect of school transition on the families and the teachers who influence and participate in the change. The very act of children transitioning to school not only creates new relationships between school employees and parents as children enter broader social contexts (school microsystems) but also changes the relationships between children and their parents (Pianta et al., 1999; Pianta et al., 2007). Whereas children were largely steered by parents or paid preschool teachers influenced by the parents, kindergarten teachers represent authorities mostly 
outside of the direct influence of the parents; therefore, children, having new contexts and authority figures guiding their cognitive and social maturation, may grow differently than before and thus alter their relationships with their parents and the home microsystem (O'Connor \& McCartney, 2007; Pianta et al., 1999; Pianta et al., 2007). This broader scope of influence creates a more holistic definition of school readiness in that parents, teachers, and children all must maintain quality communication and positive relationships to promote successful onboarding and children's future academic success ( $\mathrm{O}^{\prime} \mathrm{Connor} \&$ McCartney, 2007).

Summary and Implications. Though much of state and school policies defining school readiness use the maturational model to determine if students are ready for kindergarten, other models broaden the definition of readiness to include neurobiology, multiple social contexts, interactions/relationships, and the effects of culture to understand how children transition to school. This study examines the lived experiences of kindergarten teachers. As such, the ecological perspective model is significant because it promotes analysis of the transactive influence inherent in teacher-student and teacher-parent relationships. By bracketing myself from the traditional child-centric view of school readiness, I am more receptive to the changes experienced by teachers as they work with kindergarten cohorts. Moreover, the nuanced changes teachers describe provide important details of how teacher microsystems are altered by contact with parents and students, how those interactions affect teachers within their home and work microsystems and the relationships in those ecologies, as well as potentially insightful perceptions of how those relationships influence children's transition to school and academic success. 
Examining the readiness phenomenon from teachers' perspectives may illuminate details that help us understand teacher-child relationships and their association with academic and social outcomes. Although children's abilities, resulting from genetic and environmental associations, significantly impact student success, teachers' beliefs and understandings of the varied home ecologies with which they interact influence not only children's transition to a new microsystem but also their later achievement and engagement in education ( $\mathrm{O}^{\prime}$ Connor \& McCartney, 2007). The changing nature of the American home has also diversified the experiences of children entering kindergarten and thus changed the complexity of the teacher-child relationship. An increasing number of children are spending more time outside of the home under the care of preschool teachers, daycare workers, and other non-guardians as more women have entered the workforce (NEGP, 1997, 1998). Furthermore, a 33\% increase in the number of students living in poverty and an $8 \%$ increase of students living in homes where English is not the primary language since 1987 has created greater discrepancies in the home microsystem of many children and their English-speaking, middle-class teachers' home ecologies (Sparagana, 2007). Therefore, the perceptions of teachers working with students from divergent home experiences are important to gauge potential risk and protective factors within the school microsystem that either hinder or support students from diverse ecologies (Dotterer et al., 2012; Graue, 2006; Fomby \& Mollborn, 2017).

In addition to the experiences teachers have had with students and parents, interviewees may also detail the influence of collegial relationships and their relationships with school institutions. Examining these microsystem relationships may explicate how teachers use support systems and other resources to manage stress and 
develop instructional strategies to meet students' changing needs. Though much of the focus on school readiness has centered on children's abilities, the support of colleagues and institutions to provide resources, manageable class sizes, and professional development affect teachers' morale, self-efficacies, and their relationships with students and their parents (O'Connor \& McCartney, 2007). As a result, insights into teachers' supports and stressors may divulge the effects of those school microsystems' impacts on pedagogy and focus professional development efforts to better support teachers to meet students' needs. Exploring how teachers use collegial relationships and school resources to develop themselves and their students may also elevate the personal and professional cost of working with kindergarten students. Such data may contribute to discussions concerning preschool, pre-kindergarten safety nets, funding for social programs supporting child development, and professional development that improves teachers' effectiveness with diverse student populations.

\section{Strand 2: Risk and Protective Factors}

Introduction. This study began in earnest when I met my first class of kindergarten students. As each child arrived at their pre-arranged appointment to be tested for kindergarten readiness, they brought bags of school supplies, their parents, and wide-eyed excitement about becoming a kindergartener. Their boundless optimism was charming and contagious. Each of them expressed big aspirations, albeit without the tethers of realistic limitations, to become something great. A future artist, professional athlete, teacher, musician, and yes, a president, all merrily talked with adults who reflected their enthusiasm. Had zeal been a metric on the kindergarten readiness test, all

of our incoming students would have been above the bar. Unfortunately, the outcome of 
our incoming students' pre-emergent literacy and numeracy skills greatly contrasted with the ambitious futures our students proclaimed. Though each of these students was enriched by their lived-experiences and cultural funds of knowledge, the assessments used by my school stratified students by predetermined academic measures. These data would determine students' reading groups, how small group work and pods would be arranged, as well as the instructional strategies the teacher used to improve their scores.

Of that first kindergarten class I welcomed four years ago, more than half were designated not ready for kindergarten. Many of these children did not know the alphabet, could not count past ten, struggled with recognizing basic shapes and colors, and lacked the perceived behavioral self-regulation of their peers from home ecologies more aligned with school expectations. Some of these students were in the early stages of being identified for special education but most were cognitively capable to learn grade-level standards without accommodations. In the capable hands of our teachers, these students and their ready classmates grew over the year. Only two students were retained. Despite our efforts to close school readiness gaps, the students who came to school identified as not ready grew but did not achieve the same achievement percentiles of their classmates, many of whom were moving on to first-grade standards by the end of the year. Having watched these students grow now into third-graders, I regret that the kindergarten readiness gap has been a mostly accurate predictor of achievement gaps, as defined by district and state assessments, in later grades. Though these students may possess funds of knowledge unrecognized by school employees and constructs, success in kindergarten, which is predicated by childhood experiences at home or in preschool often predicts later success in the school system (Entwisle \& Alexander, 1999; Foster \& Miller, 
2007; Fryer \& Levitt, 2004). Though some of our students have closed this gap entirely, most are capable of moving to the next grade but few are represented among our gifted students and honor roll achievers.

Because children come from varied home settings with differing experiences and influencers, educators are addressing skills and knowledge gaps from the onset (Dotterer et al., 2012; Fomby \& Mollborn, 2017; Graue, 2006; Kentucky Department of Education, 2020; Sparagana, 2007). Although outstanding teachers and schools may be able to close achievement gaps for some students and subpopulations, decades-long achievement gaps indicate the difficulty educators have had in overcoming academic deficits, which are evidenced in kindergarten readiness data (Ansari \& Pianta, 2018; Berry et al., 2016; Christian et al., 1998; Coulton et al., 2016; Duncan et al., 2007). Even at my previous elementary school, which routinely posts among the highest Measurement of Academic Progress (MAP) assessment conditional growth percentages of any school on any level in the district, educators continue to struggle to close achievement gaps for African American, special education, and Latino students. Because many of these minority and lower socioeconomic status children are represented in our not ready for kindergarten data, which are indicated in state-wide and research statistics, analyses of students' growth and regression are ongoing (Diamond et al., 2000; Duncan et al., 2007; Engel et al., 2016; Fryer \& Levitt, 2004; Justice et al., 2017; Kentucky Department of Education, 2020; Lee \& Wong, 2004). Inevitably, these discussions and collaborative plans to combat regression and other negative impacts on students' growth and achievement include other ecologies outside of the school; therefore, understanding what research says about protective and risk factors informs not only educators' pedagogical efforts but 
partnerships with parents and community members as the school attempt to influence and improve the lives of students beyond campus. Furthermore, democratizing the method by which community members, students' families, and marginalized cultures inform pedagogical practices may ultimately help teachers use students' family and community funds of knowledge to realize students' learning potential beyond the narrow parameters of kindergarten assessment data and yet improve those metrics through informed inclusion.

Research on childhood protective and risk factors covers a wide breadth of positive and negative influences on child development and socialization (Ansari \& Pianta, 2018; Berry et al., 2016; Brown et al., 2013; Cathy \& Ann, 2003; Coley et al., 2015; Coulton et al., 2016; Morrissey et al., 2016). While studies vary on the population, time, and methodology used to explore the phenomenon, many of the studies analyzing the inimical effects of household disorder on child development operationalize risk factors into distinct categories (Ansari \& Pianta, 2018; Arteaga \& Heflin, 2014; Bradley \& Corwyn, 2002; Burger, 2010; Chang et al., 2007; Coulton et al., 2016; Engel et al., 2016; Gupta \& Simonsen, 2010; Holliday et al., 2014; Justice et al., 2017; Mollborn, 2016; Mondi et al., 2017; Morrissey et al., 2016; Qi \& Kaiser, 2003; Vernon-Feagans et al., 2012, 2016; Wolf et al., 2017). Most of the studies examine socioeconomic factors such as income, health and wellbeing, preschool placement, and changes in access to resources (Ansari \& Pianta, 2018; Arteaga \& Heflin, 2014; Burger, 2010; Chang et al., 2007; Coley et al., 2015; Coulton et al., 2016; Engel et al., 2016; Gupta \& Simonsen, 2010; Holliday et al., 2014; Justice et al., 2017; Mondi et al., 2017; Morrissey et al., 2016; Qi \& Kaiser, 2003; Wolf et al., 2017). Elements affecting children's 
developmental ecologies such as relationship instability, transience, the surrounding neighborhood or community, screen time, etc. are also investigated as risk factors (Bradley \& Corwyn, 2002; Brown et al., 2013; Coulton et al., 2016; Hart et al., 2007; Mollborn, 2016; Petrill et al., 2007; Vernon-Feagans et al., 2012, 2016). Still, other studies examine the influence of preschool placements as a protective factor to promote kindergarten readiness (Ansari \& Pianta, 2018; Barnett \& Masse, 2007; Berry et al., 2016; Burger, 2010; Currie et al., 2003; Fuller et al., 2017; Gupta \& Simonsen, 2010; Holliday et al., 2014; Rhoades et al., 2011; Temple \& Reynolds, 2007).

Socioeconomic Factors. The adverse effects of poverty have reliably predicted gaps between lower-socioeconomic status children and their peers from more affluent households in cognitive skills such as math and reading and noncognitive skills such as behavior, creativity, and focus (García, 2015). Although the nature and effects of poverty are diverse and complex, researchers have identified specific aspects of poverty that adversely affect childhood cognitive, social, and behavioral development. Of those studies analyzing the effects of poverty, particular risk factors were found to be more significant than others. Risk factors such as parent education (Engle et al., 2016; Holliday et al., 2014), parental discipline (Qi \& Kaiser, 2003), housing disorder (Coley et al., 2015), neighborhood poverty (Coulton et al., 2016; Wolf et al., 2017), access to social capital (Justice et al., 2017), food insecurity (Arteaga \& Heflin, 2014; Morrissey et al., 2016), household disorganization (Brown et al., 2013; Hart et al., 2007; Vernon-Feagans et al., 2016; Razza et al., 2012), welfare (Chang et al., 2007), and maternal nativity and teen pregnancy (Mollborn, 2016) were found to be significantly impactful. Typically, studies exploring socioeconomic effects analyze quantitative data such as parental 
income, preschool placement, parental education attainment, student academic performances, etc. (Ansari \& Pianta, 2018; Arteaga \& Heflin, 2014; Burger, 2010; Chang et al., 2007; Coulton et al., 2016; Engel et al., 2016; Hart et al., 2007; Holliday et al., 2014; Justice et al., 2017; Mondi et al., 2017; Morrissey et al., 2016; Qi \& Kaiser, 2003; Rhoades et al., 2011; Wolf et al., 2017). Other studies exclusively or partially relied on quantified attitudinal metrics derived from parental surveys, observer data, and perception data to draw conclusions (Bassok et al., 2015; Coulton et al., 2016; Diamond et al., 2010; Gupta \& Simonsen, 2010; Holliday et al., 2014; Loeb et al., 2012; Puccioni, 2015; Vernon-Feagans et al., 2016).

Though all of the studies examining potentially negative influences on child development argued that household disorder, poverty, and other risk factors impacted emergent skills, the magnitude by which these risk factors affected or accounted for learning gaps varied. Not surprisingly, researchers identified poverty and the symptoms of poverty as the primary impediments for social development and learning (Brown et al., 2013; Chang et al., 2007; Coley et al., 2015; Coulton et al., 2016; Engel et al., 2016; Holliday et al., 2014; Justice et al., 2017; Mollborn, 2016; Morrissey et al., 2016; Qi \& Kaiser, 2003; Vernon-Feagans et al., 2016; Wolf et al., 2017). Though poverty is generally defined as low-income, the effects of poverty on residential choices, parenting, household density and crowding, nutrition, etc. vary by geographic location, caregiver education and temperament, and a myriad of other variables that enhance or mitigate the harmful effects of poverty (Berry et al., 2016; Vernon-Feagans et al., 2013). As a result, many studies examine common risk factors associated with poverty and the impact of 
symptoms of poverty on various aspects of child development and kindergarten readiness.

Many studies measure the effects of poverty on cognitive measures such as mathematics and reading scores, non-cognitive development manifested as behavior, and the associations between academic hardship, child development, and behavior (Berry et al., 2016; Bradley \& Corwyn, 2002; Burger, 2010; Coley et al., 2015; Coulton et al., 2016; Doumen et al., 2008; Duncan \& Magnuson, 2005; Hart et al., 2007; Holliday et al., 2014; McIntosh et al., 2012; Qi \& Kaiser, 2003). Children who live in poverty are more likely to have behavior problems. Research conducted by Qi and Kaiser (2003) estimated that almost $30 \%$ of low-socioeconomic children were reported to have behavior problems in school. These children were also found to have less developed social skills and academic deficits that may have contributed to their misbehavior (Qi \& Kaiser, 2003). Furthermore, research indicates that the association between academic discrepancies, phonological awareness and rapid letter-naming skills, and behavior problems in kindergarten predict continued behavior issues in subsequent grades (McIntosh et al., 2012).

Other studies have explored the effects of poverty on cognitive measures for specific racial and ethnic groups (Condron, 2009; Crosno et al., 2016; Dotterer et al., 2012; Duncan \& Magnuson, 2005; Fryer \& Levitt, 2004; Lee \& Wong, 2004). Poverty may be a significant contributor to academic achievement gaps between racial and ethnic groups in that lower-socioeconomic status may affect minority children more because of the effects of poverty on parenting, particularly an association between negative/intrusive parenting and lower-income (Dotterer et al., 2012). Moreover, Duncan and Magnuson 
(2005) found that about one-half of a standard deviation of the initial readiness gap of African American and Hispanic students can be contributed to poverty; therefore, reducing the effect of family income may also reduce the achievement gap for not only children of poverty but minority students as well. Condron's study of the effect of school on white/black achievement gaps (2009) also identifies wealth as a potential protective factor despite class or race whereas poverty is a risk factor that increases the already widening racial achievement gap.

Despite the overwhelmingly negative effects of poverty on child development and kindergarten readiness, protective factors were identified in research that may mitigate these influences. Dilworth-Bart (2012) asserts that executive functioning development through improved child-parent relationships could act as a mediator between the effects of socioeconomic status/home environment and academic readiness, particularly math competence. Furthermore, Dotterer et al. (2012) argue that improving parent sensitivity, warmth, and general parent-child relationship despite income levels may mitigate some of the effects of poverty on academic and social skills development. Research on gifted students living in poverty suggests that children exposed to reading strategies by parents during childhood were more likely to become early readers, a trait less common in lowersocioeconomic children (Bailey, 2006).

Environmental and Relationship Factors. Research of risk factors that affect cognitive and behavioral development provided new insights into how deleterious influences stall or harm children's growth during their formative years. This exploration of how environmental factors and parental behaviors affect early-childhood development served as a foundation for subsequent studies of protective factors and teachers' 
experiences facilitating learning for students, many of whom are identified as not ready for kindergarten. Almost all of the schools in the geographic setting of this study serve significant populations of students living in poverty. Because $23.2 \%$ of children live in moderate-high-poverty neighborhoods with poverty rates between $20 \%$ and $39 \%$, it is reasonable to explore the ecological effects of poverty on child development and kindergarten readiness to better understand kindergarten teachers' experiences working with lower-socioeconomic students. (Wolf et al., 2017). Though children may not be obviously different upon entering kindergarten, their divergent pre-kindergarten experiences affect how they transition and the degree by which they assimilate to school rigor and structures. For example, children in poverty on average experience over seven transition events—such as parental employment, residential transitions, childcare arrangements, etc.—-before entering kindergarten (Fomby \& Millborn, 2017). Fomby and Millborn (2017) suggest that these environmental changes create ecological instability that negatively impacts early learning outcomes.

Much of the research conducted on kindergarten readiness examines pernicious and chaotic domestic conditions (Burger, 2010; Cadima et al., 2010; Coley et al., 2015; Coulton et al., 2016; De Smedt et al., 2018; Engel et al., 2016; Hart et al., 2007; Holliday et al., 2014; Justice et al., 2017; Millborn, 2017; Mollborn, 2016; Vernon-Feagans et al., 2012; Vernon-Feagans et al., 2016; Wolf et al., 2017). Other studies analyze the effects of household disorder and other risk factors on children's mental and physical health or the symptoms of those issues in preschool environments (Berry et al., 2016; Cathy \& Ann, 2003; Coley et al., 2015; Morrissey et al., 2016; Walker et al., 2011). For several studies, the development of executive functioning is the chief determinant for school 
readiness and later academic success. Household and neighborhood disorder may harm children's executive functioning, the set of processes required to adapt to situational demands while controlling and focusing thought, as they progress from infancy to toddlerhood (Blair et al., 2012; Conway \& Stifter, 2012). Maintained maternal attention is associated with higher levels of executive functioning, specifically the focused attention needed to manage multiple executive processes (Conway \& Stifter, 2012).

Much of the research of negative ecological impacts on behavior are similar to findings of research exploring the overall impacts of poverty. Generally, negative behavior in preschool children predicts behavior issues in kindergarten (Combs-Ronto et al., 2009; Vernon-Feagans et al., 2016). Moreover, these negative behaviors are associated with maternal negative parenting (Combs-Ronto et al., 2009), single-mother households (Son \& Peterson, 2017), socio-emotional development (Turney \& McLanahan, 2015), and rearing under the charge of depressed parents (Hur et al., 2015). Findings by Turney and McLanahan (2015) indicate that persistent problem behaviors are harmful to children's cognitive development before kindergarten. Mollborn (2016) argues that developmental ecologies have a strong influence on children's behavioral and self-regulatory development and that households where the indicators of disorder are common diminish children's behavioral, cognitive, and academic development.

General cognition and academic achievement too are affected by chaotic environmental influences. Hart et al. (2007) found correlations between socioeconomics, household disorder, and children's cognitive abilities on the Stanford-Binet Intelligence Test. Research by Arnold et al. (2012) suggests that emergent academic and social development are connected and potentially, negatively influenced by household disorder 
concerning kindergarten readiness. Child preemergent literacy skills development is adversely affected by conditions associated with household disorder including child maltreatment and residential instability (Hart et al., 2007). Furthermore, longitudinal studies by Silinskas et al. (2012) examine the influence of parents' reading-related activities and children's reading performance. Households where reading-related activities were less-frequent, a common risk factor of poverty, produced children with less-capable word-reading skills (Silinskas et al., 2012). Garrett-Peters et al. (2016) controlled for the covariates of children's early cognitive abilities, maternal education, marital status, race, and parenting to further prove that household disorder has a significant influence on children's academic achievement.

Protective factors that mitigate some of the negative effects of household disorder and negative relationships are explored in several studies (Faires et al., 2000). Training parents to more effectively read to their children increase participating children's reading levels by first grade (Faires et al., 2000). Improved parental attention to emotional distress is also important. Brooker and Leuty (2008) found that distressed children, especially girls, seek comfort through proximity to their mothers. Emphasizing the importance of caregiver proximity, for children living in poverty, in particular, may improve emotional regulation and executive functioning for children living in stressful home microsystems. Relationship instability, generally characterized as the movement of family members in and out of the home, has less of an effect on child development than other aspects of household disorganization like crowding, food scarcity, and overarousing stimuli; having a constant primary caregiver throughout childhood may serve as a protective factor against the instability represented by the movement of other family 
members (Berry et al., 2016). In addition to maintained attention, parents' (particularly mothers') child-directed language was found to have prevalent effects on cognitive and behavioral development for children (Bradley \& Corwyn, 2002). Other studies focused on peer influence (Henry \& Rickman, 2007), the influence of parental literacy and mathematics involvement (Andrews et al., 2006; Degol et al., 2017; Xue \& Meisels, 2004), and parent involvement in school (Ritblatt et al., 2002) suggest mediating factors that may improve low-socioeconomic children's preparedness for kindergarten despite the common risk factors associated with low-income child development.

Maternal and Paternal Education Factors. Of the many risk factors identified in the research, parental education, specifically maternal education, provides both an analytic perspective for this study as well as a potential contrast that may yield unforeseen findings. Studies have shown that low-income parents tend to have fewer years of schooling and therefore lower expectations for their children's academic success (Davis-Kean, 2005; Hart et al., 2007). By contrast, all of the kindergarten teachers interviewed for this study are college graduates. As such, research suggests that these teachers should have highly developed language skills and high academic expectations for their students (Davis-Kean, 2005; Hart et al., 2007). Many of the children they serve, however, are being raised by parents who are less educated and as such may have lower language skills and academic expectations (Magnuson et al., 2009). This contrast of perspectives on academic progress and linguistic development may result in discordant outlooks between low-income parents and kindergarten teachers on students' academic potential (Kohl et al., 2000). Low-income parents' decreased expectations for their children's development may not only mask students' academic potential in kindergarten 
because of a lack of pre-kindergarten development but may also hinder partnerships between school and home built on the consensus of academic progress and potential. Understanding how parental education influences child development and thus potentially influences support for teachers' efforts in accelerating incoming low-income students' progress toward grade-level proficiency may illuminate a contributing cause for persistent achievement gaps (Fryer \& Levitt, 2004; Gaddis \& Lauen, 2014).

Although Keage et al. (2016) found associations between paternal education and children's later educational attainment, most studies exploring the influence of parental education on childhood development examine maternal education and self-efficacy (Bojczyk et al., 2017; Christian et al., 1998; Crosnoe et al., 2016; Magnuson et al., 2009). Maternal education and self-efficacy have been associated with parent-child literacy experiences, the home literacy environment, and children's preemergent literacy skills development (Bojczyk et al., 2017; Christian et al., 1998; Magnuson et al., 2009). Cognitive underdevelopment for children reared in poverty has been linked to caregivers' lower language quality (Vernon-Feagans et al., 2013); conversely, parents with higher levels of education improve their children's cognitive and academic development through learning activities (Davis-Kean, 2005; Taylor et al., 2004). Tracey and Young (2002) found that mothers with high levels of education typically use explicit literacy-promoting behaviors that engage children's vocabulary development. Higher-educated mothers are also more prone to employ instructional strategies similar to those used in classrooms (Tracey \& Young, 2002). Although higher-educated mothers are more likely to use literacy-promoting behaviors, research by Christian et al. (1998) suggests that lesseducated mothers who maintain effective home literacy environments develop children's 
preemergent literacy skills more than higher-educated mothers who do not. Therefore, while higher parental education attainment, particularly the education level of mothers, is generally a protective factor, training and encouraging parents, regardless of education and income, may improve literacy development for children. (Holliday et al., 2014; Justice et al., 2017; Tracey \& Young, 2002; Walker et al., 2011).

Preschool and Early Education Factors. The effects of preschool (Ansari \& Pianta, 2018; Fuller et al., 2017; Magnuson et al., 2004; Temple \& Reynolds, 2007), childcare (Berry et al., 2016; Burger, 2010; Datta Gupta \& Simonsen, 2010), Head Start (Chang et al., 2007; Currie et al., 2003), and other programs (Bakken et al., 2017; Barnett \& Masse, 2007; Upshur et al., 2017) were scrutinized in other studies. These studies expound on the benefits of particular programs for preparing students for kindergarten, but their research generally focused on programs of interest without comparisons with similar programs, metrics, or populations featured in other studies. As a result, it was difficult to discern the quality of the programs and protective factors concerning other programs and factors, though the literature provided a foundation of pre-kindergarten ecologies and structures that potentially promote cognitive, social, and behavioral growth.

Much of the research reviewed for this study extolled the academic benefits of preschool, daycare, or Head Start. Temple and Reynolds (2007) found that preschool, especially high-quality preschool programs, had a profound impact on the readiness of children from disadvantaged families. Results from research by Fuller et al. (2017) suggest that not only do children benefit from exposure to preschool ecologies but children from poverty benefit more than their more-affluent peers. These findings and 
others also indicate that preschools that spent more time on academic content had a larger impact on children's emergent literacy skills and understanding of numeracy (Fuller et al., 2017; Magnuson et al., 2009). Findings by Berry et al. (2016) suggest that childcare, particularly for children in poverty, may act as a buffer to the damaging effects of household and neighborhood disorder because children are provided opportunities to develop social skills in structured environments. Bakken et al. (2017) indicate that the benefits of early childhood education may not be limited to improved readiness for kindergarten. Their analysis of five years of data suggests that pre-kindergarten programs that improve children's academic, social, and emotional development have lasting effects throughout the study—-fifth-grade for the study's first cohort (Bakken et al., 2017). Likewise, Ou and Reynolds (2006) found that children who participated in the Chicago-Child-Parent Center Preschool Program were more likely to continue their education than their peers who did not attend preschool. Such findings bolster research studying the effects of stable home ecologies on children's foundational development in that other stable microsystems such as preschool may allow children to develop the neural architecture necessary to excel in later life (Blair, 2002; Blair et al., 2007; Coley et al., 2015; Morgan et al., 2017).

In addition to the cognitive benefits of attending preschool, researchers have also examined how early education has improved social outcomes. Given that executive functioning - the skills that encompass focus, patience, and delayed gratification - is developed in early childhood, children who have access to learning environments devoid of the disorder experienced in low-income housing or at-risk neighborhoods are better prepared to succeed in school (Coley et al., 2015; Fitzpatrick et al., 2014). In particular, 
children who are served by preschools better develop attention-related and socioemotional behaviors than their peers receiving home care or attending childcare centers (Duncan et al., 2007). Furthermore, children's development of non-cognitive skills due to preschool work and parents' associations with schools will likely diminish long-term social issues involving disrupted the learning environment because of behavior, retention, school attrition, and even crime (Temple \& Reynolds, 2007). Participation in a preschool, Head start, or daycare setting offers children opportunities to engage with peers in group play; such experiences help develop self-regulatory behaviors and social skills (Bender et al., 2011). Logue (2007) argues that exposure to prekindergarten learning standards and social learning may offset difficult behaviors that result in academic delay and retention. Moreover, intervention programs such as Second Step Early Learning-SSEL taught in the pre-kindergarten environments may improve children's social-emotional and executive functioning skills to ensure a more successful transition to kindergarten (Upshur et al., 2017).

Research finds that increasing access to early education for disadvantaged students may mitigate educational problems and inequities. Several studies argue that a positive, engaging home learning environment is a predictor of subsequent academic achievement (Burger, 2010; Fuller et al., 2017; Magnuson et al., 2004). For children growing up in low-income households and at-risk neighborhoods, such environments are less likely. According to Magnuson et al. (2004), these children "have fewer books at home, spend less time reading with their parents, and have less stimulating verbal interactions with them than middle-class households." By comparison, quality preschools provide opportunities for disadvantaged children to engage in meaningful ways with 
qualified educators, academic resources, and peers. These interactions provide not only cognitive stimulation but also opportunities for children to hone behavior skills. Though research on the benefits of improved socioemotional behavior to academic achievement is inconclusive, students who learn to control their impulses are less likely to negatively affect other students, miss instruction due to misbehavior, and require intervention (Burger, 2010; Duncan et al., 2007).

The cognitive and social benefits to African American and Hispanic children are greater than for other groups, though these benefits require additional hours per week (30-40 hours) compared to their middle-class and high-income peers (15-30 hours) (Fuller et al., 2017; Magnuson et al., 2004). These children not only stand to benefit cognitively and socially but also better transition to formal schooling from preschool because they have greater familiarity with the structures and procedures of school (Burger, 2010). Hispanic children also benefit more than other groups perhaps because early education centers provide an environment for them to access English-speaking teachers and peers for collaborative learning. Parents of disadvantaged children, however, often lack the means to afford quality preschool; therefore, policymakers and educators should consider ways to provide these children with quality educational opportunities before the onset of formal schooling (Temple \& Reynolds, 2007).

While the previously addressed studies found positive correlations between preschool and children's cognitive development, others could not substantiate a connection (Barnett \& Masse, 2007; Haeck et al., 2015). Daycare and preschool produce positive externalities such as lowering crime rates and increasing maternal labor force participation, but the effect on children's cognitive and social-emotional developments 
are less compelling (Barnett \& Masse, 2007; Haeck et al., 2015). Henry and Rickman (2007) suggest that access to positive relationships with peers may be a positive influence on children's cognitive development and pre-emergent literacy skills. Though their findings were inconclusive, positive associations between peer influence and development outcomes suggest the complexity of stimuli that exists in the preschool microsystem and as such peers should be a viable variable when analyzing the effects of preschool and childcare on students' readiness (Henry \& Rickman, 2007). Simply attending a program in early childhood does not ensure a quality ecology designed to promote child development. A recent study showed that Head Start center quality was significantly lower in high-poverty neighborhoods (McCoy et al., 2015). This finding is particularly interesting considering that high-poverty neighborhoods are associated with higher levels of household disorder and thus these children of poverty are more in need of quality preschool microsystems (Bender et al., 2011; Cassidy et al., 2003; Currie \& Neidell, 2003). Moreover, the benefit of preschool may not benefit children equally. Loeb et al. (2007) found that middle-class children cognitively benefitted more than lower-socioeconomic children; therefore, investments in universal preschool to close achievement gaps may not produce the desired results.

Summary and Implications. In addition to exploring literature that investigates the risk factors that affect children before kindergarten to better understand the challenges teachers inherit, I examined protective factors that offset risk outcomes or improve children's preparation for school. While several of the studies offered protective factors antithetical to the risk factors presented in the same studies or others, some focused on the benefits of programs and institutions. Protective factors such as higher parental 
education (Holliday et al., 2014; Justice et al., 2017; Walker et al., 2011), family income and maternal education (Justice et al., 2017), parent engagement (Holliday et al., 2014), reading at home (Silinskas et al., 2012), peer influence (Henry \& Rickman, 2007), and out-of-school play (Dealey \& Stone, 2018) are central to some research findings.

Studies examining risk and protective factors not only prepared me for teacher testimonies about the lives of their students before entering school but also informed the significance of my research topic. While a myriad of researchers has explored the issues that stagnate growth for children, few studies address how these risk and protective factors carry over into kindergarten. Fewer still elicit the voices of kindergarten teachers, those whom the public entrusts to assess student readiness and the means by which to close early-education achievement gaps. Research relying on kindergarten teacher perception data is limited. Although the educational zeitgeist capturing the public's attention remains proficiency and global competitiveness, kindergarten teachers' experiences are largely absent from academic discourse and study on the subject. Those studies that elevate kindergarten teachers' experiences primarily delve into looselyconnected topics. Research examining kindergarten teacher perceptions explore retention (Okpala, 2007), the impact of in-service training on classroom practice (Gianina-Ana, 2013), early school competencies (Abry et al., 2015) and occupational stress (Lambert et al., 2019).

\section{Strand 3: Teacher Perception}

Kindergarten Teacher Perception Research. Few studies analyze kindergarten teacher perceptions of school readiness (Abry et al., 2015; Hustedt et al., 2018; Lin et al., 2003; Petrakos \& Lehrer, 2011). Kindergarten teacher perception research conducted by 
Lin et al. (2003) examined data from 3,305 kindergarten teachers in the 1998-1999

school year. Their findings asserted that readiness expectations were influenced by a teacher's age, gender, and the geographic region where he or she was teaching.

Furthermore, this study found that younger teachers valued academic skills more than older teachers and that geographic location influenced teachers' attitudes about academic rigor. Although this study offers strong evidence of disparate attitudes about the nature of school readiness amongst kindergarten teachers, its reliance on data from the Early Childhood Longitudinal Study-Kindergarten (ECLS-K), though offering a large sample size of survey data, limited its depth and complexity. In juxtaposition, qualitative studies, particularly phenomenological research, atomize interviews to offer thick descriptions that provide a more nuanced understanding of the phenomenon (Geertz, 1973). Nonetheless, one of the study's key findings that informs my research is that participating kindergarten teachers valued social indoctrination more than developing academic skills. As I explore the phenomenon of teachers' perceptions of achievement gaps, which largely entail academic indicators and aptitudes, attitudes that express a value of social skills development in isolation of academic standards may prove valuable in understanding teachers' experiences with the phenomenon of kindergarten readiness.

Research by Hustedt et al. (2018), completed fifteen years after the work of Lin et al. (2003), was conducted after a rapid change in policies and culture that have occurred since the turn of the century: emphasizing college and career readiness, governmentmandated achievement gap closure, and increasing rigor to compete globally. The researchers examined teachers' beliefs about kindergarten readiness using statewide surveys of Delaware kindergarten teachers conducted in 2000 and 2013. Like the 
findings of Lin et al. (2003), Hustedt et al. (2018) found that non-academic skills were still valued more by kindergarten teachers than academic markers, despite increased pressure and expectations of academic rigor and achievement expediency promoted by policymakers and the general public. Also, like previous research conducted by Lin et al. (2003), findings were the result of quantitative data analysis, particularly chi-squared tests of homogeneity, to determine perception changes over time; therefore, as with the previous study, the nuances and complexities elicited from interviews and co-researcher dialogue are missing from the analyses of Hustedt et al. (2018).

Abry et al. (2015) also found that preschool teachers and kindergarten teacher prioritized interpersonal and self-regulatory skills more than academic skills for incoming students because kindergarten teachers believe it is their responsibility to impart academic skills and "therefore do not deem such skills as essential for children upon entering kindergarten" (p. 85). Interestingly, research conducted by Abry et al. (2015) also concluded that surveyed preschool teachers rated academic skills as more important than the kindergarten teacher participating in the study despite kindergarten teachers' belief that they were responsible for imparting academic-related knowledge. This belief misalignment was found to be negatively associated with kindergarten adjustment and could have implications with teachers' academic expectations as well as "ongoing efforts to close the achievement gap between lower- and higher-SES children" (p. 86).

Espinosa et al. (1997) analyzed rural kindergarten teachers' perceptions about kindergarten readiness and found that teachers believed that students were less prepared than they were five years earlier. Moreover, Espinosa et al. (1997) found that teachers attributed students' increased lack of readiness to parental behaviors including working 
more and spending less quality time with their children. According to teachers' perceptions, this decrease in parental oversight and care has resulted in decreased socialization and academic readiness for children, especially those not enrolled in Head Start or preschool. Furthermore, teachers associated a lack of parent involvement and increased dysfunction with the young age of some parents, drug use, and a lack of parenting skills.

Summary and Implications. Though research on kindergarten teachers' perceptions of their students is limited to analyses of surveys, research findings that teachers across generations value developing students' non-academic skills more than academic skills could be important to this study (Abry et al., 2015; Hustedt et al., 2018; Lin et al., 2003). This study examines teachers' perceptions of their students including those identified as not ready for kindergarten. In an era of increased rigor for kindergarten and languishing improvements in readiness, teachers who favor nonacademic skills may be influenced by the cognitive dissonance resulting from their responsibility to teach grade-level standards and their belief that instruction should focus more on socialization (Bakken et al., 2017; Kentucky Department of Education; 2020). This conflict may be exacerbated by the lack of some students to cognitively grasp concepts as quickly as their peers because of the risk factors associated with household disorder, relationship instability, and other negative effects on the home microsystem.

Research by Espinosa et al. (1997) while also indicating that teachers' preferences for non-academic skills development have been evident for over twenty years and in varied geographic locations, indicates that kindergarten teachers may blame parents for their students' inadequacies. Such accusations may indicate a lack of ownership of 
students' development or may be transferred to the students themselves. Furthermore, teachers who indicate that parents less responsive to their children without first-hand accounts of the relationships between parents and their children may be expressing a bias based on their own experiences or a bias against unfamiliar others including those of differing socioeconomic statuses, ethnicities, and experiences.

\section{Summary and Implications of the Literature Review}

The purpose of this phenomenological study is to explore the lived experiences of kindergarten teachers and their perceptions of their students, many of whom are identified as not ready for kindergarten. Kindergarten teachers, by their very profession, are educated adults entrusted with the social and cognitive development of their students. Ergo, many of the students whom teachers teach come from home microsystems distant and foreign to teachers' personal histories and experiences. Because of these discrepancies, understanding how teachers' perceptions are shaped by the synthesis of memories and current experiences is necessary to explore teachers' perceptions of and expectations for their students. Moreover, examining how home ecologies shape both teachers' development and values, as well as the cognitive and social development of their students, may provide insights into achieving academic outcomes contingent on the effective convergence of teachers' expectations for their students, based on their understanding of their own experiences, and students' transition from the home microsystem to a broader context.

Researchers, institutions, and governments ambiguously conceptualize kindergarten readiness. This literature review examines general definitions and standards of kindergarten readiness, different states' working definitions of readiness, as well as 
various models for understanding the disparate views of school readiness. Although the state in which this study is conducted has its own working definition, teachers come from outside of the state and their personal views may align more with one model than another; therefore, this literature review is intended to provide a survey of varying models of kindergarten readiness to not only broaden and enrich interpretations of teachers' experiences but also illustrate the abstruse nature of assessing children's readiness for school.

Understanding the harmful impact of household disorder, relationship instability, and other risk factors on children's development is necessary to contextually conceptualize descriptions teachers may offer of their experiences with children identified as not ready for kindergarten as well as their efforts to mitigate these effects. Additionally, comprehending how home and school ecologies mold and transform children's social and cognitive development may inform analyses of how teachers describe their students and their home lives as well as how teachers themselves are affected by the interaction between their professional duty and empathy. By examining how blended microsystems simultaneously affect the participants, a more holistic understanding of the changing nature of kindergarten readiness and the effects of that change on teachers' lives may be reached. 


\section{CHAPTER III}

\section{METHODOLOGY}

\section{Chapter Overview}

This chapter describes my methodology to investigate:

- How have teachers' experiences as kindergarten students formed their expectations for and perceptions of their students?

- How do kindergarten teachers perceive their students, especially those labeled not ready for kindergarten?

- How has teaching kindergarten, particularly those students labeled not ready for Kindergarten, affected teachers' professional and personal lives?

- How has teaching students who are identified as not ready for kindergarten affected teachers' instructional practices?

I based the foundation of my research design on Husserl's seminal phenomenological principles of understanding the essence of a phenomenon through reduction, epoché, and bracketing to mitigate the influence of my preconceptions and biases on data collection and analysis (Husserl, 1931). Phenomenology provided the 
philosophical rigor for my study as it necessitated natural situations instead of the contrived contexts of laboratories or simulations. I constructed a logical data collection and analysis sequence intended to improve the rigor and validity of my study by utilizing the coding scheme of grounded theory to provide a reiterative, horizontal, and holographic analysis process that evolves in breadth and specificity as new participant perspectives and data are incorporated and synthesized (Creswell \& Poth, 2018; Giorgi, 1985).

This study was comprised of five phases: (a) phenomenological reduction, (b) semi-structured interviews, (c) coding and analysis of data, (d) creating textural descriptions, (e) and synthesizing textural descriptions to understand and articulate the essence of the phenomenon. In addition to describing my study's design in this chapter, I explain how participants were selected and how I improved trustworthiness and accuracy through analyzing myself as the research instrument as well as my ethical considerations concerning the study and my participants. The results of these processes are reported in chapters four and five.

\section{Research Questions}

I began exploring the phenomenon of kindergarten teachers' perception of their students in light of kindergarten readiness with a series of inquiry intended to initiate the discovery process. These questions included explorations of kindergarten teachers' lived experiences working with kindergarten students including those labeled not ready for kindergarten, the effects of working with kindergarteners on their professional and personal lives, and their memories of being kindergarten students themselves. Questions used to explore kindergarten teachers' complex interpretations and responses to the 
phenomenon of readying students for subsequent schooling include: How do teachers describe their experiences as kindergarten students? How do kindergarten teachers perceive their students, especially those labeled not ready for kindergarten? How has teaching kindergarten, particularly those students labeled not ready for kindergarten affected teachers' professional and personal lives? How has teaching students who are identified as not ready for school affected teachers' instructional practices?

\section{Theoretical Framework}

\section{Phenomenology}

Built on the philosophy of German mathematician Edmund Husserl (1859-1938), phenomenology focuses on collecting the perspectives and views of a number of participants about a specific phenomenon (Creswell et al., 2007; Husserl, 1964). The pursuit of phenomenology is to "grasp the very nature of a thing" through the lived experiences of people affected by the thing, the phenomenon (Van Manen, 1990, p. 177). For example, this study was designed to elicit the nature of teachers' perceptions of their students and how teaching students who are identified as not ready for school has affected teachers' instructional practices from interviews focused on their lived experiences. Therefore, it is the purpose of this study to form a composite of participating kindergarten teachers' experiences to contribute to the research base that not only reports the phenomenon of teacher perceptions but also informs other research on pre-kindergarten achievement gaps and how to close them.

To effectively collect the data required to form an understanding of the nature of a phenomenon, researchers must first analyze themselves as the research instrument (Creswell et al., 2007). This process, known as bracketing, requires the researcher to 
analyze his or her experiences with the phenomenon and potential biases that may influence how the researcher interprets data (Tufford \& Newman, 2012). Tufford and

Newman (2012) defined bracketing as the "method used by some researchers to mitigate the potentially deleterious effects of unacknowledged preconceptions related to the research and thereby the rigor of the project" (p. 81). This method is especially necessary for researchers who are close to the research topic (Tufford \& Newman, 2012). This study examines teachers' perceptions of their students, especially those labeled not ready for kindergarten, and how working with these children affects teachers' personal and professional lives. Because I am a former teacher and an evaluator who worked with both teachers and kindergarten students, my experiences necessitate that I not only introspectively inventory my historical, cultural, and academic experiences and views but also include that self-analysis in the study to explicitly divulge significant influences on the research instrument. Bracketing, also known as phenomenological reduction, thus diminishes the possible effect of unacknowledged preconceptions by making biases overt and sharing those revelations for the scrutiny of an analytic audience (Tufford \& Newman, 2012). Bracketing can also serve as an analysis of the researcher's experiences as an initial exploration of the phenomenon that promotes co-researching with the study's participants (Crotty, 1996). Furthermore, bracketing improves the research process when used as an iterative process by which the researcher's evolving understanding of the phenomenon is archived in memos as the researcher gathers more data and recursively analyzes the data in the broadening context provided by more participants' experiences (Tufford \& Newman, 2012). 
From the experiences of participants, researchers find common themes from specific statements to construct a model of the phenomenon. Generally, a small number of 5-25 participants is recommended to establish a viable understanding of the phenomenon (Polkinghorne, 1989). Researchers then atomize interview data into codes — words, phrased, and units of meaning — for open coding, the first of a three-part coding process (Strauss \& Corbin, 1998). Similar to data analysis processes in grounded theory qualitative research, open codes are assigned a theme or overarching idea (Kolb, 2012). Axial coding is then conducted that further groups and refines the associative themes through deductive and inductive thinking to refine the researcher's evolving understanding of the phenomenon (Strauss \& Corbin, 1998). Selective coding follows that further refines and provides a deeper understanding of the examined phenomenon (Kolb, 2012). Kolb (2012) identifies this coding process as theoretical sampling as coding and iterative analysis develop concepts and relationships into categorical findings until the point of data saturation (p. 85).

\section{Ecological Systems Theory}

Vygotsky, best known for the concept of proximal development, is the founder of the sociocultural theory of cognitive development, which asserts that children develop through social interaction with people, particularly those with more developed linguistic and scaffolding skills (Vygotsky, 1962, 1981, 1987). Vygotsky believed that children developed higher cognitive and psychological abilities through cultural-historical and socialization with other individuals (Vygotsky, 1978). Because language has the most significant effect on how a child develops his or her social and cultural understanding, the 
home ecology and those who inhabit it have a profound influence on how children develop cognition and self-regulation (Vygotsky, 1981).

Bronfenbrenner's theory of ecological development aligns with Vygotsky's sociocultural theory of cognitive development in that the home ecology, called the home microsystem by Bronfenbrenner, is the most prodigious influence on early child development because of the child's proximity and frequency of interactions with the people who inhabit the home (Bronfenbrenner, 1979, 1989). According to the theory of ecological development, the fundamental building block of the home microsystem is the dyad, a phenomenon that happens when two people "pay attention to or participate in one another's activities" (Bronfenbrenner, 1979, p. 56). In the home microsystem, children establish reciprocal dyads with other children and caregivers. Dyads with caregivers are the foundation for the acquisition of social skills and a more complex understanding of the concept of interdependence. Like Vygotsky, Bronfenbrenner identified the primary dyad between children and their caregivers as the most important relational influence on child development.

According to Bronfenbrenner (1979), the school serves not only as the second most significant microsystem in children's lives but also as an opportunity to investigate the impact of the home microsystem and perhaps improve the prospects of children. This safety net, however, is more likely to occur if the teacher develops an emotional attachment with the child (Bronfenbrenner, 1979). Moreover, a classroom's developmental potential is improved if the physical and social environment engages children in progressively more complex interactions and activities that activate cognition (Bronfenbrenner, 1979). 
The ecological systems theory informed this study in that it provided a framework for how home ecologies, particularly the relationships children have with their guardians and caregivers, affects child development. These foundational environments either promote or hinder normative growth towards kindergarten readiness and the acquisition of cultural funds of knowledge and in-kind potentially influence teachers' perceptions of their students' home microsystem and academic potential. Additionally, teachers' perceptions of their students may impact the relationships and emotional attachments they have with their students as well as the interactions and activities they facilitate. In essence, if teachers perceive students as being less capable, they may not provide activities and interactions with peers and adults that promote proximal development (Hoxby, 2000; Slavin, 1987; Wilkinson, 1988). Exploring these phenomena may provide insights that improve school transitions for children identified as not ready for kindergarten and could illuminate a potential contributing factor to enduring achievement gaps.

\section{Methodology}

The experiences of kindergarten teachers are largely absent from research literature analyzing kindergarten readiness (Coley et al., 2015; File \& Gullo, 2002; Holliday et al., 2014; Vernon-Feagans et al., 2016). I chose a phenomenological design to acquire a deeper understanding of the meaning of Central Kentucky kindergarten teachers' lived experiences and their perceptions of meeting the needs of their students. This research study uses a Husserlian phenomenological approach that explores the lifeworlds of kindergarten teachers as a means to define the common homeworld experienced by kindergarten teachers in general (Husserl, 1931). Furthermore, I chose a 
Husserlian, transcendental, phenomenological design because it requires that I introspectively identify and set aside my experiences and schemas with kindergarten education that could potentially influence my interpretation of teachers' testimonies (Husserl, 1983; Moustakas, 1994; van Manen, 1990). Moustakas (1994) defined transcendental, phenomenology as "a scientific study of the appearance of things, of phenomena just as we see them and as they appear to us in consciousness" (p. 49). That is, transcendental phenomenology promotes analysis that examines the wholeness of lived experience in a search of the essence of the phenomena. To bracket conceptual frameworks forged over decades of attending school and working in education, I found the transcendental approach necessary to increase my self-awareness to approach teachers' descriptions with the wonder of inexperience.

The research I reviewed in preparation for my study informed my understanding of the phenomenon and the inquiry I used to explore teachers' experiences, but the findings of other researchers, as well as my own experiences, could have potentially affected my interpretation of interview data without explicitly bracketing those ideas before analysis (Tufford \& Newman, 2012). Therefore, though my survey of literature informed my understanding of previous research on the phenomenon and related factors, phenomenological bracketing was necessary "to mitigate the potentially deleterious effects of unacknowledged preconceptions related to the research and thereby increase the rigor of the project" (Tufford \& Newman, 2012, p. 81). In practice, bracketing involves writing memos concerning my presuppositions during the data collection and analysis processes. These notes allowed me to examine my engagement with the data and the potential influence of internal (e.g., emotions, assumptions, biases) and external 
suppositions (e.g., culture, profession, contexts) (Tufford \& Newman, 2012). Moreover, because I revisited data and my notes throughout the reiterative analytic process, this multilayered reflection allowed me to "access various levels of consciousness" as contexts changed and new data were added to the totality of data collected and analyzed to understand the essence of the phenomenon (Tufford \& Newman, 2012, p. 84).

Though a phenomenological methodology limited the number of participants included in my study compared to quantitative studies exploring the same phenomenon, this framework was necessary to explore the complexity of the phenomenon identified in my research questions (Polkinghorne, 1989). How teachers' experiences as kindergarten students may have formed their expectations for their students cannot be adequately examined through Likert survey data and other quantitative measures; the depths of how teaching kindergarteners affects teachers' professional and personal lives can only be effectively explored through dialogue resulting from open-ended questions; and how entering students from varied home microsystems affect teachers' instructional practices are more easily described than identified quantitatively.

\section{Participants}

I interviewed ten kindergarten teachers from three Central Kentucky elementary schools to participate in the study. My inclusion criteria included full-time employment as a kindergarten teacher and availability for in-person interviews. Participating teachers varied in age, geographic origin, and professional years of service. Moreover, the schools they serve represented communities of varying degrees of ethnic, socioeconomic, national origin, etc. heterogeneity. Although my participants were limited to those who 
responded to my request, I believe I offer a varied sample that represents the diversity of the district's teaching professionals and communities the schools serve.

I contacted prospective participants via professional e-mail accounts. My initial inquiry included a brief explanation of the purpose of the study, how the study may benefit the profession and professionals, the semi-structured questions I used as a foundation for the interview, informed consent form, and my contact information. I also explained how participants will have access to transcripts, available on a shared drive for

feedback to ensure accuracy. I asked that those interested in participating in the study to reply with convenient times, days, and modes (i.e., a phone call or an online platform). I also provided my cell phone number if any of those interested in participating prefer texting or calling with the requested information.

\section{Data Collection Methods}

Interview platforms were private to ensure confidentiality. Face-to-face interviews were not permissible per Kentucky government COVID-19 guidelines; therefore, all interviews were conducted with Microsoft Teams or phone calls. I audiorecorded interviews on my laptop and cellular phone to ensure the data was recorded because of technology issues. After the recordings were reviewed for fidelity, I used Rev.com, a transcription service, to transcribe the interviews. In some cases, the transcriber incorrectly transcribed words or phrases; therefore, I edited each of the transcriptions to match the recording verbatim. To further increase accuracy, participants were provided with the audio recordings and transcriptions of their interviews and invited to correct or clarify any inconsistencies. 
I began each session with a brief social conversation that segued to the interview to create a casual and trusting environment (Moustakas, 1994). I followed this introduction by conducting interviews with semi-structured and open inquiry to create conditions conducive for dialogue (Creswell \& Poth, 2018; Wallen \& Tormey, 2019). Though all interviews featured previously written, semi-structured questions, responsive questions varied based on the teachers' responses. I shared the semi-structured questions with participants before the interview to encourage participation by allaying fears and to elicit feedback. Moreover, I interviewed participants in one session consisting of three parts: past perceptions and experiences as kindergarten students themselves and with kindergarten students, including those identified as not ready for kindergarten, present experiences and perceptions of the phenomenon of kindergarten readiness, and the effect of the phenomenon on their professional and personal lives.

\section{Data Analysis}

Phenomenological research studies do not follow a prescribed analysis method (Creswell \& Poth, 2018). Instead, Giorgi (1985) suggests that phenomenological research should ensure that (a) the researcher identifies the phenomenon, (b) the data come from participants' descriptive accounts, (c) themes and patterns are identified from the data, (d) and findings are shared with participants. As a means to provide my study with a rigorous data analysis process, I used the analytic coding process most commonly associated with grounded theory, though this process is not uncommon for phenomenological studies (Creswell \& Poth, 2018). This coding process includes three coding progressions that occur throughout the data analysis process: open coding, axial coding, and selective coding (Creswell \& Poth, 2018; Moustakas, 1994). Open coding 
involves my first survey of the data and categorizing the data into themes. During axial coding, I collaborated with another reader to further refine, combine, and narrow themes through a deductive and inductive analysis of the data. Next, I analyzed the data further during selective coding to better understand the common themes and the essence of the phenomenon (Kolb, 2012).

While I was completing the open coding, axial coding, and selective coding processes for each new set of interview data, I reanalyzed and recoded previous data for previous interview data as new data are incorporated (Miles et al., 2014; Saldaña, 2016). This reiterative and holographic analysis process allowed for new ideas to influence previously identified meaning units to represent my broadening understanding of the phenomenon as new perspectives were added (Moustakas, 1994). Once selective coding yielded core categories, I created textural descriptions for each participant and then synthesized those descriptions to convey the essence of experience with the phenomenon (Moustakas, 1994).

In summary, my data analysis process consisted of:

1. First, describes my experiences with the phenomenon (epoché) and bracket my subjectivity to increase my awareness of my preconceptions and predispositions of the phenomenon (Husserl, 1931).

2. Next, I began the iterative, progressive, and holographic data analysis process. That is, I collected data through semi-structured interviews and reexamined the totality of data as new data were collected and as I moved through the coding process. 
3. I then examined data from interview transcriptions as equal-value statements during horizontalizing. I then analyzed for significant statements (narrow units/horizons).

4. Next, I categorized these statements into meaning units during open coding (phenomenological reduction) to discover common perceptions and themes (Moustakas, 1994).

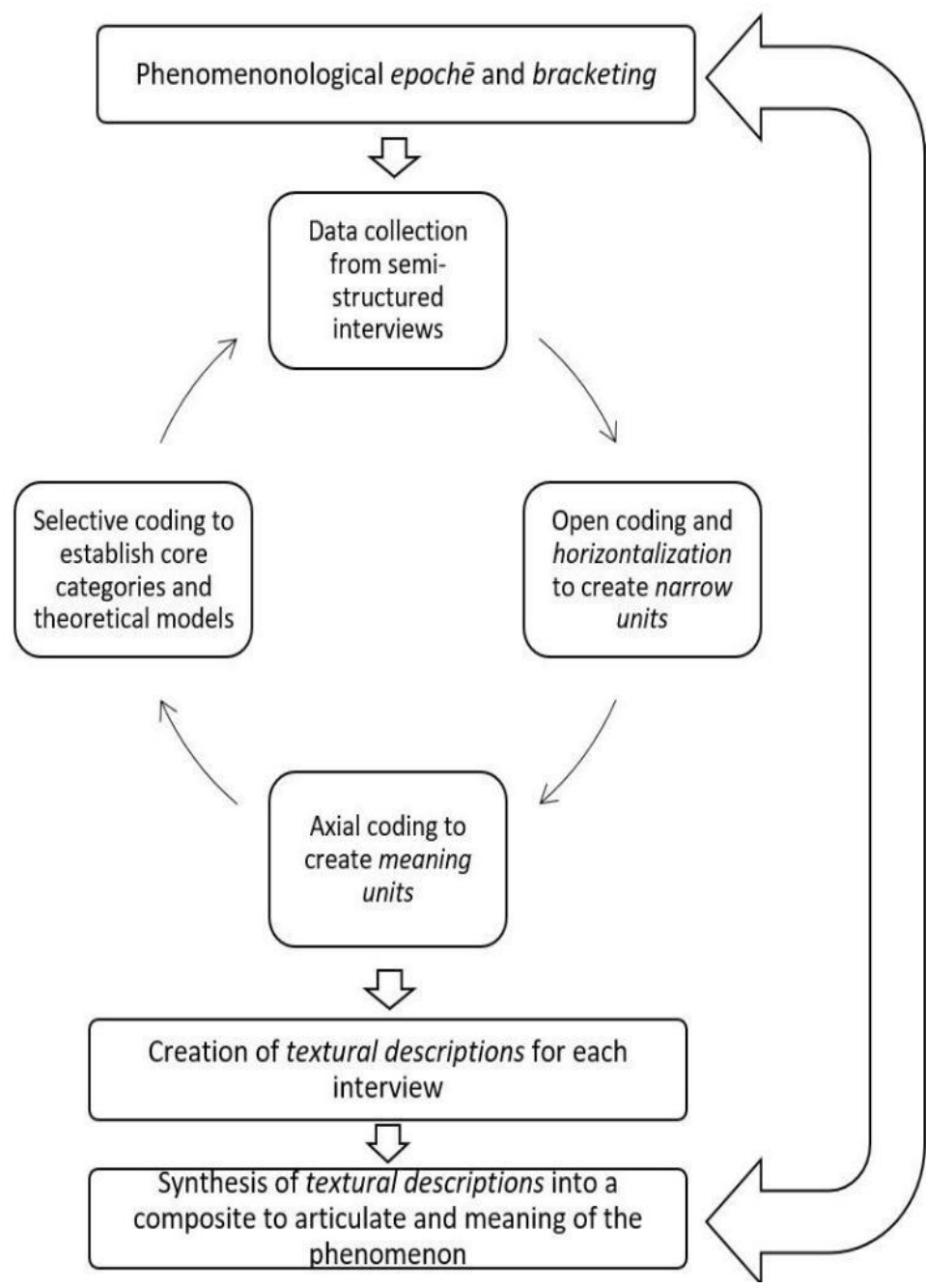

Figure 2 provides the data collection and analysis process.

codes into "core themes of experience" of the phenomenon (Moustakas, 1994, p. 121).

6. I then collaborated with another reader to further analyze axial codes during the selective coding stage to establish core categories and 
theoretical models of the observed phenomena (Miles et al., 2014;

Saldaña, 2016).

7. I followed selective coding by creating textural descriptions, explanations of participants' perceptions of the phenomenon, with the verbatim interview data and identified core themes (Moustakas, 1994).

8. Last, I synthesized participants' textural descriptions into a composite account of the meaning and essence of experience with the phenomenon and categorized this account into themes (Moustakas, 1994).

\section{Epoché and Positionality}

The phenomenological design of this study includes an analysis of myself as the research instrument and interviews of ten kindergarten teachers from three Central Kentucky elementary schools. To suspend judgment (Husserlian phenomenological reduction/bracketing) to focus exclusively on the phenomenon, I unpacked the symbolic meanings of my own personal and professional experiences interacting with kindergarten teachers and students. This self-analysis largely served as an inventory of my perceptions and biases that potentially influenced inquiry and interpretations of interview data (Husserl, 1983).

My experiences with kindergarten students have been largely positive though my interactions with some students and parents have piqued my curiosity about the role of home regardless of designation, race, class, and history—with whom I have interacted have delightfully worked and grown during their first year of school. My own experiences as a kindergarten student are likewise positive. While I understand that kindergarteners are provided more rigor than I did in the same grade, my perception of an 
increase in difficulty transitioning from homes to school for some students causes me to consider how children are raised and how schools can better meet their needs. Moreover, my interactions with enabling parents as a teacher and administrator may offer some explanation for this difficulty. Though I have interacted with a multitude of kindergarten parents and students, I admit that the circumstances for many of my interactions with parents and students may not represent the general public because my work concerns discipline issues; therefore, my perception may be skewed by the frequency and volatility of these encounters. Although research about the effects of disciplinary duties on administrators' perceptions of students is limited, studies suggest that student behavior could be a significant cause of ongoing achievement gaps (Griggs et al., 2016; McIntosh et al., 2012) and the increase in teacher retention issues (Evers et al., 2004; Ingersoll, 2001). Instructional leadership and staff management are integral parts of my professional responsibilities; therefore, student misbehavior compounds instructional leadership problems by limiting time devoted to pedagogical and curricular works and potentially lessening the effectiveness of teachers' efforts.

My experience with kindergarten teachers has formed my opinion that they are overwhelmingly caring and dedicated. Because of the amount of monitoring and work necessary to grow kindergarten students, I view kindergarten teachers as an essential part of the socialization and academic maturation of students in public education. Furthermore, I respect and sympathize with kindergarten teachers for their sacrifices: redundancies, constant vigilance, liability, and occasionally, potty training.

At the time of my writing this epoché, I am a father of three small children. My sons, ages 4 and 7, and my daughter, age 1, continue to be wonderfully intimate, informal 
case studies of child development for me to examine. Through their growth, I have developed a broader and personal understanding of the influence of parenting (dyads) and the home microsystem. My children have benefitted by being raised by two educators who look after their developmental needs. In this microsystem, I have seen my children improve their creativity, cognitive reasoning, and empathy and understanding. My relationship with my children has increased my own empathy for the responsibilities of parents as well as potential obstacles and hardship that complicate or potentially compromise preparing children for life after childhood. Moreover, I am more appreciative of the numerous manners in which parents instill funds of knowledge in their children that differ my own experiences. Having spent time with parents and their children from different backgrounds and communities through my children's activities and pre-schooling, I have witnessed effective parenting practices and considerations that help their children grow.

\section{Ethical Considerations}

Because of my position as an administrator in a school in the district represented in my study, I overtly communicated the intent of the study, the confidentiality and anonymity of my data collection design, as well as my non-evaluative role as a researcher. Before collecting data from interviews, I met briefly with each of the teachers to explain the purpose of the research and answer any questions they have about the study and their roles as participants. For all ten teachers, my initial contact by email specified that I intended to explore kindergarten teachers' lived experiences. Moreover, I shared the interview questions and offered participants opportunities to modify the questions if they believed they unfairly or inaccurately probed their experiences. 
Before the interviews, I reiterated my study's purpose and non-evaluative nature. I also offered participants transcripts of the interviews to be used as evidence for their professional growth plans or for their interests or records as reciprocity for their time and willingness to share their experiences. To build rapport with the study's participants, I offered to conduct interviews at times and through modes convenient to those being interviewed.

Though I carefully considering how to build trust and rapport with my participants and how my research study ethically presents their voices and experiences, I used the structured ethical reflection (SER) tool (Appendix B) to further explore ethical considerations throughout the research process and through various values important to the study (Stevens et al., 2016). The SER tool provided a grid by which I considered essential, ethical values at each stage of the research process: developing partnerships, planning, recruiting participants, collecting and analyzing data, working with participants, and publishing. Because I utilized a phenomenological methodology to explore teachers' lived experiences, open-mindedness was a required value to bracket my personal biases and experiences. Moreover, building relationships with research participants required the development of reciprocal respect, trust, and empathy to elicit candor and a willingness to provide feedback. Last, integrity and validity were necessary qualities to ensure that teachers' experiences were not only analyzed and reported authentically to their intent but effectively synthesized and communicated to a wide audience of professionals and researchers.

The SER tool and process validated many of my prior ethical considerations while manifesting new sensitivities to aspects of the research process I had not yet explored. 
While I valued research participants' time and experiences before, during, and after the interview process, I had not reflected on how these teachers might co-construct interviews through dialogue and provide feedback during the research process. Transparently offering findings as they emerge and mature to participants not only improved validity but also improved rapport with and advocacy for those who provided the foundation of my research. Additionally, opening myself to divergent perspectives in the latter stages of the research process further reinforced bracketing my own biases, which became more influential as I transitioned from interviewing to the mostly solitary work of synthesizing data to discover themes.

\section{Summary of Chapter Three}

The purpose of this chapter is to explain the research methodology, data collection, and analysis processes intended to investigate the phenomenon of kindergarten teachers' lived experiences working with kindergarten students, including those labeled not ready for kindergarten, the effects of working with kindergarteners on their professional and personal lives, and their memories of being kindergarten students themselves. In this chapter, I explained the inquiry that directed this study, how I selected prospective participants, and the processes I used to prepare them for interviews. Furthermore, I explained the eight-step process I employed to rigorously structure an iterative, progressive, and holographic data analysis process. Last, I explained my positionality concerning the studied phenomenon as well as ethical considerations intended to improve myself as the primary research instrument, remain opened-minded throughout the research process, and build rapport, trust, and collegiality with my 
participants. The following chapter provides the research study results and demonstrates how the methodology described in this chapter yielded significant findings. 


\section{CHAPTER IV}

\section{FINDINGS}

\section{Introduction}

The purpose of this phenomenological study was to report how kindergarten teachers at three Central Kentucky elementary schools describe their attitudes about their own kindergarten teaching experiences, vocation, and students in an era of kindergarten readiness. The following chapter details the findings of this phenomenological study to answer my study's research questions:

- How have teachers' experiences as kindergarten students formed their expectations for and perceptions of their students?

- How do kindergarten teachers perceive their students, especially those labeled not ready for kindergarten?

- How has teaching kindergarten, particularly those students labeled not ready for kindergarten affected teachers' professional and personal lives?

- How has teaching students who are identified as not ready for kindergarten affected teachers' instructional practices?

This chapter is organized into two distinct sections: textural descriptions for each of the ten participants and the synthesis of these descriptions into the essence of the phenomenon, kindergarten teacher attitudes about their experiences, articulated through four core categories that emerged from selective coding 
I used Bronfenbrenner's ecological systems theory as the conceptual framework for coding my study's semi-structured interviews into narrow units, meaning units, and lastly, theoretical models and themes; therefore, ecological systems theory served not only as a means to understand students' experiences as detailed by their teachers but teachers' experiences in the school microsystem. Through this framework, the themes of Vocation (teachers' professional journey and their dedication to their profession), The New First Grade (teachers' descriptions of how kindergarten has changed), Wobbly Colts (teachers' description of their students), and The Costs and Rewards (the effect of teaching kindergarten on teachers' professional and personal lived) emerged.

\section{Demographic Characteristics of Participants}

\section{Table 1}

\begin{tabular}{lcccccc}
\hline Participant & & & & \multicolumn{2}{c}{ Years of Professional Service } & Work Site \\
& Ethnicity & Gender & Age & Elementary & Kindergarten & \\
\cline { 1 - 1 } Barbara & White & Female & 39 & 18 & 3 & Pinewood \\
Linda & White & Female & 43 & 18 & 3 & Pinewood \\
Dorothy & White & Female & 54 & 26 & 14 & Sunnyside \\
Mary & White & Female & 32 & 6 & 6 & Sunnyside \\
Patricia & White & Female & 50 & 6 & 6 & Sunnyside \\
Elizabeth & White & Female & 25 & 3 & 3 & Ferndale \\
Jennifer & White & Female & 24 & 1 & 1 & Ferndale \\
Margaret & White & Female & 47 & 9 & 4 & Ferndale \\
Maria & White & Female & 26 & 5 & 2 & Ferndale \\
Susan & White & Female & 42 & 6 & 6 & Ferndale \\
\hline
\end{tabular}

Note. Participant names and work sites are pseudonyms.

\section{Distant Interviews in the Time of COVID}


In March 2020, schools across the nation transitioned from in-person traditional instruction to various forms of distant, non-traditional instruction (NTI) because of an outbreak of COVID-19. The district in which the participants of this study work, closed on March 16. Teachers who had never used a learning management system (LMS) were forced to design lessons and learning activities in Google Classroom in a few short weeks to continue their students' learning for the foreseeable future. That future continued throughout the school year and into the 2020-2021 school year. Interviews for this study were conducted from July through September of 2020 in a time of pandemic uncertainty and civil unrest resulting from the death of George Floyd and other African Americans from the actions of law enforcement. Breonna Taylor, who was from Louisville, Kentucky, was among the fatalities.

Because participant interview questions asked teachers to reflect on their personal and professional experiences generally, no questions were asked specifically about teachers' NTI experiences. Nevertheless, the semi-structured nature of the study encouraged dialogue and did not differentiate between traditional and non-traditional instruction and experiences. Although teachers' descriptions of their experiences and their students drew from the depth of their personal and professional histories, references to online learning, NTI, and the difficulties of engaging students through technology arose. These were minor themes that did not warrant inclusion in this study, but references to these recent phenomena are found in some of the quotes that follow.

\section{Textural Descriptions}

\section{Margaret}


When describing her love and dedication to kindergarten teaching, Margaret proclaimed "I'm never leaving. Y'all have to fire me." Her love of kindergarten, kindled by her "amazing" kindergarten teacher, though starting at the onset of education has endured into middle-aged adulthood. Her teacher's "fun" and "inviting" approach, which made learning blossom through "trust" and "love," left such an impression on Margaret that more than forty years later, she invited her former teacher and mentor to her class to witness what grew from those seeds sown long ago. Though Margaret admits that today's kindergarten is "extremely different" from her formative kindergarten experience, she remains dedicated to a classroom culture that engenders a love of learning through rapport and fun.

Although her love of kindergarten connects her childhood experience to her current vocation, Margaret's path to kindergarten teaching winds and detours. Margaret and her husband moved frequently for his job - moving four times in five years at one point. As a result of compromising her professional stability for her husband's work, Margaret has worked in multiple states and irregular stretches. Margaret, starting as an assistant, has been employed at her current school the longest at thirteen years. The last four years of teaching kindergarten, however, have been her most enjoyable.

They are just so sweet and loving and excited ... I can be having the worst day and even my assistant that I teach with, she said, this morning, we came in this morning, I was like super stressed out and she was like, you know what, but in about five minutes, you're going to get on that computer and you're just going to go, "Hello." You know? And I'm like, you're right. They just bring it out in me. 
They can make a bad day, it just goes away. They just, they're so ... eager to learn.

Despite the joy Margaret gleans from teaching kindergarten, she acknowledges the challenges, specifically the changing nature of the kindergarten curriculum and students' experiences.

But if you think back over many years, [kindergarten] has changed a lot. We expect way more of these kiddos. The expectations are higher. The things that we're asking of them, like the standards that we're introducing and expecting of them, are much more than what kindergarten used to be ... I would say it's kind of just shifted more from learning through play to more of the rigid, the expectations are just higher and they're expected to do more.

Like other teachers interviewed for this study, Margaret attempts to balance increased academic expectations of the school readiness era with the traditional carefree environment generally associated with kindergarten. Despite the durable association of kindergarten and fun, Margaret described the changes in students' households and experiences as potential obstacles to not only academic achievement but the general enjoyment of early education.

Sometimes [academic expectation] puts stresses on these kiddos that they can't handle because they are coming from these homes that they're not okay ... the expectations are so much higher than they used to be ... Like, I think, not for all kids, but home lives are just very different. Parenting is very different. Many kids and I'm kind of comparing back to many years ago, kind of my kindergarten experience. Many homes are single-parent family homes ... [children] are on 
their screen time way more ... It's just a lot, kids are more, they require more, what's the word I'm looking for? Immediate gratification.

While Margaret acknowledges risk factors such as relationship instability and screen overexposure, she said that teaching kindergarten and working with children has changed her. She explained that teaching kindergarten students, especially those from challenging circumstances, has increased her empathy and understanding. Margaret described this evolved awareness as, "[seeing] the bigger picture, the reality of some of these kiddos and their home lives ... the scale is huge of what you see these kiddos come from." Moreover, she explained that the effect of divergent access to resources and social mobility for students' families on learning has affected her understanding of equity.

So, one kiddo has such advantage and this other kiddo is just at such a disadvantage just where he's starting and how far he has to come ... I think that that reality is probably the biggest thing that it's done, changed in me or that I've seen."

\section{Linda}

Linda had the rare experience of attending kindergarten twice. Because of her summer birthday, she was not old enough to enter first grade when her mother transferred her to a public school. Notwithstanding her different school setting, her experiences were similar. Both the private and public schools were primarily focused on socialization, roleplaying, and fun. Students attended school until noon and took naps. Furthermore, the literacy- and numeracy-focused curricula were delayed until later grades. 
I wasn't really interested in learning to read and that sort of thing. I didn't really gain that until well into upper elementary school ages, I guess. I liked the play and that sort of thing, but the having to sit down and learning to write and to read, and things like that I wasn't the biggest fan of ... when I went to school and did kindergarten, it was a lot more about exploring and play. We had the kitchens and we had the, I guess, costumes you could put on. I remember things like that, nurses, kind of doctors, things that you could play with. It was a lot of play and a lot of exploring. I guess just trying to be in an organized social setting and not at home and not at a daycare. But we were still trying to learn, but I just want to say it was more fun.

After eighteen years of teaching and three years teaching kindergarten, Linda says that current students' kindergarten experience is markedly different. Naps have been replaced by movement breaks; roleplaying has been replaced by reading groups; play kitchens have been replaced by learning stations. Instructional targets like "learning how to cut, how to color, things like that, and play and socialize" have been diminished in favor of "getting them ready for the next grade [by] knowing all their letters, all their letter sounds ... [wanting] them reading, putting words together.” This curricular shift from upperprimary into kindergarten extends to preschool. Despite Linda benefitting from educator parents, her students are academically more advanced than she was at the same age. Linda explained, "some kids do come reading to us now, and a lot come knowing a lot more information than maybe what I knew going in, or some other kids my age." Linda acknowledges, however, that not all pre-school experiences are equal. 
I want to say that when I first started teaching, it seemed like there were more kids that came into kindergarten that had been either in a preschool setting or a daycare setting that actually really taught the kids their numbers, their letters, letter sounds. So, they came in knowing more than they do now. Now it's almost like, "Okay, these parents said these kids went to daycare, but they don't know anything. They don't know letters, they don't know numbers, they don't know the ABC song." And I'm thinking their parents spent money to send them to a daycare or preschool and I feel like they're not ready for kindergarten at all.

Although students come to school at varying degrees of school readiness, Linda laments that she has little time to socially acclimate her students. Instead, she feels "the pressure of making sure I'm getting the content that I need to teach out there to them." She explained that the acceleration to instill literacy and numeracy earlier "puts a lot of pressure on them" and her. Instead of allowing "kids to develop on their own in a way," the current kindergarten zeitgeist pushes teachers and students to work harder and play less. As Linda put it, "We want our kids to end kindergarten knowing all their letters, all their letter sounds ... reading, putting words together." Whereas students a generation ago played, took naps, and mastered fewer standards, Linda wonders if the current curriculum is too taxing on her students' stamina. After a few weeks of onboarding, Linda's students are expected to fully adjust to the rules and expectations of the school.

We expect them to remember that they need to walk completely quiet in the hallway, walk on a straight line. You can't get up and just wander the room whenever you want. You can't get up and just go to the bathroom whenever you want. And we go straight through, we go from 7:45 to 2:35. Yes, we take breaks, 
but not like when we had nap time. And when I went to school, we had like two or three recesses and things like that.

Linda said exploration and socialization are the costs of shifting the standards of primary down to kindergarten. She mentioned fewer recesses, less time to socially experiment with peers, and fewer opportunities for imaginative play as the unfortunate sacrifices for increasing academic expectations.

Even with the changing nature of kindergarten education and students, Linda does not regret her principal's decision to move her from fourth grade to kindergarten two years ago. Whereas the pressure of school accountability is ever-present in intermediate teaching, kindergarten still offers adequate time necessary to ignite an excitement for learning for children new to the school. This excitement is contagious. As Linda said, "it kind of energized me ... it's more exciting in a way because the kids are excited." This excitement and rewards of seeing children grow are what motivate Linda to continue working with kindergarteners, even in the era of kindergarten readiness. "I've always just really enjoyed being around kids and watching them grow and teach them," Linda explained.

\section{Maria}

"I am not a super outgoing person, but with kids, I am," said Maria as she considered how teaching kindergarten for the past two years of her five years working in elementary has changed her. She spoke softly and paused for a moment after each question before answering. Her answers were short but precise; her responses were similar to her peers in this study despite the brevity. The child of a teacher, Maria credited her mother for motivating her to enter the profession. While lineage pointed her 
life's compass to teaching, her students' reactions have held that needle steady. "I've just always wanted to [teach] and just really love kids ... I love when they get excited about learning."

According to Maria, children are still excited about kindergarten despite the changes to kindergarten education for the current generation. "Thinking of when I went to kindergarten, in the past, it's just so much more rigor now," explained Maria. "I feel like how we teach kindergarten now, it's like back in the day how first grade was taught." Although kindergarten academic expectations have increased, Maria said that many of her students are up for the challenge. A former first-grade teacher, Maria said, "about half my class really, they act like first graders ... They catch on really quick ... I was impressed, surprised by that." These students, according to Maria, demonstrate more developed motor skills, emergent literacy and numeracy skills, and general academic knowledge than she anticipated. She doesn't attribute this outcome to any particular cause, but she notes that all students, regardless of readiness, are excited to attend kindergarten and learn. "They're really proud of themselves for accomplishing something on their own ... they get just really excited about new concepts."

\section{Elizabeth}

Elizabeth has always been drawn to children. She babysat and helped in a nursery before college, and as she put it, "I always just felt kind of drawn towards kids, and just helping them succeed, and grow." After considering a career as a nurse, Elizabeth realized that teaching was her calling. An admitted "kid at heart," Elizabeth loves to "just be silly with them, and they think it's the funniest thing ever ... I love what I do." In addition to the fun of teaching kindergarten for the past three years, Elizabeth said that 
her students' eagerness to learn and please her motivates her to continue teaching kindergarten instead of intermediate grades where students "get those attitudes."

Although Elizabeth highlighted the enjoyment she and her students have in school, she acknowledged the challenges as well. She talked about some of her students experiencing divorce, living in single-parent households, being placed in foster care, and living with parents who do not take an interest in their lives and education. Elizabeth said experiencing these circumstances vicariously through her students not only made her appreciate her parents and upbringing but also motivated her to provide a supportive culture for students in her classroom. Elizabeth explained that this conscious care provides students with a hidden curriculum.

You see so much growth throughout the year. Especially, with just socially, and dealing with their emotions ... just seeing them being able to deal with their emotions. Like last year I had a kid who would get super angry, and wouldn't know how to calm himself down. And, then later on in this year he was able to tell other kids how they can calm their selves down.

In addition to her pride in the social-emotional growth she nurtures, Elizabeth acknowledges that she likewise appreciates her students' academic growth. Elizabeth said, "I feel like we're asked a lot to make sure we're teaching ... standard[s]." Though academic expectations have increased since her kindergarten experience, she said that her students were up to the task. She conveyed that she is motivated by experiencing students "grow from not knowing anything to being able to read a book at the end of the year." Her current students' emotional and academic growth notwithstanding, Elizabeth 
still pines for some of the simplicity and openness of her kindergarten experience. "I wish there was a little bit more playtime," she explained.

\section{Barbara}

Kindergarten may have changed since Barbara attended it, but the location has not. Barbara works in the very school she attended over thirty years ago. At the time she attended kindergarten, the program was half-day and primarily focused on play. Barbara described her teacher as "caring and nurturing" and the curriculum as "more about socialization and making friends and how do we talk to each other." Though she admits that time has faded her memories, she does not recall learning sight words, letter sounds, or much of the current curriculum she teaches today. She remembers the feeling more than the content.

Barbara's feelings of vocation have endured from childhood through adulthood and eighteen years of teaching. Her desire to be a teacher started early. Even as a young child, she asked her mother for school supplies and grade books to teach her stuffed animals in class. Many years later, when she finally became a teacher, the curriculum remained similar to what she experienced as a student. Though Barbara admitted that kindergarten has changed since she started teaching, she continues her kindergarten teacher's gentle legacy. Like her kindergarten teacher, Barbara considers herself "a natural nurturing person" and "a little mother hen." Though academic expectations have changed, Barbara's dedication to the social-emotional well-being of her students has changed little.

I want to high five my kids, I want to hug my kids, I want to see them face to face and smile at them and I want them to tell me what they did last night and build 
that relationship. So that is still my number one priority, always. But then of course, things, the standards are different and expectations are different now than when I was in kindergarten. So, we have to work hard too. But I feel like I do a good job at making learning for the kids fun and just in a fun, relaxed atmosphere so they don't feel so just like they're sit and get or I'm just lecturing them or anything like that.

When describing her professional experiences, Barbara admits that she did not always want to teach kindergarten. Her principal recognized the "kindergarten spunk" in her and moved her from upper primary to kindergarten. Barbara initially cried and begged her principal not to move her. She later realized the importance of kindergarten and embraced the challenge.

I have learned that it is definitely my passion and I just, I love the responsibility of creating a love for learning in these young kids. It's most of their first experience at school. I mean, it kind of sets the tone for the rest of their life how they feel about school and learning, and I love that responsibility and I feel like I do a good job of a positive attitude towards learning with the kids and just watching that light bulb go off and them getting it and they learn so quick and just absorb everything. It's the most rewarding job ever.

After teaching kindergarten for a year, she approached her principal and begged her not to be taken out of kindergarten. Barbara's desire to continue teaching kindergarten comes from newfound respect for the long-lasting effects good kindergarten pedagogy can have on children. She said that while many may misconceive kindergarten as merely 
"babysitting," what students learn is the "foundation of everything." A good kindergarten teacher, Barbara explained, can provide "just what each kid needs to move them in the right direction."

In addition to changing her mindset on the value of kindergarten education, teaching kindergarten has improved Barbara's patience and empathy. She now resists the impulse to assume struggling students simply do not want to learn or that their parents are not willing to help. Instead of making dismissive assumptions, Barbara communicates with parents more about their child's learning, leverages her relationships with students to diagnose academic obstacles to improve engagement, and attempts to understand the unique contexts of students' experiences to connect with them.

\section{Mary}

Like other participants in the study, Mary has a natural affinity for children. As she told it, "I could walk into a room full of adults now and I would gravitate towards the five children that are in that room because I just, I enjoy spending time with them and getting to know them." The child of middle-school teacher mom, Mary was reared in the profession, first vicariously through her mother's experiences and later as an aid in her mother's after-school program. During college, she worked as an aid in preschool and elementary classrooms. Here, she found her calling. Mary explained, "I loved seeing kids get that a-ha moment."

Despite Mary's forays into early education, she found having the responsibility of teaching kindergarten in a public school markedly different from her own experience as a student and as an aide. While Mary's private school experience twenty years earlier 
focused on socialization and play, her kindergarten teaching curriculum sidelined traditional kindergarten to introduce academic standards previously taught in first grade. I thought it was going to be a lot like my kindergarten experience, with a lot of socialization, and hands-on, and just social skills. And I mean, that is part of it, but it's something you squeeze in with other things because you don't have time to play. By the end of kindergarten, they're reading on a level D, they're writing multiple sentences ... it's changed dramatically. And I think the child portion of it has been taken out, it's more to the books. I think what ... I did in first grade is what we're doing now in kindergarten.

To meet the social needs of her students, Mary uses the parts of her day that have not been dedicated to reading groups, math learning centers, and cross-curricular lessons. Like many elementary schools in the district, Mary's school allows students to go to their classrooms with their breakfast before school officially begins for recreational activities, one-on-one help, or to socialize with friends outside of the noisy cafeteria. Mary uses this time to revive parts of the traditional kindergarten curriculum that were sacrificed for academics.

We hit the ground running. I mean, last year we were able to implement 45 minutes at the beginning of the day, from where they come in to where we actually start school, with different toys that they could work within groups. And that seemed to really help with socialization and getting them to get along because that's such a big skill. Most of these kids either come from in-home daycares or they've been home with grannies and aunts and uncles, so they don't have the interaction that a lot of kids do when they stay at home. 
Mary finds this time not only beneficial for socialization but also for developing nonacademic abilities such as fine motor skills through drawing. Mary explained, "with the fine motor, if they were playing on the ground with Legos, even for 15 minutes a day...just to get those fine motors because they don't have time for that." Furthermore, this time also allows her to talk with students about their home lives and non-academic experiences to build rapport and trust that may otherwise be lost during reading and math rotations.

In addition to describing the joy she has interacting with students both academically and socially, Mary addressed the nuanced difficulties of her job. She questions whether kindergarten-age children are academically or socially ready for the level of literacy and numeracy evident in kindergarten standards. As she explained, "Some of them aren't mature enough yet to start some of this deep dive into learning." Mary also sees differences between her male and female students, "I find that with boys more than girls, they just have a more rambunctious side to them, so getting them to stay in a seat." She also explained that the managerial aspects of kindergarten teaching including "cutting everything out for them so they can put it all back together" and completing paperwork are necessary but not as rewarding as working directly with students. As Mary explained, “people don't understand how much of teaching has become just paperwork, on paperwork, on paperwork ... so I'll take any time available to just be more personal with them."

\section{Susan}

For Susan, education is the family business, "My mom was a teacher. I married a teacher, so teaching was always in my blood." Though Susan has taught kindergarten for 
six years, she did not realize this birthright initially, however, as she entered the profession later in life. Despite the late start, she said that she has always felt like a teacher even while working jobs outside of education. While teaching elementary was her mission, teaching kindergarten happened by chance because of her son's preschool enrollment at a school where kindergarten was also taught. Susan became familiar with the school and the principal as an SBDM parent and eventually applied for a kindergarten position. As she puts it, "I fell into it." Though teaching kindergarten was not a calling at first, Susan now speaks of teaching spiritually. Susan said that teaching kindergarten "feeds my soul" and "gives me meaning."

Susan may have used lofty language to describe kindergarten holistically, but her description of teaching kindergarten and the students she serves is grounded in experience. The curriculum she teaches starkly contrasts with her experience as a kindergarten student.

One, it's full day. Two, the content. I mean, we hit the ground running now. I mean, we start off and these kids are reading and writing by the time they're leaving kindergarten. And I mean, I don't remember looking at a book and understanding the words until the middle of first grade easy ... there's a different focus in kindergarten now. I've heard people say that it's the new first grade and that's my experience too.

For Susan, this intersection of increased academic expectations and transitioning from home to school creates complexities that make teaching kindergarten challenging. According to Susan, these challenges necessitate that kindergarten practices go beyond traditional notions of facilitating exploration and fun. 
Honestly, I think we have a few more behavior issues in kindergarten. We come in and we expect a lot from these students. I think everybody thinks it's a fun, happy place, but we do have to manage a lot of different behaviors. We diagnose a lot of things in kindergarten that might not see at home because we're in a different environment. So, I think it's not always the sunshine and roses that people are like, "Oh, kindergarten, you learn your letters and your colors." And so, it can be a bit challenging.

Though these challenges have not changed Susan's general feelings about teaching kindergarten, working with students in the current environment has affected her. She considers herself "a more empathetic person" as a result of interacting with students and their families. This increased empathy has also broadened her perception of the people and cultures her school serves.

I've worked with a lot of people, a lot of parents especially who work hard for their kids and they do the best they can, and I think I am able to see a wider scope of what home looks like for people. So, I tend to feel that I'm a bit more empathetic to people's situations, especially when I see them try hard. The family unit is different for me.

Susan also reiterates this idea of parental support and home-school partnerships when describing how teaching has changed her view of supporting her children.

[Teaching] puts definitely an emphasis on being supportive of education for your kids and how successful kids can be when they've got that extra support at home. When they know that there is an emphasis on education, there's definitely more enjoyment and you get more out of school, you get what you put into it. I know 
what their school day is going to look like. I have a better relationship with their teachers because of it.

Susan said that she can tell when students lack support from home. These students "miss more" and "get distracted, they don't bring their folders, they're missing things." She described unsupported students as "missing something" when other students are having a "fun day." "There's just a sadness there and behaviors pop up because of that too," explained Susan.

\section{Dorothy}

At 26 years of service, Dorothy is one of the most experienced teachers interviewed for this study. At the time of this interview, Dorothy was in her penultimate year of teaching and looking forward to retirement. During the interview, Dorothy spoke about the many changes that she has experienced since beginning elementary school teaching in the early 1990s. Her descriptions vary from wholesale criticisms of society to explicit details about her students and their families. Generally speaking, Dorothy described her current students as not as prepared, more often distracted, and more prone to behavior problems than their predecessors.

When I started teaching, the students were very different. Children came prepared and ready to learn. They were kindergarten-ready. It was great to start the school year with students who were ready for the content. Today, my students aren't nearly as prepared. Many of them don't have support from home, really. Parents aren't as involved as they used to be and this causes students to be more easily distracted and act out. 
Of society, Dorothy attributed much of her students' changing aptitudes and attitudes to advances in technology, specifically children's access to mobile technology and media. She explained that because of technology access and the internet children are more aware of the world beyond their communities but with this knowledge comes an awareness of ideas and realities that are developmentally inappropriate. "They know things at five and six years of age that I didn't know until college," explained Dorothy. She alluded to students' access to violence in media in particular as a deleterious influence on students' behavior. "They are shooting people in video games like Fortnight and that's okay?" rhetorically asked Dorothy as she transitioned to describing a decline in parenting. "Who is monitoring these kids? Maybe some parents are working a second job or something, but their kids are home alone with free access to anything they want on the internet."

In addition to changes to students, Dorothy described how the kindergarten curriculum had changed over the last three decades. She described kindergarten during the first years of her career as "time for kids to explore and socialize." Though she taught upper primary initially, she said she inherited children from kindergarten classes who were full of energy but lacking the academic preparedness of her current kindergarteners upon exit to first grade. "My kindergarten students are doing what my first-grade students were doing years ago," recounted Dorothy. Although she believes some of the students are ready for the current reading and mathematics standards, she criticized the current curriculum as being "too fast for a lot of kids" and the math curriculum as "teaching them to add and subtract before they understand how to count." For Dorothy, 
the hands-on, teacher-led activities of the past provided more time to get to know students without the pressure of meeting Measures of Academic Progress (MAP) targets.

Even as Dorothy looks forward to retirement, she said that she is still learning from her students. Her students come from different home lives and cultures than her students even fifteen years ago. "I have a lot more ELL (English Language Learners) students than I had before ... they have taught me a lot about empathy ... I am more aware of what kiddos go through," said Dorothy. She extends the description of what her students endure outside of school to include violence, both in their neighborhoods and domestically, exposure to adult issues and concepts, and a lack of access to adequate food and shelter. "It's heartbreaking ... they are so innocent and can't help themselves," said Dorothy as she described her recent students.

\section{Patricia}

Patricia's sense of vocation developed as she grew up babysitting and working with young children in her church. She described her interest in teaching as a subconscious urge more than a conscious decision, "basically there was no thought really behind it." "So, I just went with it and have enjoyed it ever since," said Patricia referencing her pursuit of a career in education. Her professional calling took her through college and eventually to her first position as a preschool teacher. When a kindergarten position opened at the same school, Patricia said it "felt right ... and I went with it." After four years, her husband's work and starting a family postponed Patricia's career. She resumed kindergarten teaching when her family moved back to her home town. This is Patricia's twentieth year of teaching kindergarten. 
Students and their love of learning serve as one of Patricia's primary motivators for continuing to teach. "The kids enjoy, for the most part, $90 \%$ of them love coming to school, love their teacher and are excited to be there every day ... most of them have a smile on their face," explained Patricia. She said that her kids" "innocence" and lack of "their own opinions or more outspoken about their own opinions" are some of the reasons why she continues to work with kindergarten-age children. These children, according to Patricia, have not changed much throughout her career. "I don't feel like the kids have changed ... I feel like maybe the system has changed," she clarified.

Patricia further specified systemic change as deviations from traditional kindergarten curriculum and pedagogy. Patricia, referencing her twenty-year career as a kindergarten teacher, said that the academic expectations of kindergarten have increased at the expense of time for exploration and creative play.

There was more time for, and I don't want to say just playtime, maybe structured play, maybe hands-on learning, maybe just different where they're able to explore and learn on their own. Whereas, and we still do that, I think we're coming around to some of that, but I feel like, oh, it's this reading program and now it's this math program and we got to do this on the computer. We got to do that. And so, and I feel like the kids don't have as much time as they used to, to do their own exploration and kind of be a little bit more able to problem solve on their own, and maybe a little less creativity than I would like, anyway.

In addition to the introduction of district-purchased curricular programs, Patricia said that parent expectations and advances in technology have transformed kindergarten. Patricia described her students and their parents as coming from two experiences, those who 
attended preschools and structured environments that promoted kindergarten readiness and those who did not.

Some students who come in and they're not as prepared as some of the other kids who have been to preschool and been in a structured environment ... I felt like the [parents whose children attended preschool] were, we want homework and we want this and we want that. And how can we do this? And they want all the kids to be working on the future ... the parents pushed them a little bit too much. Whereas Patricia attributed parental influence with the advent of more standards-focused curricula in kindergarten, she stated that advances in technology have influenced every aspect of kindergarten and changed it from a play-based, hands-on experience to practice through digital interfaces. She explained that "different routines, practices, procedures for academic aspects" have evolved from increased use of and access to technology in schools. "Technology factors into everything as well and has been a big change from back then," said Patricia.

\section{Jennifer}

In her second year as a kindergarten teacher, Jennifer has the rare distinction of working in the same school she attended for kindergarten. "I actually teach at the same school that I attended kindergarten at, so it's kind of full circle for me" explained Jennifer. Her sense of vocation, however, was not immediate and it took a middle school teacher taking a special interest in her for Jennifer to see the profound effect teachers can have on children's lives. Jennifer said this bond was created when the teacher "really took the time and poured a lot of her time into me to make me feel like I was really important." The relationship Jennifer had with her middle school teacher allowed her to 
understand the importance of relationships, but working with younger children in 4-H allowed her to teach. "I just loved seeing kids get really excited about finally doing something they really struggled with ... education just kind of made sense because I love those aha moments," explained Jennifer.

Whereas the building where Jennifer attended kindergarten is the same as where she works, her kindergarten instruction is markedly different. Jennifer briefly mentioned kindergarten academic changes as spending "a lot more time on literacy ... than we do math," but the majority of her remaining contrasts focused on behavior and socialemotional education. "I remember getting in trouble and having to pull my color one day [a colored ticket in a behavior management system that a student pulls from his or her chart to indicate a misbehavior], and so that has affected how I use classroom management in my own classroom now because that was very traumatizing as a child," said Jennifer as she reflected on how her kindergarten experience influenced her teaching. She further explained that her school's inclusion of a social-emotional curriculum ensures her students will not suffer as she did.

I would say that there's a lot more focus on the social-emotional aspect now in what we teach now. I don't specifically remember that when I was in kindergarten, but I know that that's a big focus for us now, especially with all of the different things going on in today's society. And I appreciate that because my personal philosophy is that, I could teach a kid to read or write all day long, but I see myself as a successful teacher if my child and my class feels loved and cared for, and feels like they belong in society. So, the social-emotional aspect is really interesting to me and I enjoy teaching that. 
Jennifer sees a natural extension of her school's social-emotional curriculum to her philosophy of classroom management and behavior.

We'll talk about some sort of constructive activity for them to do, whether that's going to our safe place, which is for students who are just continuing to struggle and taking deep breaths or playing with some sort of sensory item or reading a book, maybe for a few minutes to reset or even writing or drawing a picture. And so that's kind of how I redirect behavior in my classroom. I treat them more as respected people, than I do just bossing them and telling them to stop. I like to explain to my students why behavior is not okay and to have a discussion with them as to how we can change that in a way that they can understand.

In addition to building teacher-student relationships, Jennifer prioritizes working with parents. She described her current parents, "I have some really great and supportive families ... having the support at home as well as from the children ... has just been really very eye-opening for me.” Jennifer attributed her partnership with families with creating a sense of "respect" that was reciprocated with support for holding "my students accountable for their own learning."

Balancing academic expectations and supportive relationships do not come without cost. As Jennifer put it, "It takes a really large mental and emotional toll on yourself." She does not believe many people outside of kindergarten education appreciate the work necessary to onboard students and prepare them for first grade.

People see kindergarten teachers, as it's really easy. "You're teaching kindergarten. How hard can it be?" And people just don't really understand how hard that can be. So, when I tell people now, "I'm a kindergarten teacher." And 
they're like, "Oh, that's sweet." And it's almost kind of condescending, I think. Sometimes people come across that way because they don't think of that as a really hard job, when it really is.

She mentioned lacking knowledge of students' home lives, onboarding students who have not been in a formal setting like school, and diagnosing special education needs as kindergarten teacher responsibilities the public either is unaware of or under appreciates. "Yeah, it's kindergarten, they're cute and we sing songs and we dance all day...that's how we teach, but there's a lot of behind the scenes things that people do not see and don't understand how hard that can be." Despite the challenges and lack of public understanding, Jennifer said that she "wouldn't trade it for anything."

\section{Summary}

In the previous section of this chapter, I attempted to faithfully share the voices and experiences of this study's participants. These textural descriptions relied on both verbatim quotes and my synthesis of data collected from interviews to provide a narrative of each teacher's story as it relates to the focus of this study, teachers' perceptions of their students in the age of kindergarten readiness.

The section that follows provides composite textural descriptions, offered as themes, that identify the common experiences participants had with the phenomenon. These themes were determined through three coding progressions that categorized the data. After data were categorized, I analyzed common meaning units, similar statements and expressed sentiments, to reduce the totality of the data to four distinct themes that represent participants' thinking about the profession of kindergarten teaching, how 
kindergarten has changed, their perceptions of their students, and the costs and rewards of teaching kindergarten in the current system.

\section{Composite Themes}

Each of the kindergarten teachers interviewed for this study offered their experiences with the phenomenon of kindergarten, specifically working in a kindergarten classroom in the age of kindergarten readiness. Their accounts of experiencing kindergarten as students themselves, working with kindergarten students as teachers, reasons for entering the profession and teaching kindergarten, and how teaching kindergarten has affected them provided rich descriptions that I synthesized into composite descriptions of the experience. These common experiences, offered in this section as themes, represent the composite kindergarten teachers' perspectives of working in kindergarten classrooms in a Central Kentucky school district. I chose four pervasive themes that align with this study's research questions:

\begin{tabular}{|l|l|}
\hline \multicolumn{1}{|c|}{ Research Question } & \multicolumn{1}{c|}{ Theme } \\
\hline $\begin{array}{l}\text { How have teachers' experiences as } \\
\text { kindergarten students formed their } \\
\text { expectations for and perceptions of their } \\
\text { students? }\end{array}$ & $\begin{array}{l}\text { Vocation: How teachers' experiences, } \\
\text { including their experiences as } \\
\text { kindergarten students, formed their desire } \\
\text { to teach and expectations for teaching } \\
\text { kindergarten. }\end{array}$ \\
\hline $\begin{array}{l}\text { How has teaching students who are } \\
\text { identified as not ready for } \\
\text { kindergarten affected teachers' } \\
\text { instructional practices? }\end{array}$ & $\begin{array}{l}\text { The New First Grade: How changes to } \\
\text { kindergarten curricula and pedagogy have } \\
\text { transformed teachers' perception of } \\
\text { kindergarten education and student } \\
\text { achievement. }\end{array}$ \\
\hline $\begin{array}{l}\text { How do kindergarten teachers perceive } \\
\text { their students, especially those labeled not } \\
\text { ready for kindergarten? }\end{array}$ & $\begin{array}{l}\text { Wobbly Colts: Teacher perceptions of } \\
\text { their students in the age of kindergarten } \\
\text { readiness. }\end{array}$ \\
\hline $\begin{array}{l}\text { How has teaching kindergarten, } \\
\text { particularly those students labeled not } \\
\text { ready for kindergarten affected teachers' } \\
\text { professional and personal lives? }\end{array}$ & $\begin{array}{l}\text { The Costs and Rewards: The personal } \\
\text { and professional costs and rewards of } \\
\text { teaching kindergarten. }\end{array}$ \\
\hline
\end{tabular}




\section{Vocation}

All but two of the participants for this study wanted to be a kindergarten teacher from a very early age. Patricia, Barbara, Dorothy, Margaret, Elizabeth, Linda, and Susan describe their desire to work with children as innate or ever-present. Barbara knew she wanted to be a teacher "since I started talking." Maria said she "always wanted to do it," Susan explained that "teaching was always in my blood," Dorothy expressed that she "always loved helping kids learn," and other participants likewise repeated these sentiments with words like "passion" (Margaret), "in my nature" (Linda), and "drawn" (Elizabeth). Although Mary and Jennifer said that their desire to teach kindergarten came after childhood, their love of working with younger children as a teen and college student respectively instilled a love of early education. As Jennifer explained, "I just loved seeing kids really excited about finally doing something they really struggled with."

For several of the participants, this strong inclination to teach children may have been reinforced by their relatives' professions. Both of Linda's grandmothers were teachers and her mother was an elementary music teacher. Dorothy's aunt taught first grade and was later a principal at her school. She recalled helping her aunt with planning and preparing materials. Susan, detailing her many relationship connections to teaching, said that "teaching was always in my blood" after explaining that her mother taught in an elementary school. Maria and Mary were likewise raised by elementary teaching mothers. Maria explained this legacy simply as "I grew up with my mom being a teacher and I've just always wanted to do it." In each of these teacher's responses to the question of why they pursued education, their relationship to a teaching family member was the 
first reason they give before explaining their love of teaching, kids, and primary education in general.

In addition to education being a calling perhaps reinforced by relationships, participants overwhelmingly said that working with young children is a primary motivator for teaching kindergarten. All ten of the participants expressed some semblance of loving working with children. Patricia identified kindergartener's "innocence" as what inspires her to a teacher at the onset of her second decade of service. Linda exemplified this same sentiment by explaining that her students' innocence inhibits the academic insecurity and discouragement often experienced by older students.

I would say just the enjoyment the kids have overall of wanting to learn and being at school, being around their friends and their teachers. They haven't had those bad experiences for the most part, really, that kids start getting once they hit second and third grade. Where they might notice that the boy next to them can do things faster or quicker or knows more than you do. In kindergarten I don't think they really notice that as much, even though they are kids...I guess maybe they just haven't been able to pick up that concept yet or even relate to it that, "Well, how come Steven can add and count all the way up to 100 and I don't even know the numbers zero through 20?" They don't have that concept yet and so I guess that's one reason why I really like it.

Elizabeth said that watching students "grow from not knowing anything to being able to read a book at the end of the year [and \} being able to deal with their emotions ... drives me to continue [teaching]." Like Elizabeth, Maria and Margaret identified students' 
excitement for new concepts, growth, and love of learning as the impetuses for their excitement to teach them.

\section{The New First Grade}

All but one of this study's participants stated that kindergarten has undergone a dramatic change since the interviewees attended kindergarten themselves. Patricia explained this change as, "I feel like kindergarten now is more of what first grade used to be." Maria echoed this sentiment by saying, "I feel like how we teach kindergarten now, it's like back in the day how first grade was taught." Susan, reflecting on her current instructional strategies, said "I don't remember looking at a book and understanding the words until the middle of first grade." When asked to compare what she teaches to her students with what she was taught in kindergarten, Margaret said "I would say more first grade, in my experience."

This shift of first-grade academic expectations to kindergarten was described in teachers' juxtapositions of former kindergarten practices to current pedagogy. Of kindergarten instruction of the past, most participants used the word "play" to epitomize the experience. Linda described past kindergarten classrooms as being "more about exploring and play" than their contemporary counterparts. Teachers who taught kindergarten before a focus on kindergarten readiness emphasized, "learning how to cut, how to color, things like that, and play and socialize" (Linda) and allowing students to "explore and learn on their own" (Patricia) as the instructional focus. Kindergarten classrooms of the past had centers that promoted free-play and socialization. Barbara said, "our centers were more play-based and social skills" before giving a kitchen center and sensory tables as examples. In addition to having the ubiquitous kitchen station, 
classrooms provided children with costumes, areas designated for naps, and materials for self-selected craft projects according to participants.

Kindergarten teachers described teaching before the shift in expectations as being less stressful. Dorothy said that teachers had more control over what they taught and where. She described this freedom through her explanation that kindergarten teachers could take their students outside when they wanted, take breaks when necessary, and incorporate new content and teachable moments when applicable. Academic expectations, according to Margaret, were "just learning the letters." Learning letters and play are now more associated with pre-school than kindergarten. Margaret, Patricia, and Linda explicitly said that the shift of first-grade curricula to kindergarten has consequently moved kindergarten instruction and learning to preschool. Even the previous half-day schedule of having different AM and PM groups can only now be found in the district's preschool programs.

If kindergarten of the past allowed students time to socialize and explore and teachers the autonomy to create the conditions for play, is the antithesis true of current practices? While participants said that play was not completely absent from the kindergarten experience, it has been pushed to the fringes to make space for literacy and numeracy practice. The inclusion of previous first-grade standards in kindergarten, according to the kindergarten teachers interviewed for this study, is a byproduct of the zeitgeist of preparedness that manifests as college and career readiness down to kindergarten readiness. Barbara identified "the standards" and the resulting "expectations" as the reason for kindergarten students having to work harder than previous generations. Patricia said that her students' parents' concerns for their 
children's futures promote a curriculum focused more on literacy and numeracy than exploration and socialization. "The kindergarten parents were, we want homework and we want ... all the kids to be working on the future," said Patricia as she offered her opinion on parents' influence, "the parents pushed them a little bit too much."

The transformation of the kindergarten classroom in a generation is evident in the physical layout of the classroom, the implements of learning, and the content students learn and the skills they procure. According to Barbara, learning centers that used to serve as dedicated sensory tables and free-play have been repurposed, "the centers are, okay, let's match the uppercase and lowercase letters ... the focus has changed, not so much on social skills and more towards academics." Centers now feature interactive technology in place of activities that refine fine motor skills because the programs districts purchase and promote are digitally integrated. Patricia said, "it's this reading program and now it's this math program and we got to do this on the computer ... the kids don't have as much time as they used to, to do their own exploration and kind of be a little bit more able to problem solve on their own, and maybe a little less creativity." To expedite kindergarteners' learning of new standards, to "end kindergarten knowing all their letters, all their letter sounds ... reading, putting words together" (Linda), districts have invested in corporate curricular products that promise grade-level standards mastery. "I'm more aware and conscious and with the Wonders program and our Math Investigations Program," replied Patricia when asked about how kindergarten has changed. Both programs, purchased a few years ago by the district, require students to engage both with the teacher and classmates in traditional, cooperative learning as well as individually with the online programs. Jennifer argued that kindergarten is "more of 
trying to get them to understand things that come fairly easily to older children." To expedite learning that would have been expected of older students in the past, programs promote their online learning platforms as a means to tailor and extend education with games, colorful animations, and an experience similar to many students' entertainment preferences. Dorothy explained that children's behavior and engagement was decidedly different when they were solitarily engaged with tablets than when they were expected to socialize, collaborate, or communally learn.

As a result of this dramatic shift in kindergarten education, teachers have adjusted their pedagogies. Linda said that "some kids do come reading to us now, and a lot come knowing a lot more information than maybe what I knew going in," as she considered the effect of preschool programs. This broad spectrum of readiness, as defined by the state, for students from divergent preschool systems and home microsystems was evident in other participants' descriptions of their students and the effects of unpreparedness in a kindergarten with higher expectations for standards mastery. Dorothy explained that teaching counting to students during the early years of her teaching tenure aligned with children's developmental level whereas current expectations of kindergarteners to quickly move into addition and subtraction create anxiety and behavior problems. Even the transition to school norms and behavior expectations have been truncated for teachers to cover more academic ground. As Linda explained, "we don't spend a lot of time letting them just get acclimated to school."

Despite the changes to kindergarten, teachers have adjusted their approaches to incorporate some of the nuances of the traditional kindergarten experience. Mary said opportunities for students to develop their fine motor skills are "something you squeeze 
in with other things." She uses the time before the school day officially begins to provide students with the exploratory stations that were part and parcel of the school day in the past. Dorothy intentionally looks for opportunities for her students to "log off of their devices and socialize with each other." Jennifer, notwithstanding the pervasively perceived correlation between student achievement and teacher effectiveness, feels successful if "my class feels loved and cared for and feels like they belong in society." Elizabeth and Margaret regret that regardless of their intentions, there simply are not enough opportunities for their students to have adequate playtime.

\section{Wobbly Colts}

Participants' descriptions of their students provided both the traditional portrait of kindergarteners as well as first-hand accounts of how children have struggled or adapted to the changing nature of kindergarten. Experienced kindergarten teachers also described how societal changes have changed the composition of their classrooms and how those changes have affected their pedagogies and views. Less-experienced teachers provided fewer details concerning changes in society but were still descriptive about their students' transitions to school, the possible effects of preschool placements, and the effects of kindergarten expectations on their students.

Most of the participants described students' dispositions with the expected positivity generally associated with children in kindergarten. Mary called her students "go-getters." Patricia said that some of her students are "bubbly and energetic." Jennifer said that her kindergarteners are ready "to learn new things and make new friends." Margaret described her students as "sweet and loving and excited." Regardless of 
students' pre-school settings and experiences, Margaret said that her students were eager to come to school to "get their love."

Though participants fondly described students' vivacity, they also attributed students' struggles to the intersection of their childhood experiences and increased kindergarten academic and behavioral expectations. Linda suggested that some of her students were not learning what she considered basic skills like cutting, coloring, and knowing the alphabet at home. Dorothy provided a similar description that included frustration that children seemed to only be learning what is taught in school without reinforcement or valued-added instruction at home. Maria said half of her students "really don't know letters and numbers, or they can just identify four or five" while "about half my class really, they act like first graders." Mary attested to the same division she sees in her students' readiness to their home and preschool microsystems.

Most of these kids either come from in-home daycares or they've been home with grannies and aunts and uncles, so they don't have the interaction that a lot of kids do ... their world isn't as big as some other kids, they don't have the experiences and the ability to learn those things at home. So, we start pretty low, but that's also how ... I group kids because you do have that handful of kids who come in completely prepared, and know their address, and their phone number, and everything.

Elizabeth said that some children are at a disadvantage because they come from adverse circumstances such as splitting time between divorced parents or being raised by 
grandparents. Margaret explained that kindergarten expectations put "stresses on these kiddos that they can't handle because they are coming from these homes that they're not okay." Susan related some of her students' behavior problems with a more structured environment at school than at home. Though many of the participants presented varying effects of childhood microsystems, the primary measure by which they made these assertions was kindergarten readiness, both academic and behavioral.

While kindergarten teachers I interviewed stated that their students had to adjust to kindergarten expectations and structures because of misaligned pre-kindergarten contexts, a few teachers provided divergent opinions. Patricia said that she thought "a lot of the kids are able to handle it." Jennifer described her students' resiliency and creativity, "I also really find it interesting that my kids, while I present a problem to them, they come up with different ways to solve that problem.” Jennifer also said that though her class lacked diversity, her students' families were very supportive of the school curriculum and her teaching. Margaret and Dorothy implied that working parents, especially those who work more than normal, have fewer opportunities to prepare their children for kindergarten.

\section{The Costs and Rewards}

When asked about how teaching kindergarten has affected participants'

professional and personal lives, teachers reluctantly talked about themselves. Answers to this question were shorter and often refocused on students and their preparation. Nonetheless, teachers provided details that indicate that a loss of time and resources, as well as newfound and unexpected stress from the expectation to ready children for first 
grade, are the personal and professional costs. The rewards, conversely, include deepening empathy, broadening worldviews, and even finding the hidden child within.

Teachers pointed to managerial tasks, the stress of working with children in an age of readiness, and the time necessary to meet students' needs as examples of the primary costs of teaching kindergarten. Mary explained that much of her work was relegated to "just paperwork, on paperwork, on paperwork." In addition to the paperwork necessary to evidence students' progress, Mary said that her principal's changing focus for student development including socialization or other characteristics made planning difficult. Linda also found planning kindergarten lessons problematic because "you're trying to teach them how to do something that they've never done before." The duality of planning developmentally-appropriate and engaging lessons for students designated as ready and not ready for the content requires additional time and energy. Dorothy explained that planning appropriate lessons takes more of her free time than preparing materials for her students during the early years of her career. Jennifer relayed similar frustrations when describing the encroachment that parent conferences and planning, especially during NTI, took on her time. "Last night, I was up until 2:30 in the morning, trying to fix things," she explained. Maria conveyed that kindergarten planning and preparation made her feel "worn out."

In addition to the changing nature of kindergarten planning, participants said that working with their kindergarteners takes an emotional toll. Susan mentioned that students' lack of home support creates academic and behavioral issues. She explained that "those kids get distracted, they don't bring in their folders, they're missing things ...there's just a sadness there and behaviors pop up because of that too." Margaret echoed 
this sentiment by saying "one kiddo has such advantage and this other kiddo is just at such a disadvantage just where he's starting and how far he has to come" when explaining how teaching kindergarten affected her. In addition to the distress of meeting the expectations for first-grade readiness, the responsibility of diagnosing students' learning disabilities and other obstacles falls within the purview of kindergarten teachers despite insufficient data and understanding of students' lives. Jennifer detailed this frustration.

There is a good percentage of our students, that they have never been in a school environment before at all. So, we have no data on them. Besides a quick little Brigance at the beginning of the year, I mean, that's all we know about them. And we have students without IEPs and students without services or anything. We have no information on them. So, I think that's what a lot of people don't see, is the kindergarten teachers basically having a child and knowing nothing about them.

Though participants conveyed the personal and professional costs of teaching kindergarten in the modern era, their accounts of the rewards highlighted how teaching young children engenders personal growth and a fuller appreciation of the community and its people. Susan and Dorothy conveyed that working with students from varied backgrounds, national origins, and life experiences increased their empathy for others. Margaret articulated that working with children from different home environments increased her appreciation for the struggles of others. "You see the bigger picture, the reality of some of these kiddos and their home lives and it's just, the scale is huge of what you see these kiddos come from," Margaret expressed when asked how teaching kindergarten had affected her. Linda said that teaching students from varied home lives 
helped her realize "that every single one that comes to us has a completely different experience coming in ... some did go to a preschool, some went to just daycare, some stayed home, some have never been exposed to any type of written language." Elizabeth disclosed that teaching kindergarten provoked a greater appreciation for the influence her parents and upbringing had on her development into adulthood.

Participants also revealed how teaching kindergarten has improved their patience, sense of proportionality, and their appreciation of childhood wonder. Barbara said that teaching kindergarten has taught her tolerance and a desire to connect and learn more authentically with her students.

It's definitely helped me become more patient, a more patient person in general. Just to kind of not take everything for face value, I guess, like to think about what else could be going on ... you got to think about where these kids are coming from and where their families are coming from, kind of choose your battles with some kids and what's really important, and to listen to them too. Like I said, in the beginning, I learn from my kids every day just like they learn from me.

Margaret expressed this same understanding in an anecdote about a child "throwing a fit in the store." Instead of assuming the child's or parent's fault, Margaret said that being a kindergarten teacher enlightened her to the possibility that the child was "probably just hungry, thirsty, or tired." Patricia noted that teaching kindergarten for 19 years taught her to be "more understanding with kids that have challenges, struggles, that kind of thing, in their life ... to be more aware of their home life and their situation and family."

The infectious excitement and energy kindergarteners effectuate were rewards that Mary and Elizabeth described. "I could walk into a room full of adults now and I 
would gravitate towards the five children that are in that room because I just, I enjoy spending time with them and getting to know them," explained Mary. Elizabeth said simply, "I feel like they teach me a lot just like having fun, and just being a kid again."

\section{Summary of Chapter Four}

This chapter reported how ten kindergarten teachers at three Southeastern elementary schools described their attitudes about their own kindergarten teaching experiences, vocation, and students in an era of kindergarten readiness. In this chapter, I provided textural descriptions of each participant to offer individual accounts of teachers' experiences. I also offered the composite or essence of these descriptions as four themes that I identified from the coding and analysis of meaning units from participant interviews. These themes, resulting from analysis with Bronfenbrenner's ecological systems theory as the conceptual framework, provided participants' descriptions related to my study's generative research questions:

In the next and final chapter, I offer my conclusions from these findings including my advocacy for a return to exploratory play in kindergarten, funds of knowledge professional development for teachers, and the incorporation of teacher voice in kindergarten readiness research. In addition to articulating my thinking of the data concerning the phenomenon of kindergarten readiness through teacher perception, I share my reflections as the researcher, offer recommendations for improving kindergarten education for teachers and students alike, and suggest the implications of this study for future research. 


\section{CHAPTER V \\ DISCUSSIONS}

\section{Introduction}

In this chapter, I discuss the results of this study in terms of the nature of school readiness and teachers' perceptions of their experiences. In addition to these discussions, I draw on my study's findings to provide the important implications for kindergarten educational practice and professional development as well as make recommendations for future research of teacher perception and kindergarten education.

This study provided the rich and nuanced voices of kindergarten teachers as a means to explore the phenomenon of kindergarten teacher perceptions of their students in the age of kindergarten readiness. Although this study included only ten participants from a specific region, common experiences with the phenomenon emerged and provide evidence of shared beliefs, similar vocational pathways, and analogous challenges facing kindergarten teachers. These accounts, along with teachers' descriptions of their students, provide insight into the zeitgeist of readiness, the costs and rewards of current practice, and suggestions for structural and pedagogical changes that may improve teacher efficacies and student experience and achievement.

\section{Researcher Reflection}

I began this research journey in earnest seven years ago with the birth of my first child. Like many new parents, I redefined my home as a place of learning as soon as my wife told me she was pregnant. As an educator, I knew the skills, knowledge, and 
competencies that should promote success in school which should propel my child to succeed in life. I bought card decks to promote language, blocks and stackable toys to help with fine motor skills, board books to engender love and understanding of literacy, an $\mathrm{ABC}$ blanket to wrap him in, etc. I leveraged my resources to give him an advantage and followed through by engaging him with these tools throughout his pre-school childhood. My plan appeared to work. Not only was my son identified as ready for kindergarten but he was near the top of his class in reading and numeracy.

While I believe my choices benefitted my son, I have a newfound appreciation for the role culture plays in kindergarten preparation, or at least how culture shapes our view of kindergarten readiness. The teachers I interviewed for this study are kind, caring, and take pride in their work and professionalism. I hold kindergarten teachers in high regard as the vanguards for American society. I also recognize that all of the teachers I interviewed appear to reflect my middle-class American values, share my ethnicity, and were raised in some of the same circumstances. These similarities, however, are not shared with many of the children they serve. Perhaps my child's success in kindergarten had as much to do with this alignment of our culture and values with the school's as the emergent academic exposure I provided him. Perhaps children identified as not ready for kindergarten also have robust understandings of the world that do not align with the majority and are thus not perceptible by the measures used to determine readiness.

As a teacher, I am also reflecting on the thousands of students I have taught over the past two decades. So much of education, especially in high school, is unilateral. I possessed the content, ability to grade their work, and the curriculum. They were required to meet my expectations, but I knew very little about many of them. I would 
meet some of their parents at open house or talk with them via the occasional email, but my students' home lives were largely absent from my pedagogy. It is likely my students' parents did not view me as a partner but as an instructor, even if they trusted me enough to teach their children. I imagine what class could have looked like, what topics we could have explored, and what new knowledge we could have learned together had my relationship with my students and their parents been more personal, more intentional. Although I cannot change the past, as a teacher and parent, I can advocate for improving these bonds for others in my profession.

\section{Implications for Practice}

\section{A Need for Play}

Although all of this study's participants except one (Dorothy) were trained to be kindergarten teachers in preparation programs focused on the current model, many of them asserted that increasing play would benefit students. Patricia's desire was a return to Froebel's model of "structured play, maybe hands-on learning ... where they're able to explore and learn on their own." Linda said that current practices "don't always allow kids to develop on their own in a way." Elizabeth wished "there was a little bit more playtime." Margaret said kindergarten teachers at her school agree that kindergarteners need more play. Though several of these teachers did not elaborate on why increasing play is important, others said play and unstructured activities allowed for exploratory learning (Patricia), fine motor skills development (Mary), and socialization (Barbara).

Incorporating guided play, or at least balancing academic work with opportunities to play, may allow teachers to broaden their understanding of formative assessment and diagnoses (e.g., for occupational therapy, special education, counseling) of students and 
decrease the stress and struggle several interviewees described of their not ready for kindergarten students. Unstructured play aligns more closely to students' experiences in their home microsystems, daycares, and even preschools (Bender et al., 2011;

Bronfenbrenner, 1979; Logue, 2007). As such, observing students socially interacting with other children while doing preferred tasks — as opposed to curriculum-oriented tasks - may provide teachers with the information necessary to not only advocate for responsive behavioral interventions but also to better understand how children exhibit and reconcile pre-kindergarten behaviors in the school setting. For example, children who exhibit hyperactivity and aggression at an early age are prone to have more problems with general academic success and being socially accepted by peers (Stormont, 2000). By monitoring guided play, teachers are better able to observe such behaviors and how their students use critical thinking as well as social and emotional strategies through their actions and conversations (Kirk \& Jay, 2018). Moreover, observing students during unstructured play may help teachers recognize the effects of pre-kindergarten risk factors (e.g., neglect, parent insensitivity, poverty) that influence executive functioning development, social behaviors, and learning (Dilworth-Bart, 2012; Morgan et al., 2017). While unstructured play helps teachers identify the need for behavioral and academic interventions that support learning for students who struggle in school, the act of socializing with peers may serve as a support itself. Bender et al. (2011) and Logue (2007) argue that unstructured play, specifically group play, helps children develop selfregulatory behaviors and social skills. By incorporating exploration and play more into the school day, students have chances to not only authentically engage with resources and peers not available to them outside of school but opportunities to demonstrate knowledge 
and habits developed in the home microsystem (Bender et al., 2011; Bronfenbrenner, 1979). Although less regimented than academic work, unstructured-learning still occurs under the supervision of the teacher (Bender et al., 2011). These observations may allow teachers to more fully know their students including their abilities and knowledge that may not be exposed in literacy and numeracy work that dominates the curriculum (Birch \& Ladd, 1997; Harmon \& Viruru, 2018).

For students whose home ecologies do not align with the school culture, observing students at play may also benefit teachers' understanding of the families whom the school serves. Children develop through social interactions, particularly those in the home microsystem, during the formative years before kindergarten (Bronfenbrenner, 1979, 1989; Vygotsky, 1962, 1981, 1987). Though the school serves as one of the most influential microsystems in children's lives, the influence of the home and its inherent culture more profoundly influence how students behave and learn, especially at the onset of formal education (Bronfenbrenner, 1979). While the school can serve as a safety net for students suffering the effects of many risk factors from the home microsystem, for other children, the school culture, including acculturation to the majority's values and expectations, does not align with their upbringing (Riojas-Cortez \& Bustos Flores, 2009). For these children, who are often minorities, teachers may be considered more judges of character than mentors as cultural norms that are appropriate at home are deemed inappropriate at school (Riojas-Cortez \& Bustos Flores, 2009). By offering students opportunities for guided play, teachers create the conditions by which children more openly exhibit the values and norms instilled from outside of the school. These data 
provide teachers with a more holistic understanding of their students as cultural beings as a means to better support them socially, emotionally, and academically (Hogg, 2011).

Despite the benefits of guided play, school curricula, including the vertical K-12 standards progression, require students to begin literacy and numeracy instruction in kindergarten; therefore, isolated changes to kindergarten instructional practices affect the continuity of learning inherent in state standards. Advocacy for changes to kindergarten practices, consequently, must consider the ramifications to curricula in subsequent grades. Nonetheless, incorporating guided, unstructured play may positively impact the literacy and numeracy skills already the focus of kindergarten standards and curricula. Roessingh and Bence (2018) found that guided exploratory play (e.g., textile experiences in which children handle and manipulate objects) allowed students to interact with realworld phenomena that aided in their construction of conceptual models. These models served as foundations for the conceptual understanding of number deconstruction (i.e., understanding number place), narrative and numeric sequencing, procedural language (e.g., articulating the steps one took to do something), and spatial reasoning (Pyle et al., 2018; Roessingh \& Bence, 2018). Moreover, guided play featuring sociodramatic performances, integrated into established literacy blocks, in which children construct their own literacy games has been shown to improve student self-efficacy with literacy as well as behavioral self-regulation (Cavanaugh et al., 2017; Weisberg et al., 2013). Both guided exploratory play and sociodramatic performances are complementary to the intent of the literacy and numeracy blocks of participants' district and require minimal time to execute — the latter being recommended for fifteen minutes (Cavanaugh et al., 2017). Including such practices could potentially improve students' learning and diminish 
cultural barriers that impede minority students' success in school by allowing these students more agency in their learning (Riojas-Cortez \& Bustos Flores, 2009).

Incorporating guided play opportunities into existing kindergarten structures alone is insufficient to meet the needs of students from cultures that do not align with that of the majority. For teachers who have internalized deficit theorizing, observing students at play may reinforce monocultural biases (Riojas-Cortez \& Bustos Flores, 2009). To improve teachers' cultural competencies, professional development focused on students' funds of knowledge, family-school partnerships, and the cultural norms of the cultures the school serves may provide the conceptual frameworks and processes necessary to appreciate the diversity of values, thought, and behaviors found in many kindergarten classrooms (Hogg, 2011; Kelley, 2020; Moll, 2000). Moreover, professional learning focused on utilizing teachers' knowledge and understanding of students' "intercultural and hybrid knowledge base" to inform instructional strategies may enhance the learning experience for students who struggle in the current system (Gonzalez et al., 2005, p. 37).

\section{Broadening Our Thinking of Readiness}

The Kentucky Department of Education defines kindergarten readiness as the child's ability to "engage in and benefit from early learning experiences that best promote the child's success" (Curriculum Associates, 2019b). For Kentucky kindergarteners, success is defined by kindergarten standards that a generation ago were taught in firstgrade classrooms. Whereas success for past kindergarteners encompassed cheerful play with classmates, sitting on carpet squares for stories, and walking in a line to the cafeteria for a snack and milk, current kindergarteners are expected to memorize sight words, practice addition and subtraction, and work more independently at learning stations. A 
casual observer passing a kindergarten classroom may find familiarity with the noise, primary-colored décor, and the kind words of the teacher as she addresses her friends. If asked if kindergarten has changed, however, a kindergarten teacher would likely enlighten the unaware observer with the pedagogical nomenclature and practices generally associated with upper primary and intermediate classrooms.

The stagnation in the increased percentage of students designated as kindergarten ready may be a byproduct of the model used to determine readiness (Kentucky Department of Education, 2020). The interactionist perspective model, adopted by Kentucky, asserts that readiness is measured by a battery of tests intended to assess the acquisition of skills and content necessary to begin the journey to success (Meisels, 1996). To put this simply, a child is either ready or not ready based on a composite score from the 15-minute BRIGANCE screener (Glascoe, 1996, 1997). By itself, BRIGANCE provides a baseline for understanding what a child can and cannot do academically. I assert that such a baseline is beneficial to begin understanding how to support a child's learning. I also argue that giving too much credence to a screener and forming perceptions of learners, who have acquired complex and nuanced knowledge from their microsystems, based on a test given to children when they step foot into the school building for the first time, is problematic.

Given a lack of data to make decisions, kindergarten teachers use the BRIGANCE as the primary metric by which they initially form reading groups, schedule special education screeners, and plan their instruction. With half of Kentucky's children identified as not ready for kindergarten, teachers stratify reading and math groups between those who come prepared and those who do not (Kentucky Department of 
Education, 2020). With first-grade readiness as the goal, students identified as not ready for kindergarten must quickly catch up with their peers or risk being retained. Generally, these not ready for kindergarten students represent minorities, children of poverty, English Learners, and students with disabilities. This overidentification of children from poor and minority families may be predicated on the data used to predict the likelihood of their success. Duncan et al., (2007) found in their meta-analysis of six longitudinal studies that readiness indicators such as emergent understanding of math concepts (e.g., knowledge of numbers and ordinality) and emergent reading skills were "powerful predictors of later learning" (p. 1443). Duncan et al., (2007) also asserted that skills such as vocabulary, knowing letters and word sounds externalizing and internalizing behaviors and social skills were not reliable predictors of later success. The BRIGANCE screener determines readiness with several of these indicators, including letter recognition and phonemic awareness (Glascoe, 1996, 1997). Because income and racial/ethnic achievement gaps persist through at least fourth grade, rethinking the measures we use to understand learners and the supports needed to help them succeed is necessary (Reardon \& Portilla, 2016). Moreover, reevaluating other aspects of kindergarten readiness — such as children's knowledge of their address, ability to identify pictures, and spoken fluency - that have not been proven to be predictive of later success may illuminate cultural gatekeeping that promotes a monocultural bias.

Cognitive disabilities notwithstanding, not ready for kindergarten students have constructed knowledge of the world through the rich experiences within their home ecologies and other microsystems (González et al., 2005; Hogg, 2011; Kelley, 2020; McDevitt, 2016; Moll, 2000; Moll \& González, 1997; Rodriguez, 2013; Riojas-Cortez \& 
Bustos Flores, 2009; Vélez-Ibáñez \& Greenberg, 1992). The BRIGANCE assessmentwhile providing a baseline for emergent literacy, numeracy, fine motor skills, and other indicators - does not provide teachers with the nuanced data necessary to tailor instruction and the school microsystem to promote learning and achievement. Moreover, broadening teachers' understanding of how children use language, mathematics, and literacy in their home and community microsystems not only helps teachers build rapport with families but also enriches planning through co-constructed knowledge (RiojasCortez \& Bustos Flores, 2009; Vélez-Ibáñez \& Greenberg, 1992). That is, teachers who bridge students' home and school ecologies are better able to understand students' academic needs while contextualizing assessment results from traditional sources of data, such as BRIGANCE.

Generally, participants in this study expressed school-family relations unilaterally. That is, though teachers interviewed for this study indicated a desire to have support from families, little was said of teachers' efforts to build those relationships through bidirectional communication. When interviewees mentioned students' home lives, references indicated obstacles and a lack of support. Margaret said that some of her students were coming from "homes that they're not okay," Susan indicated that her students' behavior problems stemmed from less-structured home environments, Elizabeth said that "one of the hardest parts about teaching is you have to deal with the parents," and Dorothy explained that parent involvement is not as good as it was when she started teaching 26 years ago. Although teachers' assessments of probable risk factors are part of understanding and supporting students as learners, enriching that understanding with home contexts may improve academic support and diagnoses that serve as protective 
factors through advocacy and teacher-family partnerships (Ansari \& Pianta, 2018; Berry et al., 2016; Brown et al., 2013; Cathy \& Ann, 2003; Coley et al., 2015; Coulton et al., 2016; Morrissey et al., 2016).

Synthesizing teachers' understanding of academic readiness with an appreciation of students' funds of knowledge may shift teachers' paradigms from a deficit model, predicated on readiness assessments, to one that accounts for how students learn in environments outside of school (González et al., 2005; Hogg, 2011; Moll, 2000; Moll \& González, 1997; Rodriguez, 2013; Valencia, 2010). By building on the expertise of students and their families, teachers can better design learning experiences that connect to real-world situations and cultural competencies while improving students' mastery of academic standards through relevancy (Hindman et al., 2013). Connections from teachers and schools to home microsystems are especially important for kindergarteners from culturally diverse families because of the immediate impact of the difference in home and school cultures (Andrews \& Yee, 2006; Velez-Ibanez \& Greenberg, 1992). Furthermore, teachers who are more aware of students' funds of knowledge may benefit from accounting for how their experiences and culture interact with their pedagogical and academic knowledge. Such self-analysis may help teachers grow professionally as well as incorporate new strategies that help students find meaning in academic activities (Hogg, 2011; Vélez-Ibáñez \& Greenberg, 1992).

Moreover, strengthening the dialogue and trust between the school and students' homes will increase the relevancy of academic learning in the home ecosystem. Because children are more greatly influenced by relationships in the home microsystem, coconstructing learning with families improves not only support for academic learning at 
home but guardians' means to support academic achievement (Andrews \& Yee, 2006; Bronfenbrenner, 1979; González et al., 2005; Hogg, 2011; Kelley, 2020; McDevitt, 2016; Moll, 2000; Moll \& González, 1997; Rodriguez, 2013; Riojas-Cortez \& Bustos Flores, 2009; Vélez-Ibáñez \& Greenberg, 1992). González et al. (2005) recommends that teachers engage students and families about their backgrounds, interests, and heritage (i.e., values, beliefs, traditions). These engagements may include opportunities for students to talk about themselves and their families as well as activities that provide student choice of content and possible ways to find solutions (Moll \& González, 1997; Riojas-Cortez \& Bustos Flores, 2009). Additionally, connections to families, especially for those of kindergarten students, should be established through home and community visits, invitations for parents and caregivers to visit the classroom to observe and share their knowledge, and family projects (e.g., an art project about the family culture) that allow families contribute to children's learning (Pianta et al., 2007).

\section{Talk with Teachers}

Although past studies have examined kindergarten teacher perceptions of school readiness, data from these studies largely represent teachers' ideas distilled into Likert scales and other quantitative measures (Abry et al., 2015; Hustedt et al., 2018; Lin et al., 2003; Petrakos \& Lehrer, 2011). One of my impetuses for using semi-structured interviews as the chief means to explore the phenomenon was the realization that the rich, thick descriptions provided through described experiences may offer a better account of the complexities of teacher perceptions than quantitative data (Geertz, 1973). Teachers instructional preferences, demographic data, quantitative data of teachers' changes in perception over time are worthy studies that contribute to the discourse of school 
readiness, but the synthesis of teachers' experiences as students, their vocation and professional experience, and perceptions of their students can only be explored through dialogue and interviews (Abry et al., 2015; Espinosa et al., 1997; Lin et al., 2003).

Interviews and dialogic inquiry give teachers more agency by including their verbatim descriptions in the data (Wallen \& Tormey, 2019). The teacher and student experience within a microsystem rely on the interactions and relationships established within (Bronfenbrenner, 1979). For transformative changes to teachers' and students' experiences and success to occur, the complexities of these interactions and relationships must be studied and understood. The teachers who participated in this study indicated that curricular and structural decisions happened outside of the classroom and often at the district level. According to their descriptions, academic programs, standards, and pacing guides are handed to teachers for implementation without classroom-level context. Meaning, while many teachers argue that increased play would benefit their students, the locus of control at the district and state level does not allow for such arguments to influence practice and policy. Collecting interview data from teachers, however, may provide the data necessary to not only tailor previously unilateral initiatives but increase teacher ownership, buy-in, and self-efficacy (Wallen \& Tormey, 2019).

Teacher verbatim explanations and descriptions should be a data source used to inform school and district decisions. Instead of bottlenecking responses with surveys, which often lead responses through the diction and syntax of the question, provide teachers opportunities to discuss issues collaboratively through processes like semistructured interviews, group-level assessment, or other processes that encourage dialogic inquiry. School districts should also provide school leaders with professional learning 
focused on semi-structured interviews that encourage dialogue and co-constructed meaning through inquiry. By authentically listening and conversing with teachers, school leaders will able to ask follow-up and clarify questions based on teachers' responses (Creswell \& Poth, 2018; Dearnley, 2005). Likewise, teachers will able to ask if their responses properly address the questions or ask for more details about questions' intents. Moreover, semi-structured interviews allow for tangential but relevant details to emerge that could broaden thinking and planning (Dearnley, 2005; Moustakas, 1994). In addition to providing professional learning on inquiry-based data collection, professional learning on data literacy and analysis should build school leaders' acumen for finding meaning from not only the overarching ideas expressed but also the diction, syntax, pauses, reiterations, etc. that come from conversations with teachers (Gilligan \& Eddy, 2017).

Last, incorporating semi-structured interviews, group-level assessment, or other data collecting processes intended to account for teacher perception into school practices and planning potentially enhances relationships within the school microsystem and beyond. Like the students they serve, teachers are cultural beings who are affected by the relationship and culture of the workplace (Bronfenbrenner, 1979; Lesinger et al., 2018). Lesinger et al. (2018) found that communication, transparency, and collaboration increased trust between teachers and school leaders. Providing time and space for teachers to communicate their perspectives to inform school-level decisions not only encourages reflection as "integral to the processes of maintaining a collaborative and transparent approach" but enhances school leaders' sensitivity to teachers' contexts and decisions (Dearnley, 2005, p. 27). Consequently, modeling these processes within the 
school microsystem could promote similar outreach practices outside of the school as teachers encourage similar dialogue with parents and families (Hindman et al., 2013).

\section{Implications for Future Research}

\section{A Familiar Story Worth Exploring}

According to Bronfenbrenner's theory of ecological development, children form close bonds with the people who "pay attention to or participate in one another's activities” (Bronfenbrenner, 1979, p. 56). Like Dorothy's experiences helping her aunt prepare for teaching, reciprocal relationships, called dyads, are the foundation for the development of social skills and a sense of interdependence (Bronfenbrenner, 1979). For many of the teachers who participated in this study, the blending of the school and home microsystems through their parent's or relative's home and professional interactions likely reinforced their sense of familiarity, comfort with the profession, and vocation.

Because eight of the ten teachers interviewed for this study stated that being raised or influenced by family members in the profession of teaching affected their decision to pursue teaching, further research on the phenomenon of teaching as a family business is warranted. According to Bui and Miller (2017), family professional legacies are common, especially for members of the same sex, fathers and sons and mothers and daughters. In this study, this connection is evident in participants' descriptions of the influence of female relatives in the profession. However, unlike other professions mentioned in research by Bui and Miller (2017), such as bakers, boilermakers, and factory workers, in which a tradesperson is judged by their craft, teaching effectiveness is

judged by students' learning; therefore, teaching legacies necessitate further study because of the impact of pedagogy on student achievement (Bui \& Miller, 2017). 
Furthermore, research focused on teachers' childhood experiences, especially in terms of attitudes towards the profession of teaching, may provide insights that inform efforts to improve teacher recruitment and hiring protocols, increase minority representation in teaching, and improve teacher preparation programs.

\section{Expanding Explorations of Perception}

This study explores teacher perceptions to understand the phenomenon of teaching kindergarten in the age of kindergarten readiness. In interviews, teachers shared insights on how kindergarten has changed, their experiences teaching kindergarten, their perceptions of their students, and suggestions for improving the kindergarten experience. Though participants provided a spectrum of attitudes about their students, teachers' descriptions often incorporated the language of readiness. That is, the teachers who participated in this study appear to have internalized a deficit model focused on the polarity of prepared and not prepared with an emphasis on what students could not do rather than what they could. Though participants described the frustration and struggle not prepared students experience with the current academic expectations of kindergarten, they often attributed these obstacles with circumstances outside of students' control. Meaning, participants expressed empathy for their students who struggled with increased academic expectations and attributed these issues to pre-kindergarten risk factors [e.g., divorced parents (Elizabeth), domestic and neighborhood violence (Dorothy), general adverse circumstances in the home (Margaret)]. Participants did not discuss the larger role society plays in these risk factors and how schools might ameliorate such conditions.

I used a semi-structured interview data collection method to explore teacher perceptions about their students, but the limited scope of this study and the need for other 
data to fully understand how these perceptions influence student achievement warrants further exploration. How kindergarten teachers form their perceptions, the degree to which bias impacts those perceptions, and how teacher perception correlates to academic outcomes, student perceptions and self-efficacies, and school-family collaboration requires research that broadens data collection to include students, their families, and other stakeholders. In essence, this study focuses on one side of the relationship dyad formed in the school microsystem (Bronfenbrenner, 1979; Vygotsky, 1981).

Although research exploring the effect of teachers' perception of effective pedagogy on student achievement have increased awareness of the importance of teacher perception, the unique context of teaching kindergarten necessitates an examination of both kindergarten teachers' perceptions of kindergarten and the effectiveness of transitioning to kindergarten from the perspective of those teachers serve, children and their families (Darling-Hammond 2000; Muñoz \& Chang, 2007; Muñoz et al., 2013). To fully understand the complex interactions between teachers and students, which significantly impact learning, students' voices must be incorporated and synthesized with those of teachers. Broadening this study into students' home microsystems and with those within would provide a holistic understanding of how students navigate multiple microsystems, perceive similarities and dissimilarities between home and school, and how they reconcile those differences (Bronfenbrenner, 1979, 1989).

\section{Conclusion}

This phenomenological study intended to provide an exploration of teachers' perceptions of their students in the age or kindergarten readiness. The research questions included: 
- How have teachers' experiences as kindergarten students formed their expectations for and perceptions of their students?

- How do kindergarten teachers perceive their students, especially those labeled not ready for kindergarten?

- How has teaching kindergarten, particularly those students labeled not ready for kindergarten affected teachers' professional and personal lives?

- How has teaching students who are identified as not ready for kindergarten affected teachers' instructional practices?

Urie Bronfenbrenner's ecological systems theory (1979) was used as the conceptual framework to guide my research. Bronfenbrenner's concepts of the microsystem, the influence of relationships within the microsystem on development, and the disruption of transitioning between microsystems provided both the foundation for my understanding of the divergence of home and school influences on children as well as the framework by which I analyzed and synthesized data from teachers' interviews (Bronfenbrenner, 1979). This conceptual framework was instrumental in my analytic juxtaposition of teachers' school experience and those of their students as well as how teachers described students' domestic settings and acclimation to school.

This study's findings are significant because the rich and complex voices of teachers were used to determine common experiences with the phenomenon of teaching kindergarten after a transition to increased academic expectations. In this study, teachers described their experiences as kindergarten students, reasons for pursuing a teaching career, and attitudes about their students and kindergarten education. Though each teacher brought their unique experiences to this study, common themes emerged. 
Teachers described changes in kindergarten academic expectations, their motivations to continue teaching kindergarten, and how their students either adapted to or struggled with the transition to formal schooling. The composite themes that arose indicate potential pitfalls of the current system, how teachers have adjusted their instructional strategies to meet school and district expectations and the needs of their students, and how students have adjusted, or not, to the current system. Moreover, this study provides discussions and findings that could be used in future research to explore the phenomenon of kindergarten readiness through students' and families' voices as a means to fully understand the complexity of the experience.

Throughout teachers' testimonies, both a love for teaching children and the frustration of teaching kindergarten in the modern era were woven in their descriptive tapestries. This tension was best exemplified by teachers' expressed desires for guided play while also describing the skills many students lacked. While these concepts appear mutually exclusive in juxtaposition, the play-based kindergarten experiences of teachers and the relation of these experiences to their strong sense of vocation provide a different interpretation. Participants' descriptions of their unstructured play kindergarten experiences and the profound influence of family members in the teaching profession are connected by relationships. The current kindergarten curricula, focused on academic standards, may not provide the same opportunities teachers experienced in their own learning. Teachers' longing for more play could be an unstated desire for more connectedness with their students, to be like the teachers who influenced them. Including a funds of knowledge approach to kindergarten education, even in an era of standards mastery and first-grade readiness, maybe the missing safety net for 
students from cultures not aligned to school norms and a benefit for teachers who want to leverage relationships to better students' social and academic success. The kindergarten teachers who offered their experiences to this study described their students as academic beings navigating curricular programs and standards and students' families remotely through the details students shared of their lives. Improving communication and collaboration with students' families and incorporating the knowledge and skills students learned in their home microsystems reconciles the divide between students' home and school experiences and provides teachers with the authenticity and trust required to influence the next generation of teachers. 


\section{REFERENCES}

Abry, T., Latham, S., Bassok, D., \& LoCasale-Crouch, J. (2015). Preschool and kindergarten teachers' beliefs about early school competencies: Misalignment matters for kindergarten adjustment. Early Childhood Research Quarterly, 31, 7888.

Alexander, K., Entwisle, D., \& Olson, L. (2007). Lasting consequences of the summer learning gap. American Sociological Review, 72(2), 167-180.

Andrews, J., \& Yee, W. (2006). Children's "funds of knowledge" and their real-life activities: Two minority ethnic children learning in out-of-school contexts in the UK. Educational Review, 58(4), 435-449.

Andrews, R., Torgerson, C., Beverton, S., Freeman, A., Locke, T., Low, G., . . Zhu, D. (2006). The effect of grammar teaching on writing development. British Educational Research Journal, 32(1), 39-55.

Ansari, A., \& Pianta, R. (2018). The role of elementary school quality in the persistence of preschool effects. Children and Youth Services Review, 86, 120-127.

Arnold, D., Kupersmidt, J., Voegler-Lee, M., \& Marshall, N. (2012). The association between preschool children's social functioning and their emergent academic skills. Early Childhood Research Quarterly, 27(3), 376-386. 
Arteaga, I., \& Heflin, C. (2014). Participation in the national school lunch program and food security: An analysis of transitions into kindergarten. Children and Youth Services Review, 47, 224-230.

Augustine, J., Prickett, K., Kendig, S., \& Crosnoe, R. (2015). Maternal education and the link between birth timing and children's school readiness: Maternal education. Social Science Quarterly, 96(4), 970-984.

Bakken, L., Brown, N., \& Downing, B. (2017). Early childhood education: The longterm benefits. Journal of Research in Childhood Education, 31(2), 255-269.

Barnett, W., \& Masse, L. (2007). Comparative benefit-cost analysis of the abecedarian program and its policy implications. Economics of Education Review, 26(1), 113125.

Bassok, D., Latham, S. \& Rorem A. (2015). Is kindergarten the new first grade? EdPolicyWorks Working Paper Series, No. 20. Retrieved from http://www.cde.state.co.us/sites/default/files/20_Bassok_Is_Kindergarten_The_N ew_First_Grade.pdf

Bell, M. A. (1998). Frontal lobe function during infancy: Implications for the development of cognition and attention. In J. Richards (Ed.), Cognitive neuroscience of attention: A developmental perspective (pp. 287-323). Mahwah, NJ: Erlbaum.

Bender, S., Fedor, M., \& Carlson, J. (2011). Examining protective factors and risk factors in urban and rural head start preschoolers. Journal of Community Psychology, 39(8), 908-921. 
Berry, D., Blair, C., Willoughby, M., Garrett-Peters, P., Vernon-Feagans, L., \& MillsKoonce, W. (2016). Household chaos and children's cognitive and socioemotional development in early childhood: Does childcare play a buffering role? Early Childhood Research Quarterly, 34, 115-127.

Birch, S. H., \& Ladd, G. W. (1997). The teacher-child relationship and children's early school adjustment. Journal of School Psychology, 35, 61-79.

Blair, C. (2002). School readiness. integrating cognition and emotion in a neurobiological conceptualization of children's functioning at school entry. The American Psychologist, 57(2), 111-27.

Blair, C., Berry, D. J., \& Friedman, A. H. (2012). The development of self-regulation in infancy and early childhood: An organizing framework for the design and evaluation of early care and educational programs for children and poverty. In E. Pungello, S. Odom, \& N. Gardner-Neblett (Eds.), Infants, toddlers, and families in poverty: Research implications for early childcare (pp. 127-152). New York: Guilford Press.

Blair, C., Knipe, H., Cummings, E., Baker, D., Gamson, D., Eslinger, P., et al. (2007). A developmental neuroscience approach to the study of school readiness. In R.C. Pianta, M. J. Cox, \& K. L. Snow (Eds.), School readiness and the transition to kindergarten in the era of accountability (pp.149-174). Baltimore, MD: Paul H. Brookes.

Blair, C., \& Raver, C. (2015). School readiness and self-regulation: A developmental psychobiological approach. Annual Review of Psychology, 66, 711-731. 
Blair, C., Raver, C., \& Ansari, D., Editor. (2014). Closing the achievement gap through modification of neurocognitive and neuroendocrine function: Results from a cluster randomized controlled trial of an innovative approach to the education of children in kindergarten. Plos One, 9(11).

Bloch, M. N., \& Kim, K., (2015). A cultural history of "readiness" in early childhood care and education: Are there still culturally relevant, ethical, and imaginative spaces for learning open for young children and their families? In J.M. \& W. Parnell (Eds.), Rethinking Readiness in Early Childhood Education: Implications for Policy and Practice (1 ${ }^{\text {st }}$ ed., pp. 1-19) Palgrave Macmillan.

Bojczyk, K., Haverback, H., \& Pae, H. (2018). Investigating maternal self-efficacy and home learning environment of families enrolled in head start. Early Childhood Education Journal, 46(2), 169-178.

Bronfenbrenner, U. (1979). The ecology of human development: Experiments by nature and design. Cambridge, Mass.: Harvard University Press.

Bronfenbrenner, U. (1989). Ecological systems theory. Annals of Child Development, 6, 187-249.

Bradley, R., \& Corwyn, R. (2002). Socioeconomic status and child development. Annual Review of Psychology, 53(1), 371-399.

Brown, E., Ackerman, B., \& Moore, C. (2013). Family adversity and inhibitory control for economically disadvantaged children: Preschool relations and associations with school readiness. Journal of Family Psychology: Jfp: Journal of the Division 
of Family Psychology of the American Psychological Association (division 43),27(3), 443-52.

Bui, Q. \& Miller, C. C. (2017). The jobs you're most likely to inherit from your mother or father. Retrieved from https://www.nytimes.com/interactive/2017/11/22/upshot/the-jobs-youre-mostlikely-to-inherit-from-your-mother-and-father.html

Burger, K. (2010). How does early childhood care and education affect cognitive development? an international review of the effects of early interventions for children from different social backgrounds. Early Childhood Research Quarterly, 25(2), 140-165.

Cadima, J., McWilliam, R., \& Leal, T. (2010). Environmental risk factors and children's literacy skills during the transition to elementary school. International Journal of Behavioral Development: Ijbd, 48(1), 24-24.

Cassidy, D., Mims, S., Rucker, L., \& Boone, S. (2003). Emergent curriculum and kindergarten readiness. Childhood Education, 79(4), 194-99.

Cathy, H., \& Ann, P. (2003). Behavior problems of preschool children from low-income families: Review of the literature. Topics in Early Childhood Special Education, 23(4), 188-216.

Cavanaugh, D. M., Clemence, K. J., Teale, M. M., Rule, A. C., \& Montgomery, S. E. (2017). Kindergarten scores, storytelling, executive function, and motivation improved through literacy-rich guided play. Early Childhood Education Journal, $45(6), 831-843$. 
Chang, Y., Huston, A., Crosby, D., \& Gennetian, L. (2007). The effects of welfare and employment programs on children's participation in head start. Economics of Education Review, 26(1), 17-32.

Christian, K., Morrison, F., \& Bryant, F. (1998). Predicting kindergarten academic skills: Interactions among child care, maternal education, and family literacy environments. Early Childhood Research Quarterly, 13(3), 501-21.

Coley, R., Lynch, A., \& Kull, M. (2015). Early exposure to environmental chaos and children's physical and mental health. Early Childhood Research Quarterly, 32, 94-104.

Combs-Ronto, L., Olson, S., Lunkenheimer, E., \& Sameroff, A. (2009). Interactions between maternal parenting and children's early disruptive behavior: Bidirectional associations across the transition from preschool to school entry. Journal of Abnormal Child Psychology, 37(8), 1151-63.

Comer, J., \& Haynes, N. (1991). Parent involvement in schools: An ecological approach. The Elementary School Journal, 91(3), 271-277.

Condron, D. (2009). Social class, school and non-school environments, and black/white inequalities in children's learning. American Sociological Review, 74(5), 683-708.

Conway, A., \& Stifter, C. (2012). Longitudinal antecedents of executive function in preschoolers. Child Development, 83(3), 1022-1036. 
Corapci, F., \& Wachs, T. D. (2002). Does parental mood or efficacy mediate the influence of environmental chaos upon parenting behavior? Merrill-Palmer Quarterly, 48(2), 182-201

Coulton, C., Richter, F., Kim, S., Fischer, R., \& Cho, Y. (2016). Temporal effects of distressed housing on early childhood risk factors and kindergarten readiness. Children and Youth Services Review, 68, 59-72.

Creswell, J. W. (2007). Research design: Qualitative and quantitative approaches (2nd ed.). Thousand Oaks, CA: Sage.

Creswell, J. W. (2013). Qualitative inquiry \& research design: choosing among five approaches (Third). SAGE Publications.

Creswell, J., Hanson, W., Clark Plano, V., \& Morales, A. (2007). Qualitative research designs. The Counseling Psychologist, 35(2), 236-264.

Creswell, J., \& Poth, C. (2018). Qualitative inquiry \& research design: Choosing among five designs. Thousand Oaks, CA: Sage Publications, Inc.

Crosnoe, R., Ansari, A., Purtell, K., \& Wu, N. (2016). Latin American immigration, maternal education, and approaches to managing children's schooling in the united states. Journal of Marriage and Family, 78(1), 60-74.

Crotty, M. (1996) Phenomenology and Nursing Research. Melbourne: Churchill Livingston.

Curriculum Associates. (2019a). BRIGANCE early childhood. Retrieved from https://www.curriculumassociates.com/products/brigance/early-childhood 
Curriculum Associates. (2019b). Kentucky's common kindergarten entry screen implementation guide 2019-2020 [PDF file]. Retrieved from https://www.casamples.com/downloads/K-Screen-Implementation-Guide-20192020.pdf

Currie, J., Neidell, M., \& National Bureau of Economic Research. (2003). Getting inside the "black box" of head start quality what matters and what doesn't? (Nber working paper series, no. 10091). Cambridge, Mass.: National Bureau of Economic Research.

Dahlberg, G., Moss, P., \& Pence, A. (2007). Beyond quality in early childhood education and care: Languages of evaluation (2nd Ed.) London: Routledge.

Darling-Hammond, L. (2000). Teacher quality and student achievement: a review of state policy evidence. Education Policy Analysis Archives, 8(1), 1-44.

Datta Gupta, N., \& Simonsen, M. (2010). Non-cognitive child outcomes and universal high quality child care. Journal of Public Economics, 94(1-2), 30-43.

Davis-Kean, P. (2005). The influence of parent education and family income on child achievement: The indirect role of parental expectations and the home environment. Journal of Family Psychology: Jfp : Journal of the Division of Family Psychology of the American Psychological Association (division 43), 19(2), 294-304.

Dealey, R., \& Stone, M. (2018). Exploring out-of-school play and educational readiness. Early Childhood Education Journal, 46(2), 201-208. 
Dearnley, C. (2005). A reflection on the use of semi-structured interviews. Nurse Researcher, 13(1), 19-28.

Degol, J., Wang, M., Ye, F., \& Zhang, C. (2017). Who makes the cut? parental involvement and math trajectories predicting college enrollment. Journal of Applied Developmental Psychology, 50, 60-70.

Demma, R. (2010). Building ready states: A governor's guide to supporting a comprehensive, high-quality early childhood state system. Retrieved from www.nga.org

De Smedt, F., Merchie, E., Barendse, M., Rosseel, Y., De Naeghel, J., \& Van Keer, H. (2018). Cognitive and motivational challenges in writing: Studying the relation with writing performance across students' gender and achievement level. Reading Research Quarterly, 53(2), 249-272.

Dhuey, E., Figlio, D., Karbownik, K., Roth, J., \& National Bureau of Economic Research. (2017). School starting age and cognitive development (Nber working paper series, no. 23660). Cambridge, Mass.: National Bureau of Economic Research.

Diamond, K., Reagan, A. \& Bandyk, J. (2000). Parents' conceptions of kindergarten readiness: Relationships with race, ethnicity, and development, The Journal of Educational Research, 94(2), 93-100.

Dilworth-Bart, J. (2012). Does executive function mediate ses and home quality associations with academic readiness? Early Childhood Research Quarterly, 27(3), 416-425. 
Dotterer, A., Iruka, I., \& Pungello, E. (2012). Parenting, race, and socioeconomic status: Links to school readiness. Family Relations, 61(4), 657-670.

Doumen, S., Verschueren, K., Buyse, E., Germeijs, V., Luyckx, K., \& Soenens, B. (2008). Reciprocal relations between teacher-child conflict and aggressive behavior in kindergarten: A three-wave longitudinal study. Journal of Clinical Child and Adolescent Psychology: The Official Journal for the Society of Clinical Child and Adolescent Psychology, American Psychological Association, Division 53, 37(3), 588-99.

Duncan, G. J., Dowsett, C. J., Claessens, A., Magnuson, K., Huston, A. C., Klebanov, P., ... Sexton, H. (2007). School readiness and later achievement. Developmental Psychology, 43(6), 1428-1446.

Duncan, G., \& Magnuson, K. (2005). Can family socioeconomic resources account for racial and ethnic test score gaps? The Future of Children, 15(1), 35-54.

Early Childhood Today Editorial Staff. (2000). Pioneers in our Field: Friedrich Froebel - founder of the first kindergarten. Retrieved from www.nga.org

Electric Learning Community (ELC) John Hopkins University School of Education. (2011). Ready for kindergarten. Retrieved from https://www.scholastic.com/teachers/articles/teaching-content/pioneers-our-fieldfriedrich-froebel-founder-first-kindergarten/

Engel, M., Claessens, A., Watts, T., \& Stone, S., School of Social Welfare, University of California at Berkeley, 120 Haviland Hall, Berkeley, CA, USA. (2016). 
Socioeconomic inequality at school entry: A cross-cohort comparison of families and schools. Children and Youth Services Review, 71, 227-232.

Entwisle, D. R., \& Alexander, K. L. (1999). Early schooling and social stratification. In R. C. Pianta \& M. Cox (Eds.), The transition to kindergarten: Research, policy, training, and practice (pp. 13-38). Baltimore: Paul Brookes Publishers.

Eschner, K., (2017). A little history of American kindergartens. Retrieved from https://www.smithsonianmag.com/smart-news/little-history-americankindergartens-180963263/

Espinosa, L., Thornburg, K., \& Mathews, M. (1997). Rural kindergarten teachers' perceptions of school readiness: A comparison with the Carnegie study. Early Childhood Education Journal, 25(2), 119-125.

Evers, W., Tomic, W., \& Brouwers, A. (2004). Burnout among teachers: Students' and teachers' perceptions compared. School Psychology International, 25(2), 131-148.

Faires, J., Nichols, W., \& Rickelman, R. (2000). Effects of parental involvement in developing competent readers in first grade. Reading Psychology, 21(3), 195-215.

Fantuzzo, J., Perlman, S., Sproul, F., Minney, A., Perry, M., \& Li, F. (2012). Making visible teacher reports of their teaching experiences: The early childhood teacher experiences scale. Psychology in the Schools, 49(2), 194-205.

Figlio, D., Guryan, J., Karbownik, K., \& Roth, J. (2013). The effects of poor neonatal health on children's cognitive development. Working Paper Series, 18846(18846). 
File, N., \& Gullo, D. F. (2002). A comparison of early childhood and elementary education students' beliefs about primary classroom teaching practices. Early Childhood Research Quarterly, 17(1), 126-137.

Fomby, P., \& Mollborn, S. (2017). Ecological instability and children's classroom behavior in kindergarten. Demography, 54(5), 1627-1651.

Foster, W., \& Miller, M. (2007). Development of the literacy achievement gap: A longitudinal study of kindergarten through third grade. Language, Speech, and Hearing Services in Schools, 38(3), 173-81.

Fryer, R., \& Levitt, S. (2004). Understanding the black-white test score gap in the first two years of school. The Review of Economics and Statistics, 86(2), 447-464.

Fuller, B., Bein, E., Bridges, M., Kim, Y., \& Rabe-Hesketh, S. (2017). Do academic preschools yield stronger benefits? cognitive emphasis, dosage, and early learning. Journal of Applied Developmental Psychology, 52, 1-11.

Gaddis, S., \& Lauen, D. (2014). School accountability and the black-white test score gap. Social Science Research, 44, 15-31.

Garrett-Peters, P., Mokrova, I., Vernon-Feagans, L., Willoughby, M., \& Pan, Y. (2016). The role of household chaos in understanding relations between early poverty and children's academic achievement. Early Childhood Research Quarterly, 37, 1625. 
García, E. (2015). Inequalities at the starting gate: Cognitive and noncognitive skills gaps between 2010-2011 kindergarten classmates. Washington, DC: Economic Policy Institute.

Geertz, C. (1973). The interpretation of cultures: Selected essays. New York: Basic Books.

Gianina-Ana, M. (2013). Kindergarten teachers' perceptions on in-service training and impact on classroom practice. Procedia - Social and Behavioral Sciences, 76, 481-485.

Gilligan, C., \& Eddy, J. (2017). Listening as a path to psychological discovery: an introduction to the listening guide. Perspectives on Medical Education, 6(2), 7681.

Giorgi, A. (1985). Phenomenology and psychological research. Pittsburgh, Pa.: Duquesne University Press.

Glascoe, F. (1996). Can the brigance screens detect children who are gifted and academically talented? Roeper Review, 19(1), 20-24.

Glascoe, F. (1997). Do the brigance screens detect developmental and academic problems? Diagnostique, 22(2), 87-99.

González, N., Moll, L., \& Amanti, C. (2005). Funds of knowledge: Theorizing practice in households, communities, and classrooms. Mahwah, N.J.: L. Erlbaum Associates.

Goodwyn, E. (2010). Approaching archetypes: Reconsidering innateness. Journal of Analytical Psychology, 55(4), 502-521. 
Graue, E. (1999). Diverse perspectives on kindergarten contexts and practices. In R. C. Pianta, \& M. J. Cox (Eds.), The transition to kindergarten, 109-142. Baltimore, MD: Brookes.

Graue, E. (2006). The answer is readiness-Now what is the question? Early Education and Development, 17, 43-56.

Graue, M. E. (1992). Social interpretations of readiness for kindergarten. Early Childhood Research Quarterly, 7, 225-243.

Griggs, M., Mikami, A., \& Rimm-Kaufman, S. (2016). Classroom quality and student behavior trajectories in elementary school. Psychology in the Schools, 53(7), 690704.

Haeck, C., Lefebvre, P., \& Merrigan, P. (2015). Canadian evidence on ten years of universal preschool policies: The good and the bad. Labour Economics, 36, 137157.

Harmon, F., \& Viruru, R. (2018). Debunking the myth of the efficacy of "push-down academics": How rigid, teacher-centered, academic early learning environments disempower young children. Journal of Family Strength, 18(1), 1-11.

Hart, S., Petrill, S., Deater Deckard, K., \& Thompson, L. (2007). SES and chaos as environmental mediators of cognitive ability: A longitudinal genetic analysis. Intelligence, 35(3), 233-242.

Henry, G., \& Rickman, D. (2007). Do peers influence children's skill development in preschool? Economics of Education Review, 26(1), 100-112. 
Hindman, A. H., Skibbe, L. E., \& Morrison, F. J. (2013). Teacher outreach to families across the transition to school: an examination of teachers' practices and their unique contributions to children's early academic outcomes. Early Childhood Education Journal, 41(5), 391-399.

Hogg, L. (2011). Funds of knowledge: An investigation of coherence within the literature. Teaching and Teacher Education, 27(3), 666-677.

Holliday, M., Cimetta, A., Cutshaw, C., Yaden, D., \& Marx, R. (2014). Protective factors for school readiness among children in poverty. Journal of Education for Students Placed at Risk, 19(3-4), 125-147.

Hoxby, C. (2000). Peer effects in the classroom: Learning from gender and race variation. Working Paper Series, 7867(7867).

Hur, E., Buettner, C., \& Jeon, L. (2015). Parental depressive symptoms and children's school-readiness: The indirect effect of household chaos. Journal of Child and Family Studies, 24(11), 3462-3473.

Husserl, E. (1931). Ideas: General introduction to pure phenomenology (D. Carr, Trans.). Evanston, IL: Northwestern University Press.

Husserl, E. (1964). Phenomenology and the crisis of philosophy. Translated by Quentin Lauer. New York City: Harper and Row Publishers, Inc.

Husserl, E. (1983). Ideas: General Introduction to Pure Phenomenology. Trans. by T.E. Klein. Dordrecht, The Netherlands: Kluwer Academic Publishers. 
Hustedt, J., Buell, M., Hallam, R., \& Pinder, W. (2018). While kindergarten has changed, some beliefs stay the same: Kindergarten teachers' beliefs about readiness. Journal of Research in Childhood Education, 32(1), 52-66.

Ingersoll, R. (2001). Section on social and institutional analysis - teacher turnover and teacher shortages: An organizational analysis. American Educational Research Journal, 38(3), 499.

Justice, L., Jiang, H., Khan, K., \& Dynia, J. (2017). Kindergarten readiness profiles of rural, Appalachian children from low-income households. Journal of Applied Developmental Psychology, 50, 1-14.

Keage, H., Muniz, G., Kurylowicz, L., Van Hooff, M., Clark, L., Searle, A., .. . McFarlane, A. (2016). Age 7 intelligence and paternal education appear best predictors of educational attainment: The port pirie cohort study. Australian Journal of Psychology, 68(1), 61-69.

Kelley, T. (2020). Examining pre-service elementary mathematics teacher perceptions of parent engagement through a funds of knowledge lens. Teaching and Teacher Education, 91.

Kentucky Department of Education. (2015). 158.030 "common school" defined. [PDF file]. Retrieved from https://apps.legislature.ky.gov/law/Statutes/statute.aspx?id=44468

Kentucky Department of Education. (2016). Inclusion of special populations in the staterequired assessment and accountability programs 703 KAR 5:070 [PDF file]. Retrieved from 
https://education.ky.gov/AA/distsupp/Documents/703\%20KAR\%205070\%20Dec \%202016.pdf

Kentucky Department of Education. (2020). Kindergarten readiness 2019-20 state results [Data file]. Retrieved from https://openhouse.education.ky.gov/Data/update?view=_KindergartenReadiness

Kim, J., Murdock, T., \& Choi, D. (2005). Investigation of parents' beliefs about readiness for kindergarten: An examination of National Household Education Survey (NHES: 93). Educational Research Quarterly, 29(2), 3-17.

Kirk, G., \& Jay, J. (2018). Supporting kindergarten children's social and emotional development: examining the synergetic role of environments, play, and relationships. Journal of Research in Childhood Education, 32(4), 472-485.

Kohl, G., Lengua, L., \& McMahon, R. (2000). Parent involvement in school conceptualizing multiple dimensions and their relations with family and demographic risk factors. Journal of School Psychology, 38(6), 501-523.

Kolb, S. (2012). Grounded theory and the constant comparative method: valid research strategies for educators. Journal of Emerging Trends in Education Research and Policy Studies, 3, 83-86.

Kramer-Vida, L., Levitt, R., \& Kelly, S. (2012). Kindergarten is more than ready for the common core state standards. Language Arts, 90(2), 93-109. 
Lambert, R., Boyle, L., Fitchett, P., \& McCarthy, C. (2019). Risk for occupational stress among U.S. kindergarten teachers. Journal of Applied Developmental Psychology, $61,13-20$.

Laughlin, C., \& Tiberia, V. (2012). Archetypes: Toward a Jungian anthropology of consciousness. Anthropology of Consciousness, 23(2), 127-157.

Lee, V. \& Burkham, D. (2002). Inequality at the starting gate: Social background differences in achievement as children begin school. Washington, DC: Economic Policy Institute.

Lee, J., \& Wong, K. (2004). The impact of accountability on racial and socioeconomic equity: Considering both school resources and achievement outcomes. American Educational Research Journal, 41(4), 797-832.

Lesinger, F. Y., Altinay, F., Altinay, Z., \& Dagli Gökmen. (2018). Examining the role of leadership, trust for school culture and policy. Quality \& Quantity: International Journal of Methodology, 52(2), 983-1006.

Lin, H., Lawrence, F., \& Gorrell, J. (2003). Kindergarten teachers' views of children's readiness for school. Early Childhood Research Quarterly, 18(2), 225-237.

Logue, M. (2007). Early childhood learning standards: Tools for promoting social and academic success in kindergarten. Children \& Schools, 29(1), 35-43.

Loeb, S., Bridges, M., Bassok, D., Fuller, B., \& Rumberger, R. (2007). How much is too much? the influence of preschool centers on children's social and cognitive development. Economics of Education Review, 26(1), 52-66. 
Love, J. M. (1995). Conception of readiness for ECLS and HSLS. Unpublished memorandum. Princeton, NJ: Mathematica Policy Research, Inc.

Love, J. M., Aber, J. A., \& Brooks-Gunn, J. (1994). Strategies for assessing community progress toward achieving the first national educational goal. Princeton, NJ: Mathematica Policy Research, Inc.

Magnuson, K., Ruhm, C., Waldfogel, J., \& National Bureau of Economic Research. (2004). Does prekindergarten improve school preparation and performance? Economics of Education Review, I25, 33-51.

Magnuson, K., Sexton, H., Davis-Kean, P., \& Huston, A. (2009). Increases in maternal education and young children's language skills. Merrill-Palmer Quarterly, 55(3), $319-350$

Matheny, A., Wachs, T., Ludwig, J., \& Phillips, K. (1995). Bringing order out of chaos: Psychometric characteristics of the confusion, hubbub, and order scale. Journal of Applied Developmental Psychology, 16(3), 429-444.

McCoy, D. C., Connors, M. C., Morris, P. A., Yoshikawa, H., \& Friedman-Krauss, A. H. (2015). Neighborhood economic disadvantage and children's cognitive and socialemotional development: Exploring head start classroom quality as a mediating mechanism. Early Child Research Quarterly, 32, 150-159.

McDevitt, S. (2016). Rediscovering and reconnecting funds of knowledge of immigrant children, families, and teachers. Childhood Education, 92(6), 470-475. 
McIntosh, K., Sadler, C., \& Brown, J. (2012). Kindergarten reading skill level and change as risk factors for chronic problem behavior. Journal of Positive Behavior Interventions, 14(1), 17-28.

Meisels, S. J. (1996). Performance in context: Assessing children's achievement at the outset of school. In A. J. Sameroff and M. M. Haith (Eds.), The five to seven-year shift: The age of reason and responsibility (pp. 410-431). Chicago: University of Chicago Press.

Miles, M. B., Huberman, A. M., \& Saldaña, J. (2014). Qualitative data analysis: A methods sourcebook (3rd ed.). London: SAGE.

Moll, L. (2000) Inspired by Vygotsky: ethnographic experiments in education. In C. D. Lee and P. Smagorinsky (eds), Vygotskian Perspectives on Literacy Research: Constructing Meaning Through Collaborative Inquiry, 256-268.

Moll, L., \& González, N. (1997). Teachers as social scientists: Learning about culture from household research. In P.M. Hall (Ed.), Race, ethnicity and multiculturalism: Missouri symposium on research and educational policy, (1), 89-144.

Mollborn, S. (2016). Young children's developmental ecologies and kindergarten readiness. Demography, 53(6), 1853-1882.

Morgan, P., Li, H., Farkas, G., Cook, M., Pun, W., \& Hillemeier, M. (2017). Executive functioning deficits increase kindergarten children's risk for reading and mathematics difficulties in first grade. Contemporary Educational Psychology, $50,23-32$. 
Morrissey, T., Oellerich, D., Meade, E., Simms, J., \& Stock, A. (2016). Neighborhood poverty and children's food insecurity. Children and Youth Services Review, 66, $85-93$.

Moustakas, C. (1994). Phenomenological research methods. Thousand Oaks, CA: Sage.

Muñoz, M. A., \& Chang, F. C. (2007). The elusive relationship between teacher characteristics and student academic growth: a longitudinal multilevel model for change. Journal of Personnel Evaluation, 20, 147-164.

National Education Goals Panel (NEGP). (1997). Special early childhood report. Washington, DC: National Education Goals Panel.

National Education Goals Panel (NEGP). (1998). Ready schools. Washington, DC: National Education Goals Panel.

National Institute of Child Health and Human Development Early Child Care Research Network. (2002). Early child care and children's development prior to school entry: Results from the NICHD study of early child care. American Educational Research Journal, 39(1), 133-164.

O'Connor, E., \& McCartney, K. (2007). Attachment and cognitive skills: an investigation of mediating mechanisms. Journal of Applied Developmental Psychology, 28(5), $458-476$.

Okpala, C. (2007). The perceptions of kindergarten teachers on retention. Journal of Research in Childhood Education, 21(4), 400-405. 
Ou, S., \& Reynolds, A. (2006). Early childhood intervention and educational attainment: Age 22 findings from the Chicago longitudinal study. Journal of Education for Students Placed at Risk, 11(2), 175-198.

Petrakos, H., \& Lehrer, J. (2011). Parents' and teachers' perceptions of transition practices in kindergarten. Exceptionality Education International, 21(2), 62-73.

Pianta, R., Cox, M., \& National Center for Early Development \& Learning (U.S.). (1999). The transition to kindergarten. Baltimore: P.H. Brookes Pub.

Pianta, R., Cox, M., \& Snow, K. (2007). School readiness and the transition to kindergarten in the era of accountability. Baltimore, Md.: Paul H. Brookes Pub.

Pianta, R. C., Nimetz, S., \& Bennett, E. (1997). Mother-child relationships, teacher-child relationships, and school outcomes in preschool and kindergarten. Early Childhood Research Quarterly, 12, 263-280.

Pianta, R. C., \& Walsh, D. J. (1996). High-risk children in schools: Constructing sustaining relationships. New York: Routledge.

Pierson, A. (2018). Exploring State-by-state Definitions of Kindergarten Readiness to Support Informed Policymaking. Retrieved from https://ies.ed.gov/ncee/edlabs/regions/northwest/blog/kindergarten-readiness.asp

Phenomenology. (1932). Aristotelian Society Supplementary Volume, 11(1), 68-11

Polkinghorne, D. E. (1989). Phenomenological research methods. In R. S. Valle \& S. Halling (Eds.), Existential phenomenological perspectives in psychology (pp. 4160). New York, NY: Plenum Press. 
Puccioni, J. (2015). Parents' conceptions of school readiness, transition practices, and children's academic achievement trajectories. The Journal of Educational Research, 108(2), 130-147.

Qi, C., \& Kaiser, A. (2003). Behavior problems of preschool children from low-income families: Review of the literature. Topics in Early Childhood Special Education, 23(4), 188-216.

Razza, R., Martin, A., \& Brooks-Gunn, J. (2012). The implications of early attentional regulation for school success among low-income children. Journal of Applied Developmental Psychology, 33(6), 311-319.

Reardon, S. F., \& Portilla, X. A. (2016). Recent trends in income, racial, and ethnic school readiness gaps at kindergarten entry. Aera Open, 2(3).

Regenstein, E., Connors, M., Romero-Juado, R., \& Weiner, J. (2017). Uses and misuses of kindergarten readiness assessment results [PDF file]. Retrieved from http://www.theounce.org/wp-content/uploads/2017/03/ PolicyConversationKRA2017.pdf

Rhoades, B., Warren, H., Domitrovich, C., \& Greenberg, M. (2011). Examining the link between preschool social-emotional competence and first grade academic achievement: The role of attention skills. Early Childhood Research Quarterly, 26(2), 182-191.

Riojas-Cortez, M., \& Bustos Flores, B. (2009). Supporting preschoolers' social development in school through funds of knowledge. Journal of Early Childhood Research, 7(2), 185-199. 
Rios-Aguilar, C., Kiyama, J., Gravitt, M., \& Moll, L. (2011). Funds of knowledge for the poor and forms of capital for the rich? a capital approach to examining funds of knowledge. Theory and Research in Education, 9(2), 163-184.

Ritblatt, S., Beatty, J., Cronan, T., \& Ochoa, A. (2002). Relationships among perceptions of parent involvement, time allocation, and demographic characteristics: Implication for policy formation. Journal of Community Psychology, 30(5), 519549.

Rodriguez, G. (2013). Power and agency in education: Exploring the pedagogical dimensions of funds of knowledge. Review of Research in Education, 37(1), 87120.

Roessingh, H., \& Bence, M. (2018). Promising practices guided physical play in kindergarten. Education Canada, 58(1), 8-11.

Sadowski, M. (2006). The school readiness gap. Retrieved from https://www.hepg.org/hel-home/issues/22_4/helarticle/the-school-readiness-gap

Saldaña, J. (2016). The Coding Manual for Qualitative Researchers (3rd ed.). London: SAGE.

Schrader, D. (2015). Constructivism and learning in the age of social media: Changing minds and learning communities. New Directions for Teaching and Learning, 2015(144), 23-35.

Silinskas, G., Lerkkanen, M., Tolvanen, A., Niemi, P., Poikkeus, A., \& Nurmi, J. (2012). The frequency of parents' reading-related activities at home and children's reading 
skills during kindergarten and grade 1. Journal of Applied Developmental Psychology, 33(6), 302-310.

Son, S., \& Peterson, M. (2017). Marital status, home environments, and family strain: Complex effects on preschool children's school readiness skills. Infant and Child Development, 26(2).

Smith, M., \& Shepard, L. (1988). Kindergarten readiness and retention: A qualitative study of teachers' beliefs and practices. American Educational Research Journal, 25(3), 307-333.

Stevens, D., Brydon-Miller, M., \& Raider-Roth, M. (2016) Structured ethical reflection in practitioner inquiry: Theory, pedagogy, and practice. The Educational Forum, 80(4), 430-443.

Stormont, M. (2000). Early child risk factors for externalizing and internalizing behaviors: a 5-year follow-forward assessment. Journal of Early Intervention, 23(3), 180-190.

Strauss, A. L., \& Corbin, J. M. (1998). Basics of qualitative research: Techniques and procedures for developing grounded theory. Thousand Oaks: Sage Publications.

Taylor, L., Clayton, J., \& Rowley, S. (2004). Academic socialization: Understanding parental influences on children's school-related development in the early years. Review of General Psychology, 8(3), 163-178.

Teaching Strategies. (2013). Teaching strategies GOLD birth through kindergarten: Touring guide [PDF file]. Retrieved from 
https://www.buffalo.edu/content/dam/www/ubccc/Documents/Teaching\%20Strat egies\%20-\%20GOLD-Touring-Guide_5-2013.pdf

Temple, J., \& Reynolds, A. (2007). Benefits and costs of investments in preschool education: Evidence from the child-parent centers and related programs. Economics of Education Review, 26(1), 126-144.

Tufford, L., \& Newman, P. (2012). Bracketing in qualitative research. Qualitative Social Work, 11(1), 80-96.

Turney, K., \& McLanahan, S. (2015). The academic consequences of early childhood problem behaviors. Social Science Research, 54, 131-145.

Upshur, C., Heyman, M., \& Wenz-Gross, M. (2017). Efficacy trial of the second step early learning (SSEL) curriculum: Preliminary outcomes. Journal of Applied Developmental Psychology, 50, 15-25.

Valencia. R. (2010). Dismantling Contemporary Deficit Thinking: Educational Thought and Practice. Taylor and Francis.

Van Manen, M. (1990). Researching lived experience: Human science for an action sensitive pedagogy. Ontario, Canada: University of Western Ontario.

Vélez-Ibáñez, C., \& Greenberg, J. (1992). Formation and transformation of funds of knowledge among U.S.-Mexican households. Anthropology \& Education Quarterly, 23(4), 313-335. 
Vernon-Feagans, L., Garrett-Peters, P., Willoughby, M., \& Mills-Koonce, R. (2012).

Chaos, poverty, and parenting: Predictors of early language development. Early Childhood Research Quarterly, 27(3), 339-351.

Vernon-Feagans, L., Bratsch-Hines, M. E., \& Family Life Project Key Investigators. (2013). Caregiver-child verbal interactions in child care: A buffer against poor language outcomes when maternal language input is less. Early Childhood Research Quarterly, 28(4), 858-873.

Vernon-Feagans, L., Willoughby, M., Garrett-Peters, P., \& Family Life Project Key Investigators. (2016). Predictors of behavioral regulation in kindergarten: Household chaos, parenting, and early executive functions. Developmental Psychology, 52(3), 430-41.

Vygotsky, L.S. (1962). Thought and Language. Cambridge, Mass.: The MIT Press.

Vygotsky, L. S. (1978). Mind in society: The development of higher psychological processes. Cambridge, MA: Harvard University Press.

Vygotsky, L.S. (1981). The genesis of higher mental functions. In J.V. Wertsch (Ed.). The Concept of Activity in Soviet Psychology. New York: M.E. Sharpe, 144-188.

Vygotsky, L.S. \& Luria, A. (1994). Tool and symbol in child development. In R. van der Veer \& J. Valsiner (Eds.) The Vygotsky Reader. Oxford: Blackwell, 99-174.

Walker, S., Wachs, T., Grantham-McGregor, S., Black, M., Nelson, C., Huffman, S., .. . Richter, L., Human Sciences Research Council \& University of the Witwatersrand, South Africa. (2011). Inequality in early childhood: Risk and 
protective factors for early child development. The Lancet, 378(9799), 13251338

Wallen, M., \& Tormey, R. (2019). Developing teacher agency through dialogue. Teaching and Teacher Education, 82, 129-139.

Weil, E. (2007). When should a kid start kindergarten? Retrieved from https://www.nytimes.com/2007/06/03/magazine/03kindergartent.html?mtrref=www.google.com\&gwh=CD3D2FCFF688AB293748F925C75C06 $\underline{\mathrm{F} 2}$

Weisberg, D.S., Hirsh-Pasek, K., \& Golinkoff, R.M. (2013). Guided play: Where curricular goals meet a playful pedagogy. Mind, Brain, and Education, 7(2), 104112.

Wilkinson, L. (1988). Chapter 5: Grouping children for learning: Implications for kindergarten education. Review of Research in Education, 15(1), 203-223.

Wolf, S., Magnuson, K., \& Kimbro, R. (2017). Family poverty and neighborhood poverty: Links with children's school readiness before and after the great recession. Children and Youth Services Review, 79, 368-384.

Xue, Y., \& Meisels, S. (2004). Early literacy instruction and learning in kindergarten: Evidence from the early childhood longitudinal study—Kindergarten class of 1998-1999. American Educational Research Journal, 41(1), 191-229. 
Zipin, L. (2009). Dark funds of knowledge, deep funds of pedagogy: Exploring boundaries between lifeworlds and schools. Discourse: Studies in the Cultural Politics of Education, 30(3), 317-33. 
Appendix A: Conceptual Model

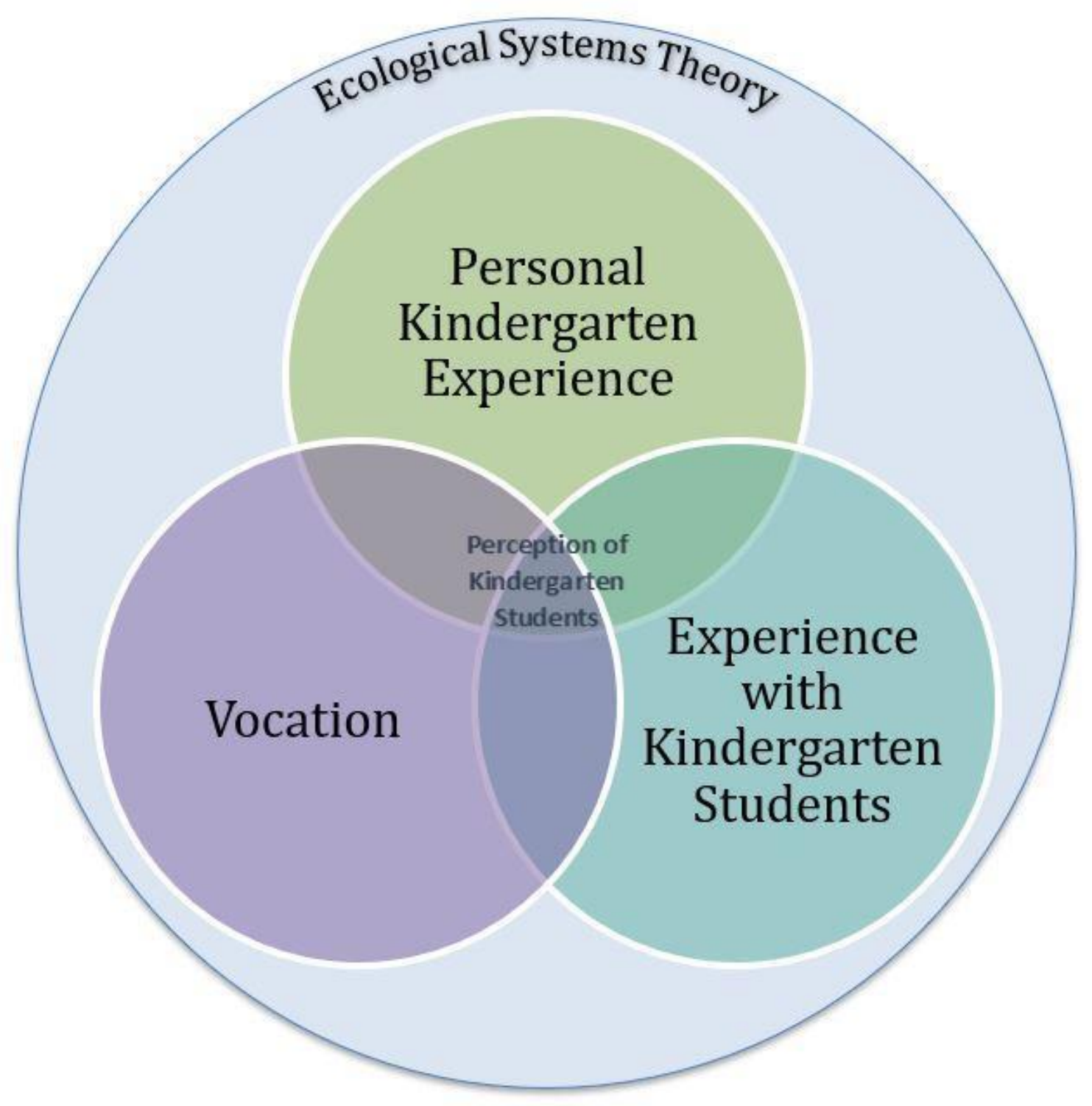




\section{Appendix B: SER Tool}

Table 1 Kindergarten teacher experiences - SER Tool

\begin{tabular}{|c|c|c|c|c|c|c|c|c|}
\hline Values & Developing Partnerships & $\begin{array}{l}\text { Constructing research } \\
\text { questions }\end{array}$ & Planning project/action & Recruiting participants & $\begin{array}{l}\text { Collecting dataltaking } \\
\text { action }\end{array}$ & $\begin{array}{l}\text { Analyzing } \\
\text { data/evaluating action }\end{array}$ & Member checking & $\begin{array}{l}\text { Going public } \\
\text { (presentation and } \\
\text { publication }\end{array}$ \\
\hline $\begin{array}{l}\text { Open- } \\
\text { Mindedness }\end{array}$ & $\begin{array}{l}\text { Searching for teachers of } \\
\text { varying experiences and } \\
\text { backprounds }\end{array}$ & $\begin{array}{l}\text { Developing questions } \\
\text { that are open and } \\
\text { malleable to participants' } \\
\text { experiences }\end{array}$ & $\begin{array}{l}\text { Being overt with } \\
\text { research design and } \\
\text { scope with participants } \\
\text { and critical peers }\end{array}$ & $\begin{array}{l}\text { Inviting a wide variety of } \\
\text { participants to participate } \\
\text { in the study. }\end{array}$ & $\begin{array}{l}\text { Revisiting data as the } \\
\text { research study evolves to } \\
\text { allow new interpretations } \\
\text { and themes }\end{array}$ & $\begin{array}{l}\text { Allowing divergent } \\
\text { interpretations of data } \\
\text { throughout the study and } \\
\text { coding process }\end{array}$ & $\begin{array}{l}\text { Authentically } \\
\text { representing participants' } \\
\text { voices }\end{array}$ & $\begin{array}{l}\text { Considering feedback, } \\
\text { criticism, and alternate } \\
\text { interpretations of data }\end{array}$ \\
\hline Respect & $\begin{array}{l}\text { Compensating } \\
\text { participants for their time } \\
\text { and energy. }\end{array}$ & $\begin{array}{l}\text { Developing questions } \\
\text { that potentially benefit } \\
\text { research participants }\end{array}$ & $\begin{array}{l}\text { Answering questions my } \\
\text { research participants may } \\
\text { have about my research }\end{array}$ & $\begin{array}{l}\text { Being transparent with } \\
\text { research intent, requires } \\
\text { time for interviews, and } \\
\text { how data is used. }\end{array}$ & $\begin{array}{l}\text { Offering data collection } \\
\text { processes and transcripts } \\
\text { to participants }\end{array}$ & $\begin{array}{l}\text { Protecting participants' } \\
\text { integrity by representing } \\
\text { the tacit meaning of their } \\
\text { responses }\end{array}$ & $\begin{array}{l}\text { Eliciting participant } \\
\text { feedback throughout the } \\
\text { research process }\end{array}$ & $\begin{array}{l}\text { Honoring participants by } \\
\text { offering the completed } \\
\text { study and eliciting } \\
\text { feedback }\end{array}$ \\
\hline Trust & $\begin{array}{l}\text { Sharing transcripts and } \\
\text { findings with participants } \\
\text { for their own } \\
\text { professional portfolios }\end{array}$ & $\begin{array}{l}\text { Creating questions that } \\
\text { engender trust through } \\
\text { genuine interest to } \\
\text { benefit participants. }\end{array}$ & $\begin{array}{l}\text { Providing transparency } \\
\text { of research design and } \\
\text { intent with participants }\end{array}$ & $\begin{array}{l}\text { Providing research } \\
\text { questions, main } \\
\text { interview questions, and } \\
\text { a brief biography to } \\
\text { participants prior to } \\
\text { interviews. }\end{array}$ & $\begin{array}{l}\text { Ensuring anonymity for } \\
\text { participants in the } \\
\text { research study }\end{array}$ & $\begin{array}{l}\text { Providing interview } \\
\text { transcripts to participants } \\
\text { (and coding, when } \\
\text { requested) }\end{array}$ & $\begin{array}{l}\text { Validating participant } \\
\text { and critical peer } \\
\text { input feedback during } \\
\text { the research process }\end{array}$ & $\begin{array}{l}\text { Ensuring that the } \\
\text { published study fairly } \\
\text { represents participants } \\
\text { perspectives and } \\
\text { experiences }\end{array}$ \\
\hline Empathy & $\begin{array}{l}\text { Listening to teachers' } \\
\text { experiences in order to } \\
\text { understand perspectives }\end{array}$ & $\begin{array}{l}\text { Developing questions } \\
\text { that illustrate my desire } \\
\text { to explore topics relevant } \\
\text { to participants and their } \\
\text { profession }\end{array}$ & $\begin{array}{l}\text { Choosing a research } \\
\text { methodology that } \\
\text { brackets my own } \\
\text { opinions and experiences }\end{array}$ & $\begin{array}{l}\text { Listening to participants' } \\
\text { replies to delve deeper } \\
\text { into their experiences } \\
\text { with responsive } \\
\text { questions }\end{array}$ & $\begin{array}{l}\text { Focusing on participants' } \\
\text { responses while } \\
\text { bracketing against } \\
\text { personal experience and } \\
\text { other interviews }\end{array}$ & $\begin{array}{l}\text { Listening for } \\
\text { participants' overt (said) } \\
\text { and covert (implied) } \\
\text { meanings in collected } \\
\text { data }\end{array}$ & $\begin{array}{l}\text { Providing participants } \\
\text { transcript access for } \\
\text { rephrasing, clarifying, } \\
\text { and redacting. }\end{array}$ & $\begin{array}{l}\text { Sharing the research } \\
\text { study with participants } \\
\text { for their professional } \\
\text { pursuits }\end{array}$ \\
\hline Integrity & $\begin{array}{l}\text { Recording participants' } \\
\text { lived experiences } \\
\text { verbatim }\end{array}$ & $\begin{array}{l}\text { Sharing research } \\
\text { questions with critical } \\
\text { peers and participants } \\
\text { throughout the research } \\
\text { process for feedback }\end{array}$ & $\begin{array}{l}\text { Offering my research } \\
\text { design and to } \\
\text { participants and critical } \\
\text { peers for feedback } \\
\text { throughout the process }\end{array}$ & $\begin{array}{l}\text { Offering a wide variety } \\
\text { of teachers opportunities } \\
\text { to interview and access } \\
\text { to the research }\end{array}$ & $\begin{array}{l}\text { Transcribing interviews } \\
\text { verbatim but ensuring } \\
\text { that the meaning of } \\
\text { interview data is gleaned }\end{array}$ & $\begin{array}{l}\text { Dissecting interviews } \\
\text { into discemable data for } \\
\text { coding }\end{array}$ & $\begin{array}{l}\text { Keeping open channels } \\
\text { of communication for } \\
\text { participant access } \\
\text { throughout the research } \\
\text { process }\end{array}$ & $\begin{array}{l}\text { Providing the research } \\
\text { studyto researchers and } \\
\text { institutions to contribute } \\
\text { to research literature }\end{array}$ \\
\hline Validity & $\begin{array}{l}\text { Providing participants } \\
\text { with transcripts and } \\
\text { findings for their own } \\
\text { scrutiny }\end{array}$ & $\begin{array}{l}\text { Designing research } \\
\text { questions that explore } \\
\text { participants experiences } \\
\text { rather than my personal } \\
\text { interests }\end{array}$ & $\begin{array}{l}\text { Referencing seminal } \\
\text { research for the } \\
\text { methodology as well as } \\
\text { current research on } \\
\text { similar topics throughout } \\
\text { the research process }\end{array}$ & $\begin{array}{l}\text { Ensuring that interview } \\
\text { participants fairly } \\
\text { represent kindergarten } \\
\text { teachers in the research } \\
\text { geography (midwestern) }\end{array}$ & $\begin{array}{l}\text { Listening to interviews } \\
\text { throughout the research } \\
\text { study to ensure } \\
\text { statements are } \\
\text { understood and coded to } \\
\text { participants' meanings }\end{array}$ & $\begin{array}{l}\text { Collaborating with } \\
\text { critical peers during the } \\
\text { coding process sto } \\
\text { broaden interpretations } \\
\text { through different } \\
\text { perspectives }\end{array}$ & $\begin{array}{l}\text { Representing the voices } \\
\text { of participants accurately }\end{array}$ & $\begin{array}{l}\text { Editing and finalizing the } \\
\text { research study to } \\
\text { accurately represent } \\
\text { participants' perspectives } \\
\text { in findings }\end{array}$ \\
\hline
\end{tabular}




\section{Appendix C: Data Analysis Process}

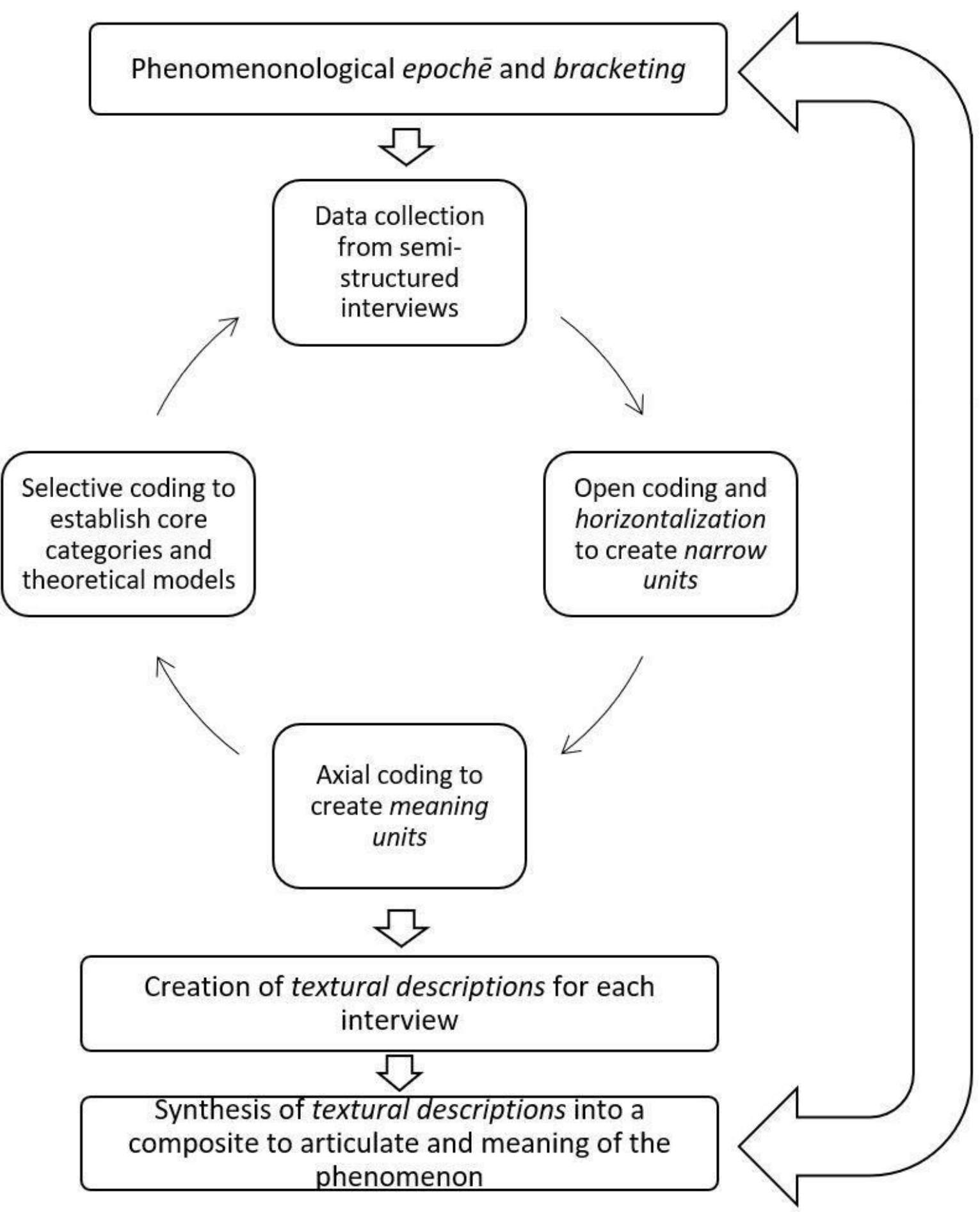




\title{
Appendix D: Interview Questions
}

\author{
Interview Questions
}

1. Please tell me about your own kindergarten experience as a student.

2. Why did you pursue elementary education?

3. Did you want to be a kindergarten teacher? Why or why not?

4. Please tell me about your experiences teaching kindergarten students.

5. Have your views of kindergarten or kindergarteners changed? Have you changed?

6. Tell me about the change that you have undergone (or are currently undergoing). How would you describe this change?

7. What triggered this change? What made this change possible?

8. What has changed in your life following teaching kindergarten? Who are you today (compared with who you were prior to the change)?

9. Did this process affect your relationships or daily life in any way? In what way were you affected? 


\section{Appendix E: Recruitment Letter}

UofL Institutional Review Boards

IRB NUMBER: 20.0548

IRB APPROVAL DATE: $7 / 8 / 20$

Dear Kindergarten Teacher,

My name is Adam Stephens from the University of Louisville. I am reaching out to you because I would like to invite you to participate in a study that I will be conducting under the supervision of Dr. Brydon-Miller from the university. We are interested in learning more about your experiences in teaching kindergarten.

As part of this study, I will be interviewing kindergarten teachers about their kindergarten experiences, reasons for teaching elementary (specifically kindergarten), experiences working with students, views of kindergarten instruction and students, and the impact of teaching kindergarten on their professional and personal lives. If you are currently employed as a kindergarten teacher in Fayette County, you meet the study's participant criteria. These interviews will be conducted at your convenience with an online platform such as Zoom, Google Meet, or Microsoft Teams. Interviews will include 9 semi-structured questions and be completed in 30-60 minutes depending on follow-up questions and your willingness to elaborate. Participants will receive copies of their transcripts to be used for their own personal and professional pursuits.

I have attached this study's Informed Consent form that details the inclusion criteria, how data will be collected and confidentially reported, and the voluntary nature of this study. You can reach me by phone or email to further discuss the details of this research study. Your participation is completely voluntary. Please let me know if you have any questions. If you agree to participate in this study, please reply to this email with your availability. Thank you!

Sincerely,

Adam Stephens

Student, Educational Leadership, Evaluation, and Organizational Development University of Louisville adam.stephens@fayette.kyschools.us

Dr. Mary Brydon-Miller Professor, Educational Leadership, Evaluation, and Organizational Development University of Louisville mary.brydon-miller@louisville.edu 


\title{
Appendix F: Consent Form
}

\author{
INFORMED CONSENT
}

\section{A PHENOMENOLOGICAL STUDY OF KINDERGARTEN TEACHERS' PERCEPTIONS OF THEIR}

\author{
STUDENTS IN THE AGE OF KINDERGARTEN READINESS
}

\section{Introduction and Background Information}

You are invited to take part in a research study of kindergarten teacher experiences teaching kindergarten in the age of kindergarten readiness. You are invited because you currently teach kindergarten in the district setting of this study, Fayette County. The study is being conducted under the supervision of Dr. Brydon-Miller at the University of Louisville. Ten teachers will be invited to participate.

\section{Purpose}

The purpose of this phenomenological study is to report how kindergarten teachers at Southeastern elementary schools describe their attitudes about their own kindergarten teaching experiences, vocation, and students in an era of kindergarten readiness. This study also explores kindergarten teachers' perceptions of their experiences with kindergarten students concerning their perceptions of their own kindergarten experience and how teaching kindergarten has affected their personal and professional lives.

\section{Procedures}

In this study, you will be asked to answer questions about your personal experiences teaching kindergarten in an interview. During this interview, I will ask you semi-structured, open-ended questions that should take 30-45 minutes to answer. Clarifying questions may extend the interview, but I value your time and will complete the interview in under an hour unless you state your desire to continue. You are welcome to decline to answer any questions that may make 
you feel uncomfortable. Though I prefer to complete interviews in single sessions to value your time, I am willing to splitting the interview if that option is more convenient for you. This interview will be conducted using a UofL approved online video conferencing platform. This interview will be audio recorded for later transcription. The audio recording and transcription will be shared with you via Google Drive for verification as well as your professional use. Aside from the interview, demographic data such as age, sex, ethnicity, and years of professional experience will be collected although identifying information such as your name and place of employment will not be identified in the published report.

\section{Potential Risks}

There are no foreseeable risks other than possible discomfort in answering personal questions. All participant information will remain confidential and participants will remain confidential in any form of writing or reporting from this study.

\section{Benefits}

The possible benefits of this study include an opportunity to share your experiences teaching kindergarten to contribute to a body or research literature focused on kindergarten readiness and teacher support. All participants will also be provided to be used as evidence for your professional growth plans or for your interests or records as reciprocity for their time and willingness to share their experiences.

\section{Payment}

You will not be paid for your time, inconvenience, or expenses while you are in this study.

\section{Confidentiality}

Total privacy cannot be guaranteed. I will protect your privacy to the extent permitted by law. If the results from this study are published, your name will not be made public.

Your information may be shared with the following:

- The University of Louisville Institutional Review Board, Human Subjects Protection Program Office, Privacy Office, others involved in research 
administration and research and legal compliance at the University, and others contracted by the University for ensuring human participants safety or research and legal compliance

- People who are responsible for research, compliance and HIPAA/privacy oversight at the institutions where the research is conducted

- Applicable government agencies, such as:

- Office for Human Research Protections

\section{Security}

The data collected about you will be kept private by remaining confidential through the use of pseudonyms for both you and your place of employment. These pseudonyms will be assigned before data is collected and your name and place of employment will not be written in the data. All data will be secured by being stored in a password-protected, and encrypted computer that only the Principal Investigator and Co-Investigator can access.

\section{Voluntary Participation}

Taking part in this study is completely voluntary. You may choose not to take part at all. If you decide not to be in this study, you won't be penalized or lose any benefits for which you qualify. If you decide to be in this study, you may change your mind and stop taking part at any time. If you decide to stop taking part, you won't be penalized or lose any benefits for which you qualify. You will be told about any new information learned during the study that could affect your decision to continue in the study.

\section{Alternatives}

Instead of taking part in this study, you could choose to not participate in the study.

\section{Research Participant's Rights}

If you have any questions about your rights as a research participant, you may call the Human Subjects Protection Program Office at (502) 852-5188. You may discuss any questions about your rights as a research participant, in private, with a member of the Institutional Review Board (IRB). You may also call this number if you have other questions about the research, and you cannot reach the study doctor, or want to talk to someone else. The IRB is an independent committee made up of people from the University community, staff of the institutions, as well as people from the community not connected with these institutions. The IRB has approved the participation of human participants in this research study.

\section{Questions, Concerns and Complaints}


If you have any questions about the research study, please contact the Principal Investigator, Dr. Brydon-Miller at (502) 852-6887 or the Co-Investigator, Adam Stephens at (859) 338-6516.

If you have concerns or complaints about the research or research staff and you do not wish to give your name, you may call the toll-free number 1-877-8521167. This is a 24-hour hotline answered by people who do not work at the University of Louisville.

\section{Acknowledgment}

This document tells you what will happen during the study if you choose to take part. By answering interview questions, you indicate that this study has been explained to you, that your questions have been answered, and that you agree to take part in the study. You are not giving up any legal rights to which you are entitled by agreeing to participate. You may make a copy of this consent form to keep for your records.

Phone number for participants to call for questions:

Dr. Mary Brydon-Miller (Principal Investigator)

Department of Educational Leadership, Evaluation and Organizational Development

Mary.brydon-miller@louisville.edu

Adam Stephens (Co-Investigator)

Educational Leadership and Organizational Development Major adam.stephens@fayette.kyschools.us

Department of Educational Leadership, Evaluation and Organizational Development

343 Porter Building

Belknap Campus

University of Louisville

Louisville, KY 40292 


\section{CURRICULUM VITAE}

Adam Stephens

Contact Information:

adam.stephens@fayette.kyschools.us

EDUCATION

Ed.D University of Louisville, Educational Leadership \& Organizational Development

Dec. 2020

MS University of Kentucky, Educational Leadership

May 2012

MA University of Kentucky, Curriculum and Instruction

July 2003

BA University of Kentucky, English

May 1999

Minored in Anthropology

Professional APPointments AND Work ExPERIENCES

Henry Clay High School, Lexington, KY August 2003 to December 2010 English Instructor

Henry Clay High School, Lexington, KY

English Curriculum Coach

January 2010 to May 2012

Henry Clay High School, Lexington, KY

July 2012 to May 2016

Administrative Dean

Picadome Elementary School, Lexington, KY

August 2016 to June 2019

Associative Principal

Frederick Douglass High School, Lexington, KY

July 2019 to August 2020

Administrative Curriculum Coach

Fayette County Public Schools, Lexington, KY

August 2020 to Present

K-5 Literacy Specialist

Professional Training 
NISL Executive Development Program

National Institute for School Leadership, Lexington, 2016

NISL Facilitators Certification Institute

National Institute for School Leadership, Lexington, 2017 